\title{
Modelling of Quaternary glacier extent and climate in Tasmania, Australia
}

\author{
by \\ Rebecca Joan O’Donnell
}

\author{
A thesis \\ submitted to Victoria University of Wellington, \\ as partial fulfillment of the \\ requirements for the degree of \\ Masters of Science with honours \\ in \\ Physical Geography
}

School of Geography, Environment and Earth Sciences,

Victoria University of Wellington

New Zealand

May 2010 


\section{AUTHOR'S DECLARATION}

I hereby declare that I am the sole author of this thesis. This is a true copy of the thesis, including any required final revisions, as accepted by my examiners.

I understand that my thesis may be made electronically available to the public. 


\begin{abstract}
The aim of this study was to improve our understanding of Quaternary glaciations in Tasmania, and to assess their climatic significance. During the Quaternary, Tasmania experienced ice cap development in the West Coast Range and Central Plateau, with smaller cirque and valley glaciers developing on surrounding mountains. Geomorphic evidence indicates at least four glacial advances occurred. A $500 \mathrm{~m}$ resolution, three-dimensional thermomechanical ice-sheet model was used to reconstruct and simulate these glacier fluctuations. The model, while a simplification of reality, provided a framework in which to understand the genesis of contemporary landforms and former glacial climate conditions in Tasmania. Input specifications of basal topography, temperature and precipitation were required, with the latter two interpolated from present-day datasets.

Numerous experiments were carried out, involving systematic alterations to temperature and precipitation, basal sliding and atmospheric temperature lapserates. Modelled output was compared to empirical evidence with the aim of optimizing the parameters (temperature, precipitation) from which model mismatch was minimised.
\end{abstract}

An annual temperature reduction of $6^{\circ} \mathrm{C}$ is required for glaciers to form in Tasmania. When temperatures cool beyond this threshold, an ice mass develops over the Central Highlands, Central Plateau, West Coast Range and other mountains. In all but the most extensive glaciations, the Central Plateau ice field consists of a relatively thin carapace of ice, and the thickest and most dynamic glaciers develop in the deep valleys of the Central Highlands. The model shows that ice readily flows down the west-facing valleys from the Central Highlands to join with West Coast Range glaciers.

A temperature reduction between 7 and $9^{\circ} \mathrm{C}$, with corresponding regional precipitation changes of between $+/-50 \%$ and an increase in orographic precipitation is required to simulate the Last Glacial Maximum (LGM) ice cover. Earlier glacial advances require larger coolings of up to $11.25^{\circ} \mathrm{C}$ depending on the regional precipitation conditions prescribed. Mismatches between geomorphic 
evidence and modelled reconstructions probably result from model grid size issues and parameters not accommodated by the model such as wind-blown snow redistribution. This means that temperature reductions derived from the model may have been overestimated. Despite these limitations, reconstructed temperatures compare well to some multi-proxy palaeo-temperature records from Tasmania, although the cooling identified was larger than that recorded in nearby ocean sediments. 


\section{Acknowledgements}

I would like to thank everyone who contributed to my work and my time here at Victoria University.

First of all, thanks to my supervisors:

- Andrew Mackintosh for making the project happen, securing the research funding and for being my primary supervisor,

- Nicholas Golledge for helping me organise and interpret numerous modelling experiments, and

- Alun Hubbard for his assistance and the time to set up the model for me.

Their constant support, guidance and enthusiasm towards this work always encouraged me to strive that little bit harder to find the fabled "best-fit model".

A very special thanks goes to:

- the Marsden Fund (Temperature or Precipitation: What drives Southern Hemisphere glaciations? March 2007-February 2009),

- the Antarctic Research Centre, and

- Victoria University’s Science Faculty Research Grant.

Without their monetary support, I would not have had the opportunity to travel to the University of Wales, Aberystwyth in order to unravel the great mysteries of glacier modelling. Sincere thanks for the generosity of the Institute of Geography and Earth Sciences and Centre for Glaciology at Aberystwyth University. Thanks to Rich, Hayley and Mewlee for putting me up in their flat and always cooking for me. The great people that I met there certainly made my stay highly enjoyable.

I am grateful to Eagle Technology for supplying me with GIS software and Kenex Knowledge Systems for their numerous datasets and GIS assistance. Particular thanks also to Paul Augustinus for providing unpublished ice limits.

Thank you to my friends and family and bike for keeping me sane and in touch with reality when modelling frustration set in. Thank you to mum and Tom for 
reading my chapters with a critical eye. They were rewarded by unexpectedly learning far too much about glacier modelling themselves. 


\section{Table of Contents}

AUTHOR'S DECLARATION ...................................................................... ii

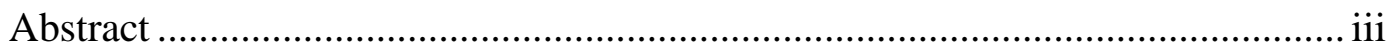

Acknowledgements .................................................................................... v

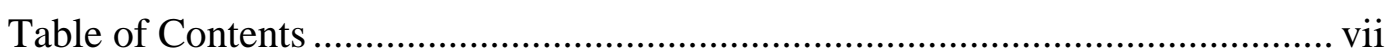

List of Figures ……………………………………………………………... $\mathrm{x}$

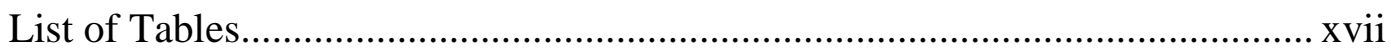

Chapter 1 Introduction .............................................................................. 1

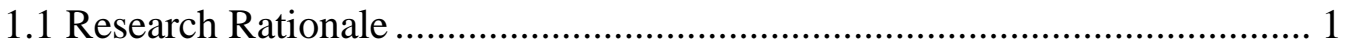

1.2 Research Questions ................................................................................. 3

1.3 Aims and Objectives ................................................................................ 4

Chapter 2 Theoretical Background ............................................................... 5

2.1 Large scale Quaternary climate change ....................................................... 5

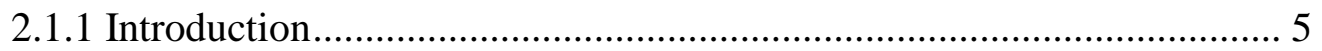

2.1.2 Drivers of Quaternary climate change ................................................. 5

2.1.3 The mid-Pleistocene Transition ............................................................... 7

2.2 The Quaternary climate in Tasmania ........................................................ 9

2.3 Glaciers as palaeoclimatic indicators ........................................................ 11

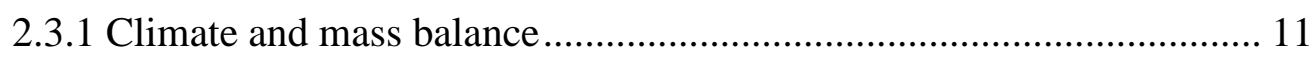

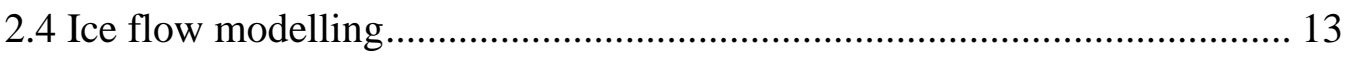

Chapter 3 Regional Setting ……………………………………………... 15

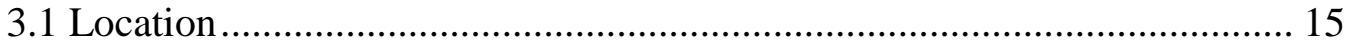

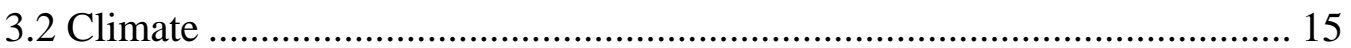

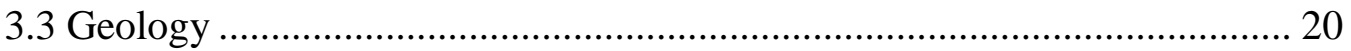

3.4 Previous research on glaciation in Tasmania …………………………….... 20

3.4.1 Patterns of ice evolution .................................................................. 22

3.4.2 Glacier dynamics ......................................................................... 23

Chapter 4 Methodology.......................................................................... 25

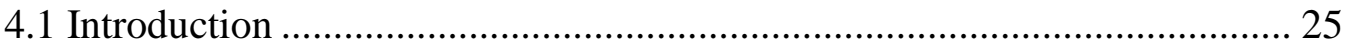

4.1.1 Digital data acquisition ................................................................... 25

4.2 Numerical ice-sheet modelling................................................................. 27 


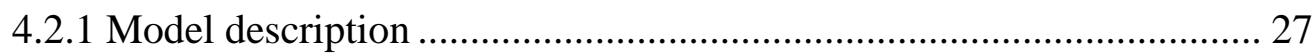

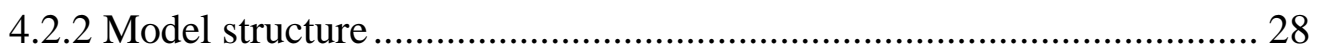

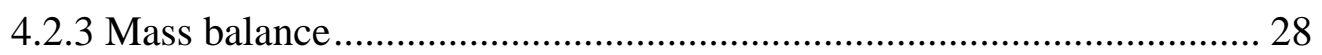

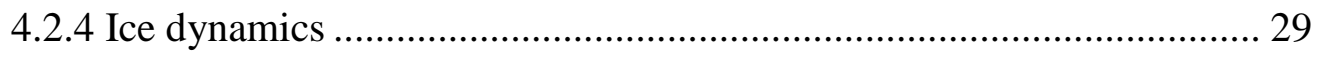

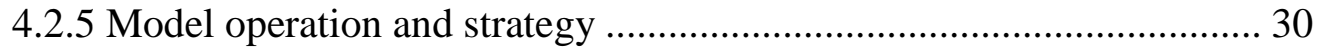

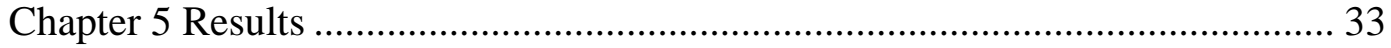

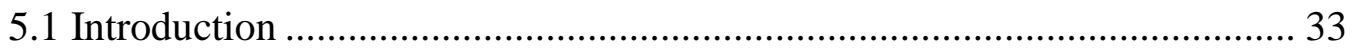

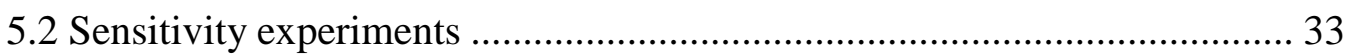

5.3 Sensitivity of the model to its internal parameters ................................... 34

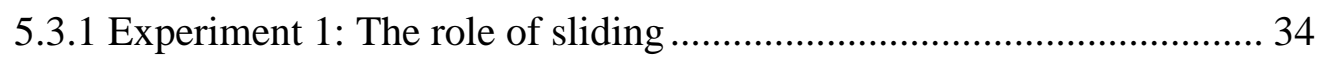

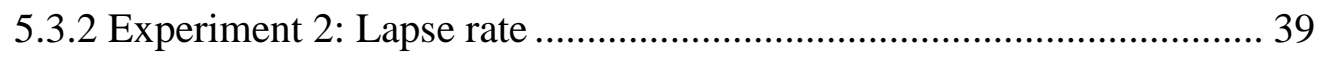

5.4 Sensitivity of the model to its input data .................................................. 41

5.4.1 Experiment 3: The influence of Temperature..................................... 41

5.4.2 Experiment 4: The influence of Precipitation ...................................... 45

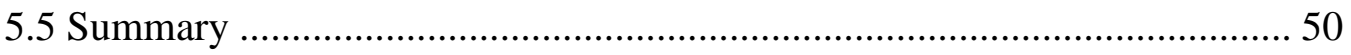

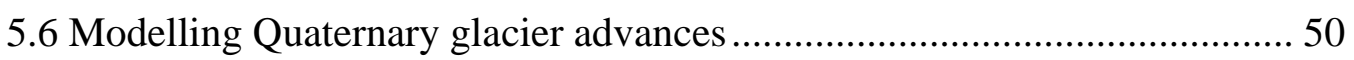

5.7 Last Glacial Maximum (LGM) advance .............................................. 50

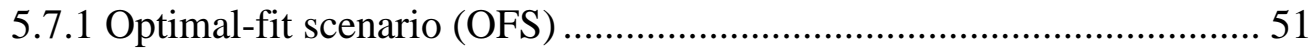

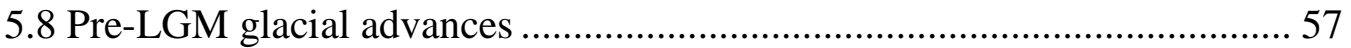

5.9 Middle Pleistocene I glacial advance ...................................................... 57

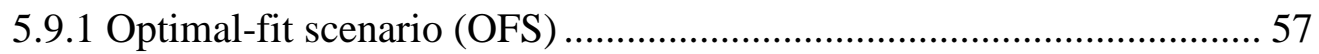

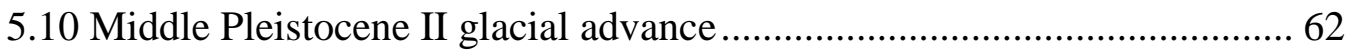

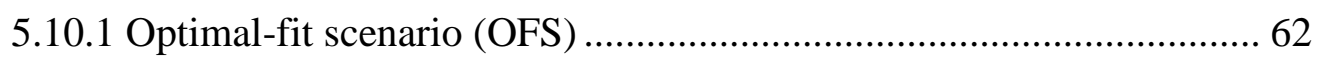

5.11 Early Pleistocene glacial advance ....................................................... 70

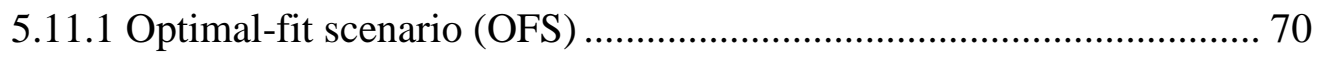

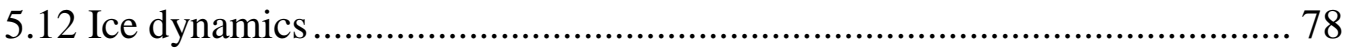

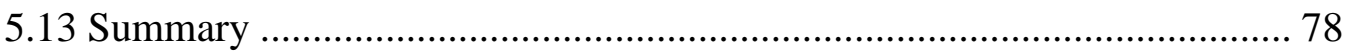

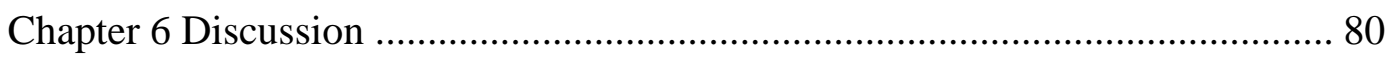

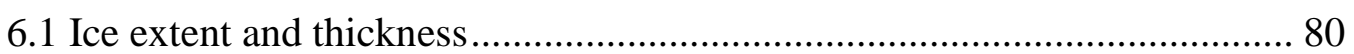

6.2 Basal processes and geomorphic implications ...................................... 82

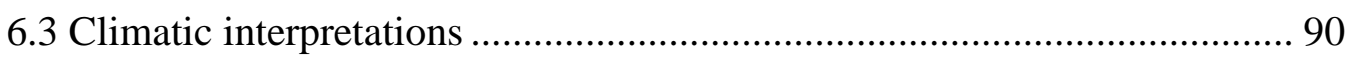

6.3.1 Empirical model mismatches ............................................................ 91 
6.3.2 Climatic thresholds and sensitivity 91

6.4 Glacial palaeoclimate in Tasmania........................................................ 92

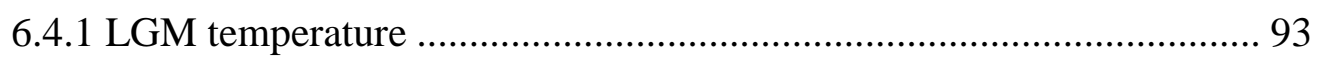

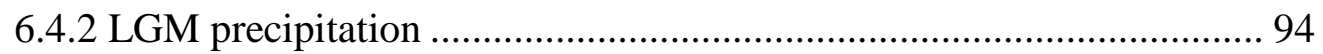

6.4.3 Earlier Pleistocene climate reconstructions ..................................... 96

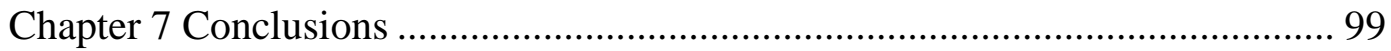

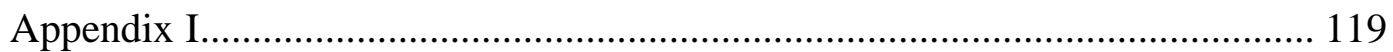

Sources for the Geographical Information Systems compilation ...................... 119 


\section{List of Figures}

Figure 2-1: The LR04 benthic $\delta^{18} \mathrm{O}$ stack constructed by the graphic correlation of 57 globally distributed benthic $\delta^{18} \mathrm{O}$ records showing Quaternary SST variability. Note the difference in the vertical axis between the two panels. Modified from Lisiecki and Raymo (2005).

Figure 2-2: Schematic cross-section through a typical valley glacier showing both the accumulation and ablation zones. The ELA is shown by the red line where mass balance $=0$. Preferential flow direction and speed are shown by the blue arrows. The longer arrows represent larger flow velocities. Modified from Granshaw and Fountain (2003)

Figure 3-1: Location of Tasmania. The main areas of former Quaternary glaciation are labelled.

Figure 3-2: Average annual precipitation across Tasmania from the years 1961 to 1990. Sourced from the Bureau of Meteorology, Australia.

Figure 3-3: Average annual temperature across Tasmania from the years 1961 to 1990. Sourced from the Bureau of Meteorology, Australia.

Figure 3-4: Pattern of glaciation over the Tasmanian Central Highlands with locations mentioned in text. The red arrows represent the general direction of ice flow during each glacial. The ice limits in black are from the early Pleistocene glacial, which is the largest known Quaternary advance.

Figure 4-1: The model domain, showing Quaternary glacier limits from empirical studies. See Appendix I for source information. 26

Figure 5-1: Areal ice extent with sliding values ranging from 0 to 50. A higher sliding value enables ice to move more freely over its bed (compared to a 0 value) and greater lateral spreading of ice is observed as the sliding value is increased. The datum control model for comparison has a sliding value of 0 , a lapse rate of $-6.5^{\circ} \mathrm{C}$ $\mathrm{km}^{-1}$, present-day precipitation conditions and a temperature depression of $-8.5^{\circ} \mathrm{C} .36$ Figure 5-2: Distribution of total ice velocity under sliding values of 0 and 25 . The regional differences are far more obvious in this figure. The dynamics of former Quaternary glacier advances may have interesting linkages with the characteristics of contemporary landforms. 
Figure 5-3: Profile view of a modelled glacier flowing down through Lake St Clair. The simulation uses a sliding value of 10 to enhance the Weertman-based sliding coefficient and produces a sensible looking valley glacier. Further modelling experiments will use a sliding value of 10 .

Figure 5-4: Distribution of ice under lapse rates of $-5,-6.5$ and $-9{ }^{\circ} \mathrm{C} \mathrm{km}^{-1}$. The differences between lapse rates are subtle, with slightly thicker and more expansive ice centered over the Central Plateau as the lapse rate increases. 40

Figure 5-5: Ice extents resulting from stepped cooling of 6 to $12^{\circ} \mathrm{C}$ under present precipitation conditions. Coolings of 6 to $8^{\circ} \mathrm{C}$ superficially resemble Quaternary ice advances, whereas the ice sheet that formed in response to a $12^{\circ} \mathrm{C}$ cooling has not occurred in the late Cenozoic.

Figure 5-6: Ice volume trajectory throughout the entire model run (1500 years) resulting from coolings of 6 to $12^{\circ} \mathrm{C}$ under present precipitation conditions.

Equilibrium is achieved in $\sim 800$ years.

Figure 5-7: Comparison of ice extent between present-day precipitation conditions and a regional precipitation decrease of $50 \%$. Both simulations were carried out with a temperature depression of $-8.5^{\circ} \mathrm{C}$, a sliding value of 0 and a lapse rate of $-6.5^{\circ} \mathrm{C}$ $\mathrm{km}^{-1}$. 46

Figure 5-8: Comparison of ice extent between present-day precipitation conditions and a regional precipitation increase of $50 \%$. Both simulations were carried out with a temperature depression of $-8.5^{\circ} \mathrm{C}$, a sliding value of 0 and a lapse rate of $-6.5^{\circ} \mathrm{C}$ $\mathrm{km}^{-1}$.

Figure 5-9: Comparison of ice extent between present-day precipitation conditions and a regional precipitation increase of $200 \%$. Both simulations were carried out with a temperature depression of $-8.5^{\circ} \mathrm{C}$, a sliding value of 0 and a lapse rate of $-6.5^{\circ} \mathrm{C}$ $\mathrm{km}^{-1}$. 48

Figure 5-10: Ice volume trajectory throughout the entire model run (1500 years) under increasing and decreasing regional precipitation (compared to present-day datum conditions). All model runs were carried out using a temperature depression of $-8.5^{\circ} \mathrm{C}$, a sliding value of 0 and a lapse rate of $-6.5^{\circ} \mathrm{C} \mathrm{km}^{-1}$. Equilibrium is achieved in $\sim 800$ years. 
Figure 5-11: LGM ice extent and thickness over the entire model domain after 1500 model years under optimal climate parameterisation. Empirical reconstructions are shown in black outline. A good match is achieved in the southern region of the main ice mass around Lake St Clair, and in northern Tasmania down the Mersey and Forth valleys. Isolated peaks in southern Tasmania are well represented, and include: Mt Field, Mt Anne and the Arthur Range. An over-prediction of ice is simulated by the model in the West Coast Range and northeastern Tasmania. Maximum ice thickness approaches 430m in Lake St Clair, Murchison Valley, Forth Valley and Mersey Valley (dark blue). Thinner ice is simulated on the Central Plateau, in agreement with field evidence

Figure 5-12: The range of temperature and precipitation conditions that produce a similar ice geometry for the LGM (red line). The three earlier Quaternary advances are also plotted for comparison (thinner lines). The yellow shading represents the range of likely combinations of temperature and precipitation required for each advance

Figure 5-13: LGM simulation (A) Close up of ice distribution in the northern region of the main ice mass. (B) Ben Lomond with excess of ice compared to the empirical data. (C) Central ice mass showing detailed ice extent against the empirical limits outlined in black. Note how the overall areal coverage of ice appears to be larger than previously interpreted by Colhoun et al. (1996). This possibly suggests that cooling values between $-7^{\circ} \mathrm{C}$ and -9 are probably too high, likely due to grid resolution issues. Numbers refer to key areas mentioned in text.

Figure 5-14: LGM time slices from the optimum model run, showing ice build-up and development in Lake St Clair. The numbers represent the main source areas of the Du Cane Range (1) and the western Central Plateau (2)

Figure 5-15: Middle Pleistocene I (MIS 6) ice extent and thickness over the entire model domain after 1500 model years under optimal climate parameterisation. A good match is achieved in northern Tasmania down the Mersey and Forth valleys, as well as in southern Tasmania around Lake St Clair, Navarre and Franklin valleys. Ice in the southern West Coast Range closely matches empirical limits, whereas the model does not produce enough ice in the northern West Coast Range. Empirical reconstructions are shown in black outline. Maximum ice thickness approaches 475 
m in Lake St Clair, Murchison Valley, Mersey Valley and Forth Valley (dark blue).

Figure 5-16. The range of temperature and precipitation conditions that produce a similar ice geometry for the middle Pleistocene I advance (red line). The three other Quaternary advances are also plotted for comparison (thinner lines). The yellow shading represents the range of likely combinations of temperature and precipitation required for each advance.

Figure 5-17: Middle Pleistocene I (MIS 6) model simulation. Close up of ice extent over the central ice mass (A). Southern region of the main ice mass (B), and the West Coast Range (C). The model does a good job simulating ice to match the empirical limits in the Derwent, Nive, Navarre and Franklin valleys, as well as in the southern West Coast Range. A clear mismatch exists in the Pieman Valley, northern West Coast Range, where the model under-predicts ice extent. In each figure the black lines mark the limits of middle Pleistocene I glacial advances.

Figure 5-18: Middle Pleistocene II ice extent and thickness over the entire model domain after 1500 model years under optimal climate parameterisation. A good match is achieved between modelled ice extent and empirical limits in the Derwent Valley, southern Tasmania and the Forth Valley, northern Tasmania. In the West Coast Range excess ice is produced by the model south of the Tyndal Plateau, whereas ice is under-predicted by the model in the Pieman Valley, northern West Coast Range. Empirical reconstructions for middle Pleistocene II limits are shown in black outline. Maximum ice thickness approaches $500 \mathrm{~m}$ in Lake St Clair, Murchison Valley, Mersey Valley and Forth Valley (dark blue).

Figure 5-19: The range of temperature and precipitation conditions that produce a similar ice geometry for the middle Pleistocene II advance (red line). The three other Quaternary advances are also plotted for comparison (thinner lines). The yellow shading represents the range of likely combinations of temperature and precipitation required for each advance.

Figure 5-20: Middle Pleistocene II ice extent over the central ice mass with a close up on the northern region of the West Coast Range (A). A clear mismatch is apparent in the Boco and Pieman valleys, where modelled ice extent is underpredicted, despite increasing the north-to-south precipitation gradient. The black xiii 
lines mark middle Pleistocene II empirical field limits. Key areas numbered in the figure are referred to in text in more detail

Figure 5-21: Middle Pleistocene II ice extent over the central ice mass with a close up of the southern region of the West Coast Range (A). Excess ice is produced by the model, flowing past the empirical limits. The black lines mark middle Pleistocene II empirical field limits. Key areas numbered in the above figure are referred to in text.

Figure 5-22: Middle Pleistocene II ice extent over the central ice mass with a close up of the southern region (A). A good match between modelled ice and empirical limits is achieved in the Franklin and Derwent valleys. Other areas lack empirical limits in which to constrain and compare modelled output. The black lines mark middle Pleistocene II empirical field limits. Key areas numbered in the figure are referred to in text.

Figure 5-23: Middle Pleistocene II ice extent over the central ice mass with a close up of the northern region (A). Empirical limits are very sparse, but a good match is achieved in the Forth Valley. It is likely that excess ice is predicted by the model east of Mt Cripps, as evidence for glaciation is absent. The black lines mark middle Pleistocene II empirical field limits. Key areas numbered in the figure are referred to in text.

Figure 5-24: Early Pleistocene ice extent and thickness over the entire model domain after 1500 model years under optimal climate parameterisation. The overall geometry of ice simulated by the model is in agreement with the empirical limits. However, ice is over-predicted in southern and western regions of the West Coast Range, northeastern Tasmania and south of the Central Plateau. Empirical reconstructions of early Pleistocene field limits are shown in black outline. Maximum ice thickness approaches $560 \mathrm{~m}$ in Lake St Clair, Murchison Valley, Forth Valley and Mersey Valley (dark blue).

Figure 5-25: The range of temperature and precipitation conditions that produce a similar ice geometry for the early Pleistocene advance (red line). The three other Quaternary advances are also plotted for comparison (thinner lines). The yellow shading represents the range of likely combinations of temperature and precipitation required for each advance. 
Figure 5-26: Early Pleistocene ice extent over the central ice cap with a close up of the southern region (A). The large valley glacier is not simulated by the model in the Derwent Valley. Ice is over-predicted southwest of the Franklin Valley. The black lines mark early Pleistocene empirical field limits. Key areas numbered in the figure are referred to in text.

Figure 5-27: Early Pleistocene ice extent over the central ice cap with a close up of the western region (A). Ice exceeds empirical limits west of the King, Queen and Henty valleys, while ice is under-predicted in the Pieman Valley. The black lines mark early Pleistocene empirical field limits. Key areas numbered in the figure are referred to in text.

Figure 5-28: Early Pleistocene ice extent over the central ice cap with a close up of the northern region (A). A good match is achieved in the Mersey and Forth valleys. Ice is over-predicted northwest of the Mackintosh Valley. The black lines mark early Pleistocene empirical field limits. Key areas numbered in the figure are referred to in text.

Figure 5-29: Early Pleistocene ice extent over the central ice cap with a close up of the northern region (A). A good match is achieved in the northern and eastern region of the Central Plateau. Ice is over-predicted by the model and exceeds the southern limits of the Central Plateau. The black lines mark early Pleistocene empirical field limits. Key areas numbered in the figure are referred to in text.

Figure 5-30: Total velocity from the optimum middle Pleistocene II run, showing zones of high and low velocity. (A) Depicts the western side of the main ice mass, with many fast flowing glaciers in red. (B) Illustrates the relatively slow moving eastern region, with some fast flowing outlet glaciers in the northern sector. Large outlet glaciers are numbered in the figure (1-4), with some referred to in text. A sliding value of 10 was used in this simulation (explained more fully in 5.4.1) ...... 79

Figure 6-1: Velocity distribution of modelled ice from middle Pleistocene glacial advance. Total velocity shown in blue and red indicates that nearly all ice flows by sliding at its bed. The areas in black reflect ice movement that is less than $2 \mathrm{ma}^{-1}$ (more or less stationary), and that flows primarily through internal deformation..... 84 
Figure 6-2: Velocity distribution and ice thickness for middle Pleistocene II model simulation. Zones of fast moving ice (400-600 ma ${ }^{-1}$ ) occur in conjunction with thick ice in steep valleys.

Figure 6-3: Velocity distribution over the eastern region of the Central Plateau for middle Pleistocene II advance. A large proportion of ice in this sector moves primarily through internal deformation $\left(<2 \mathrm{ma}^{-1}\right)$. There are zones of faster moving ice (400-600 $\left.\mathrm{ma}^{-1}\right)$ in the central valley of this figure, however, ice along the southern fringes is more or less stationary.

Figure 6-4: Middle Pleistocene II model simulation. Distribution of lakes representing zones of areal scouring across the eastern Central Plateau. These zones were superimposed on model predictions of ice thickness and the distribution of velocity. In general, scoured bedrock occurred where ice was slightly thicker and experiencing sliding at its bed. In the upper part of the catchment the lakes appeared to align with the flow of valley glaciers. This indicates that the model does a good job simulating former glacier dynamics in this area and long-term preferential flow directions.

Figure 6-5: Middle Pleistocene II model simulation. Distribution of lakes representing zones of areal scouring across the eastern Central Plateau. The black arrows represent surface velocity vectors, with the arrow pointing in the direction of flow and the arrow length representing relative velocity. 89

Figure 6-6: Possible atmospheric conditions operating during the LGM over Australia. During winter the high pressure cell operating over the Australian mainland is larger and more stable due to colder conditions. Intensification of the westerlies over Tasmania occurs in conjunction with an equatorward shift of westerly circulation. This is possibly in response to more northerly extent of Antarctic sea ice

Figure 6-7: Possible atmospheric conditions operating during the LGM over Australia. Weakening of westerly circulation is associated with a poleward shift of the westerly belt. Local orographic enhancement is simply a function of ice thickness increasing topographical elevation. .98 


\section{List of Tables}

Table 4-1: Principal parameters used in the ice sheet model, with their values and units. The model domain is defined by X-values (latitude) and Y-values (longitude). 


\section{Chapter 1 \\ Introduction}

\subsection{Research Rationale}

Rapid and dramatic changes in climate and glacial conditions on Earth have occurred throughout the Quaternary period over the last 2.6 million years. Global climate oscillated between periods of cold and warm conditions, causing glaciers and ice sheets to become more extensive than today, and to retreat accordingly. Glaciers play an important role in global climate change, serving to amplify or dampen climatic variations (Oerlemans, 1980, 1982). Trends in global temperatures are on an upward trend; having increased by $0.74^{\circ} \mathrm{C}$ since 1750 , with a further rise of $1.8-4.0^{\circ} \mathrm{C}$ is predicted for this century (Bernstein, et al., 2007). Increased warming is predicted to enhance already widespread glacier retreat, with subsequent increases in global sea level (Bernstein, et al., 2007). It is evident that by understanding the interactions between glaciers and the atmosphere, we can begin to understand the drivers of the climate system.

The response of a glacier to climate change is influenced by its bed geometry, hypsometry, substrate type and local climate (Kuhn, 1984; Oerlemans, et al., 1998). For example, the various climatic factors controlling Quaternary ice extent in the largely continental Northern Hemisphere have been well documented (Karl, et al., 1993a, 1993b; Groisman, et al., 1994; Dyurgerov and Dwyer, 2001; Bernstein, et al., 2007). However, the "traditional" Milankovitch theory cannot be easily transferred to the Southern Hemisphere because the insolation intensity signal is out of phase between the two hemispheres. While there are an abundance of both terrestrial and oceanic records in the Southern Hemisphere, the external controls governing glacier response are still poorly understood (e.g. the Last Glacial Maximum). Understanding how global climate dynamics in the Southern Hemisphere influence the advance and retreat of glaciers is vital to understanding how the climate system works on longer timescales. However, in order to establish a glacier's response to climate forcing, a thorough understanding of the complex 
feedbacks and processes involved in producing an environment conducive to glacier development in the Southern Hemisphere must first be attained.

When and where a glacier forms depends on the complex interplay of inputs, outputs and other physical systems (Benn and Evans, 1998). To put it simply, glaciers will only form and grow where the climatic and topographic conditions allow the inputs of annual accumulation to exceed the outputs of annual ablation. While there are many external climatic controls governing temperate glacier response, the two dominant ones are precipitation and temperature. Of particular interest is the relative importance of precipitation and temperature on glacier fluctuations (e.g. Anderson and Mackintosh, 2006).

Tasmania provides an ideal area to investigate the glacier-climatic linkage as it is situated in the ocean-dominated southern mid-latitudes. While it presently has no permanent snow or ice fields, extensive ice caps and numerous mountain glaciers developed in the West Coast Range and Central Highlands throughout the Quaternary. This glaciation has provided an abundance of both erosional and depositional evidence. Empirical glacier reconstructions based primarily on geological and geomorphological field data have been carried out in Tasmania, with suggestions on corresponding palaeoclimate patterns (Colhoun, 1985; Colhoun and Fitzsimons, 1990; Augustinus, 1999a). A widely used method for reconstructing climate change is to first estimate the altitude of former snowlines based on reconstructed glacier geometry. Lapse rates are then used to convert the altitude of the snowline to a temperature change. This method is valid for palaeoclimate reconstructions, but has some level of uncertainty regarding former lapse rate values. Additionally, climate reconstructions assume that glaciers in Tasmania reached equilibrium with their climate; an assumption that this study will employ.

However, by effectively employing the use of numerical ice-sheet models in combination with geological ice limits, it is possible to simulate the climatic changes necessary to grow ice that adequately matches the field evidence in Tasmania. Many of the issues concerning the uncertainties and assumptions of previous palaeoclimate reconstructions can be addressed. By using a numerical ice sheet model, not only will 
the internal variables concerning glacier dynamics be ascertained, but insights into the way ice develops under certain environmental conditions can also be established.

\subsection{Research Questions}

The overall aim of this project is to use a numerical ice-sheet model in order to investigate glacio-climatic linkages throughout the Quaternary in Tasmania. More specifically, it is hoped that these specific research questions can be adequately answered:

1. Can a numerical ice-sheet model be used to accurately simulate ice extent for discrete glacial episodes throughout the Quaternary to match existing field evidence in Tasmania?

2. What can the model tell us about the style of glaciation? Where were the principal accumulation areas, and how quickly did ice achieve its maximum extent and thickness?

3. Assuming that the model can accurately simulate ice to match existing field evidence; can the model then provide any information in terms of ice extent in areas where field evidence does not exist?

4. Does the model reveal whether or not glaciers predominantly flowed through basal sliding, or was ice deformation the governing flow mechanism? Is this reflected in the geomorphic record?

5. What do these climate reconstructions tell us about the climate drivers of Tasmania, and wider Southern Hemisphere glaciations? 


\subsection{Aims and Objectives}

During the last 20 years significant progress has been made on the age dating and mapping of glacial deposits and landforms in Tasmania, and geological records of glacier fluctuations spanning the last million years now exist (Colhoun and Fitzsimons, 1990; Augustinus, 1999a; Barrows, et al., 2002; Kiernan, et al., 2004; Mackintosh, et al., 2006). The overall aim of the proposed research is to translate these moraine records of former glacier extent into quantitative information about past temperature and precipitation, using a modelling methodology. There are two specific objectives:

1. To simulate ice extent with a glacier flow model in the mountains of Tasmania for the last million years (about four discrete glaciations are known).

2. To quantify the influence of temperature versus precipitation on glacier extent and thus resolve the dominant forcing on ice development in Tasmania. 


\section{Chapter 2 \\ Theoretical Background}

\subsection{Large scale Quaternary climate change}

\subsubsection{Introduction}

The onset of the Quaternary was officially defined by the Gauss/Matuyama palaeomagnetic transition (2.58 Ma) by the International Union of Geological Sciences in 2009 (Gibbard, et al., 2009). This episode was identified as a period where the Earth transitioned into a phase of significant cooling (Figure 2-1). Expansion of ice over the Northern Hemisphere continents at 2.6 Ma (Shackleton and Opdyke, 1977; Ding, et al., 1997; Ravelo, et al., 2004) was followed by more than 21 glacial-interglacial cycles (Benn and Evans, 1998). The geological evidence for glacial-interglacial cycles is widespread and is expressed through deep ocean sediments (Lear, et al., 2000; Lisiecki and Raymo, 2005), continental records (Dansgaard and Tauber, 1969; Rutter, et al., 1991; Ding, et al., 1993, 2002) and ice core records for the last $1 \mathrm{Ma}$ (Jouzel, et al., 1987, 2007; Petit, et al., 1999; EPICA Community Members, 2004). However, geomorphic and stratigraphic records for glaciation generally do not extend beyond four events, mainly due to much of the terrestrial evidence being destroyed by subsequent glacial advances and/or tectonic instability (Gibbons, et al., 1984; Suggate, 1990). More information regarding global Quaternary records is provided in, for example, Denton and Hughes (1981), Bradley (1985), Clapperton (1990) and Dawson (1992).

\subsubsection{Drivers of Quaternary climate change}

It has long been thought that glacial-interglacial cycles can be explained by changes in orbital parameters (Adhémar, 1842; Croll, 1864). Milankovitch (1941) built his ice age theory by examining the relationship between incoming radiation and latitude, taking into account the 

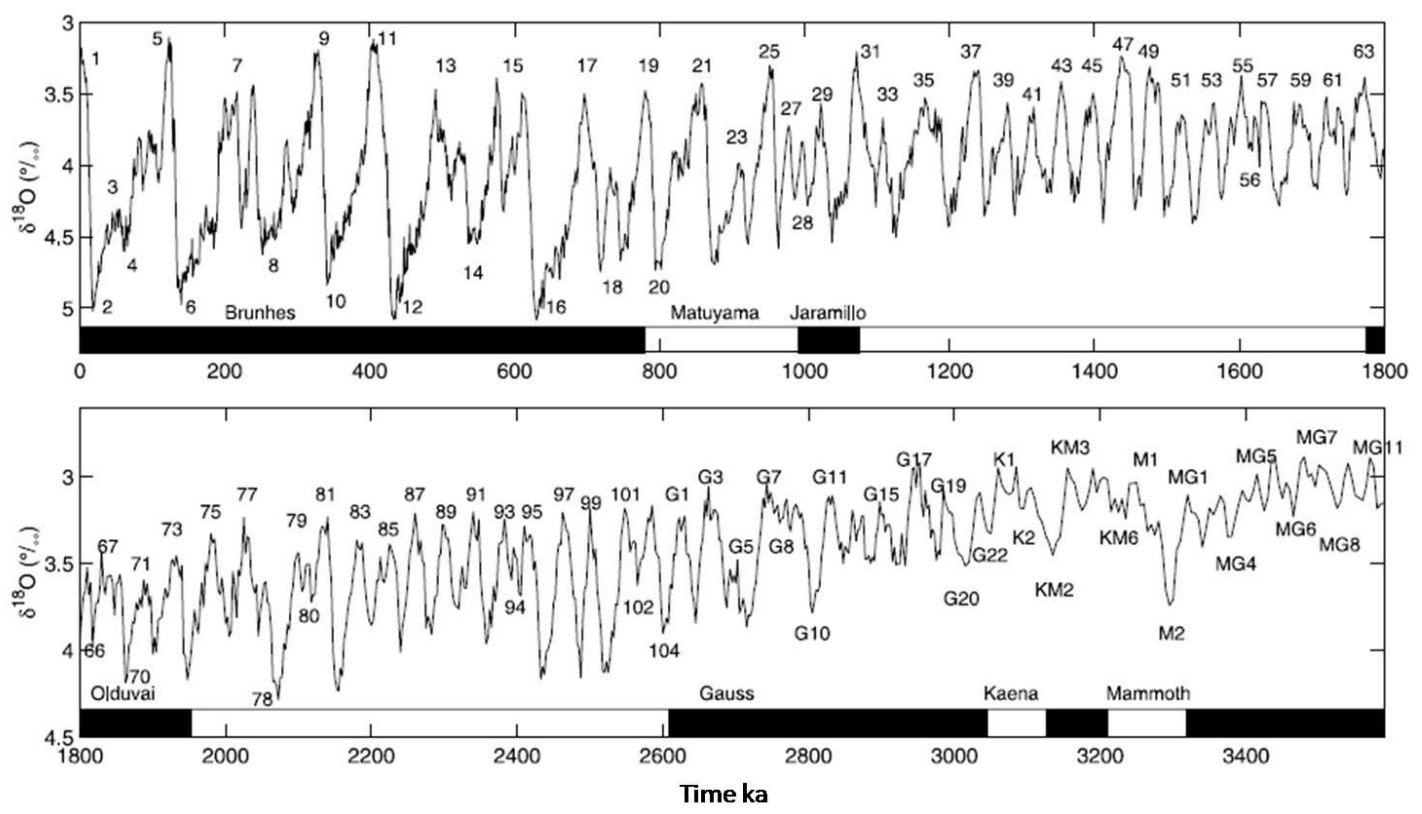

Figure 2-1: The LR04 benthic $\delta^{18} \mathrm{O}$ stack constructed by the graphic correlation of 57 globally distributed benthic $\delta^{18} \mathrm{O}$ records showing Quaternary SST variability. Note the difference in the vertical axis between the two panels. Modified from Lisiecki and Raymo (2005).

interaction of orbital eccentricity, axial tilt and precession of the equinoxes. Milankovitch proposed that glacial growth in the Northern Hemisphere was more likely during periods of less intense summer insolation, because this retards the melting of winter snow. This sequence is expressed throughout the Quaternary when perihelion occurs at the Northern Hemisphere. High latitudes were believed to be the growth centers for major Quaternary ice sheets because they were most sensitive to changes in radiation. Climatic minima have occurred during the Quaternary with frequencies initially corresponding to low obliquity $(\sim 4 \mathrm{kyr})$ cycles, and transitioning into cycles of maximal eccentricity $(\sim 100 \mathrm{kyr})$ and precession $(\sim 20$ kyr) cycles (e.g. LGM). During the 1970s/80s, marine sedimentary records provided strong support for the Milankovitch model (Hays, et al., 1976; Imbrie and Imbrie, 1980). Glacial-interglacial cycles were also documented in both Northern and Southern Hemisphere deep-sea $\delta^{18} \mathrm{O}$ records (e.g. Lourens and Hilgen, 1997; Lisiecki and Raymo, 2005), loess deposits in China (Ding, et al., 1997, 2002), 
shallow-marine records (Naish, et al., 1998) and Antarctic ice core records (Petit, et al., 1999; EPICA Community Members, 2004; Jouzel, et al., 2007).

\subsubsection{The mid-Pleistocene Transition}

High-amplitude oscillations at obliquity frequency are exhibited in numerous palaeoclimate records from 2.6 Ma through until about $0.8 \mathrm{Ma}$; prior to the midPleistocene Transition (MPT). Between 0.9 and $0.7 \mathrm{Ma}$, ice core records and benthic marine records indicated a switch in the pacing of glacial-interglacial cycle from obliquity $(\sim 41,000$ year $)$ to eccentricity $(\sim 100,000$ year $)$ rhythms. Drivers facilitating this change are unknown, with suggestions that the pacing of glacial/interglacial cycles were altered due to decreasing atmospheric $\mathrm{CO}_{2}$ (Raymo, et al., 1997a; Paillard, 1998; Berger, et al., 1999). Decreases in atmospheric $\mathrm{CO}_{2}$ are known to be facilitated by enhancement of polar atmosphere-ocean ventilation likely, given the decline in sea-surface temperatures (SST) (Sigman and Boyle, 2000; Stephens and Keeling, 2000; Martinez-Garcia, et al., 2006). Another suggestion is that ice sheets changed their bed conditions around this time (Clark, et al., 1999).

Although Earth's eccentricity varies with a period of $\sim 100,000$ years, the resulting change in insolation is too small to produce the corresponding climate cycle by direct forcing (Imbrie, et al., 1993). The onset of the MPT was characterized by an increase in the severity and duration of glaciations; based on the increase in amplitude between changes in global ice volume and long glaciation phases (e.g. Berger and Wefer, 2003). Furthermore, this increase in glacier ice volume was more marked after the mid-Brunhes event around 430,000 years BP (Jansen and Kuijpers, 1986). The result of this increase is that glacial and interglacials were less pronounced during the period between the onset of the MPT and the mid-Brunhes event. The intensity of glacial events, as well as the duration of interglacial events has increased since the mid-Brunhes event, with the current Holocene period exceeding the length of the four previous interglacial events (Petit, et al., 1999). Huybers and Wunsch 
(2005) postulate that based on the timing of glacial terminations, obliquity is still the primarily driver, and not eccentricity. Obliquity has the largest effect on insolation at high latitudes, and can explain some aspects of the bi-polar cryosphere. However, it is also recognized that glacier terminations and initiations are influenced by other forcings and feedback systems operating within the climate system (e.g. Saltzman and Maasch, 1991; Mudelsee and Schulz, 1997; Raymo, 1997b; Paillard, 1998; Tziperman and Gildor, 2003).

While the long term $10^{5}-10^{6}$ cycles can probably be explained by orbital forcing, the response of physical systems at shorter timescales within the long-term cycle are sometimes at odds with the predictions. This anomaly has been detected from investigations of the pattern of global climate change during the last 100,000 years. The effects of insolation forcing are out of phase in each hemisphere, i.e. opposite positions of perihelion and aphelion. However, near synchronous termination of the last glaciation occurred in both the Northern and Southern Hemispheres at ca. 17,000 years BP (Schaefer, et al., 2006; Clark, et al., 2009). Milankovitch's theory envisaged that the orbitally forced growth of ice sheets near $65^{\circ} \mathrm{N}$ had sufficient thermal impact upon the atmosphere to initiate the growth of ice sheets in the southern latitudes. More recent studies have suggested that while the Northern Hemisphere ice sheets had a significant impact upon local atmospheric and seasurface temperatures, they had a minimal influence on temperatures in the Southern Hemisphere (Manabe and Broccoli, 1985; Broccoli and Manabe, 1987). In the absence of a direct ice-climate link, this implies that another mechanism must exist to facilitate rapid climate fluctuations. Indeed, the oceans have been identified as a key modulator of climate, because currents driven by differences in salinity and temperature are effective agents for heat transfer from low to high latitudes (Broecker and Denton, 1989, 1990). Furthermore, atmospheric reorganization such as changes in circulation and greenhouse gas content has also been identified as key components facilitating climate variability (Broecker and Denton, 1990).

Despite the success of the Milankovitch theory in explaining many aspects of glacial-interglacial climate cycles throughout the Quaternary, several questions 
regarding glacier-climate interactions remain. There is still considerable uncertainty about whether high latitude Northern Hemisphere insolation forcing is the driver of ice ages. This mechanism does not explain why some glaciations are nearly synchronized on glacial-interglacial timescales. John Mercer (1984) described this as the 'fly in the ointment' of traditional Milankovitch theory. More recently, it has been discovered that globally synchronized obliquity cycles might be the major driver (Huybers and Wunsch, 2005; Huybers and Denton, 2008; Huybers, 2009) and that $\mathrm{CO}_{2}$ changes, perhaps linked to changes in Southern Ocean upwelling, could be more important than hitherto realized (Toggweiler, et al., 2006; Toggweiler, 2008; Anderson, et al., 2009). More specifically for this investigation, there is currently no adequate explanation for drivers facilitating Southern Hemisphere ice ages.

\subsection{The Quaternary climate in Tasmania}

Mapping and stratigraphic analysis of former glacial landforms suggested four discrete glacial advances occurred during the Quaternary in Tasmania. During the Last Glacial Maximum (LGM) the sea level decreased by $125 \pm 5 \mathrm{~m}$ (Fairbanks, 1989; Yokoyama, et al., 2000), exposing the continental shelf between Tasmania and the Australian mainland. Relatively long sequences, recording terrestrial vegetation and climate change have been recorded at Tullabardine Dam, Newall Creek and Lake Selina (Colhoun and van de Geer, 1986; van de Geer, et al., 1994; Colhoun, et al., 1999). Vegetation assemblages recorded a number of cooling intervals, which coincided with the development of extensive glacier systems. Cooling events also coincided with offshore SST reconstructions (e.g. van de Geer, et al., 1994; Barrows, et al., 2007; Sikes, et al., 2009) and Antarctic ice core data (Petit, et al., 1999; EPICA Community Members, 2004; Jouzel, et al., 2007). Quantitative regional temperature reconstructions for glaciation based on ELA reconstructions indicates a decline of 6 to $8^{\circ} \mathrm{C}$ in mean annual temperature during the LGM (e.g. Colhoun, 1985; Mackintosh, et al., 2006). Estimates of past precipitation and temperature conditions in Tasmania are uncertain prior to the LGM. However, Southern Ocean SST fluctuations and Antarctic ice core records indicate temperature changes during the 
early to mid-Pleistocene were similar to that of the LGM (van de Geer, et al., 1994; Petit, et al., 1999; EPICA Community Members, 2004; Barrows, et al., 2007; Sikes, et al., 2009).

Palaeoglaciological reconstructions by Derbyshire et al. (1965) and Peterson and Robinson (1969) suggested that most precipitation arrived from the west during the LGM. Geomorphological evidence and the reconstruction of former Equilibrium line altitudes (ELAs) indicate that the largest glaciers were located in the west, where ELA was at $835 \mathrm{~m}$ (Colhoun, 1985). Further east, where precipitation was restricted, smaller cirque glaciers on Ben Lomond had an ELA of ca. 1400 (Caine, 1983) during the peak of the LGM. This is also consistent with the development of dunes in eastern Tasmania under conditions of increased aridity (Bowden, 1983). Mechanisms behind variations in regional precipitation patterns are uncertain. There have been suggestions that the strongest westerlies were located further north (Lamy, et al., 1998, 1999), or that the overall atmosphere experienced considerable drying during the LGM (Justino, et al., 2008). Shulmeister et al. (2004) proposed that an overall strengthening of the westerly winds occurred during the LGM and this may have given rise to enhanced orographic rainfall in western Tasmania.

Widespread periglacial activity occurred throughout Tasmania, notably in Ben Lomond, Mt Wellington and Mt Jerusalem (Davis, 1958; Caine, 1983; Hannan and Colhoun, 1991; Colhoun, 2002; Barrows, et al., 2004). Glaciers waxed and waned until the last maximum advance, 17-21 kyr (Barrows, et al., 2002; Mackintosh, et al., 2006). Relatively little is known about the culmination of the LGM, but terrestrial vegetation changes indicate that the temperature increased dramatically sometime after $18 \mathrm{kyr}$ (Hopf, et al., 2000). A southward expansion of subtropical continental highs from Australia, contributing to rapid glacier recession has been suggested (Hopf, et al., 2000). Rapid warming at this time is consistent with records in the sediment cores in the Southern Ocean and Antarctic ice cores (e.g. Petit, et al., 1999; Barrows, et al., 2007). 


\subsection{Glaciers as palaeoclimatic indicators}

\subsubsection{Climate and mass balance}

In glaciological terms, mass balance involves two main components, which are both dependent on elevation: 1) accumulation, resulting from processes which add snow or ice to the glacier system and 2) ablation, where snow and ice are lost from the glacier system (Figure 2-2). Zones of net accumulation occur in the upper reaches of the glacier and net ablation towards the glacier terminus where annual ablation exceeds accumulation. These zones are divided by the equilibrium line, whose position is determined by the local and regional climate and topography. Snow and ice transfers from the accumulation zone to the ablation zone by glacier flow, which takes place by sliding, deformation of the ice, and deformation of the glacier bed (Benn and Evans, 1998). When a glacier is in equilibrium, the rates of glacier flow match the rates at which snow and ice are added and removed from the system. Mass balance investigations provide a quantitative expression of volumetric change through time. Annual variability in mass balance in response to climate change is usually expressed as positive, negative or zero, depending on the sum of accumulation and ablation over the glacier. 


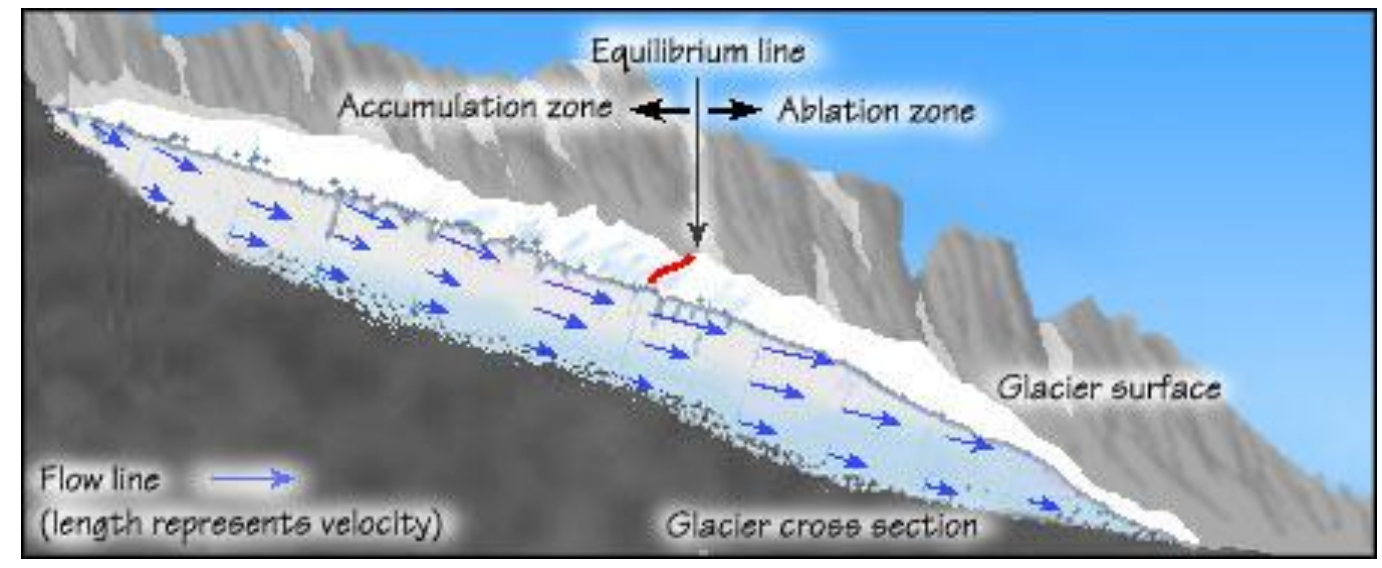

Figure 2-2: Schematic cross-section through a typical valley glacier showing both the accumulation and ablation zones. The ELA is shown by the red line where mass balance $=0$. Preferential flow direction and speed are shown by the blue arrows. The longer arrows represent larger flow velocities. Modified from Granshaw and Fountain (2003)

Glacier mass balance is a good indicator of climate fluctuation. The net mass balance integrated over the glacier (a measure of change in glacier volume) in the short term responds with little delay to climate change (Dyurgerov and Meier 2000). A response delay is expected due to the time of dynamic adjustment (Paterson, 1994) For instance, small to medium sized ice bodies (e.g. cirque, valley and ice cap glacier systems) are more useful than ice sheets for measuring short-term (decadal to centennial timescale) climate changes because of their shorter response times. On a global scale, air temperature and precipitation are considered to be the most important variables governing glacier mass balance. This is especially true for glaciers located in the mid to high latitudes, where air temperature governs the seasonality. Detailed investigations into the interactions between climate and mass balance on temperate glaciers provide a basic insight into the nature of the energy budget on glaciers (e.g. Munro and Davies, 1978; van de Wal, et al., 1991; Oerlemans and Vugts, 1993). Positive temperatures promote ablation and negative temperatures enhance the potential for accumulation (Ohmura, 2001). The rate at which mass balance on a glacier changes also varies systematically with altitude. This rate, known as the mass balance gradient, depends on the amount of local precipitation that a glacier receives. Steep mass balance gradients prevail in high 
precipitation areas, where maritime glaciers are characterized with both high rates of accumulation and ablation (Oerlemans, 1992; Oerlemans and Fortuin, 1992). Conversely, glaciers in drier and more continental environments have a smaller mass balance gradient and undergo less change in specific mean balance for a similar climate change.

Several authors have attempted to estimate palaeo-ELAs by reconstructing former glacier limits from glacial geomorpholigcal evidence (Porter, 1975; Sissons and Sutherland, 1976; Meierding, 1982; Torsnes, et al., 1993). Although it is possible to estimate the change in ELA associated with former glacial advances, it is not possible to disentangle the relative meteorological components (precipitation and temperature). Mass balance modelling, however, allows the relative importance of each variable to be assessed independently.

\subsection{Ice flow modelling}

Landform records documenting formerly glaciated areas provide a wealth of information from which interpretations of age, ice dynamics and former glacier geometry can be extracted. However, these inferences are limited to localized glaciation in the study area, and are not usually transferrable to a regional or continental scale. Numerical modelling provides an effective method of simulating the geometry, dynamics and climate of former glacier advances. Detailed field investigations, which are chronologically sound, provide the necessary constraints in which to validate the model.

The very first glacier models were simple one-dimensional flowline models (e.g. Budd, 1975; Pollard, 1978; Oerlemans, 1980). These models assumed glaciers were of uniform width, that underlying bed slope was constant and that they behaved like a perfectly plastic deformable solid. However, as advances in the understanding of physical principals underlying glacier physics and computational power improved, so has the complexity of glacier modelling. The most complex and advanced models are three-dimensional thermomechanical ice-sheet models, which are able to describe the 
time dependant flow of ice-sheets. Models of this type are used in this thesis and have been applied to a number of locations, including Antarctica, Greenland, Iceland and Scotland (e.g. Greve, 1997; Hubbard, 1997, 1999; Bougamont, et al., 2005; Hubbard, et al., 2006; Golledge, et al., 2008; Pollard and DeConto, 2009). However, no matter how detailed a numerical ice-sheet model is, it is still a simplification of multifaceted natural process. Complexities within the glacierclimate system or uncertainties in model boundary conditions prevent us from fully reconstructing and understanding past glacier advances, or making adequate predictions of the state of future glaciers. 


\section{Chapter 3 \\ Regional Setting}

\subsection{Location}

Tasmania, lying between 42 and $44^{\circ} \mathrm{S}$, is an island situated off the southeast coast of Australia (Figure 3-1). It is separated from the mainland by Bass Strait, with its remaining coastlines being bounded by the Southern Ocean on the south and west, and the Tasman Sea on the east. The land is quite rugged, despite its low overall elevation, with the highest peak, Mount Ossa, reaching $1617 \mathrm{~m}$. The Central Plateau includes several peaks in excess of $1500 \mathrm{~m}$. West of the Central Plateau are a series deeply incised peaks not exceeding $1000 \mathrm{~m}$ in elevation. Not far from the western coastline lies the West Coast Range, an area with several peaks exceeding $1200 \mathrm{~m}$. Smaller mountain ranges occur in western, southern and eastern Tasmania.

\subsection{Climate}

The mid-latitude westerly wind belt has a dominant influence on the climate of Tasmania. The annual northward and southward migration of the westerly wind belt is determined by the position of the continental sub-tropical ridge over Australia. The prevailing westerly airstreams means that Tasmania experiences a marked west-toeast precipitation gradient. The West Coast Range receives in excess of $3000 \mathrm{~mm}$ of precipitation annually, while precipitation further east reaches a maximum of only 400-500 mm per annum (Figure 3-2). Frost and snow falls are common during winter in the mountainous areas (> $500 \mathrm{~m}$ ), but do not lie for more than a few days at a time at lower elevations. Above $\sim 1200 \mathrm{~m}$, a seasonal snowpack develops, supporting several small ski fields during the winter and early spring. Another feature of the Tasmanian rainfall is the relatively modest seasonality on the east coast compared to the west coast, which exhibits high winter rainfall. Temperature variation is governed both by elevation and distance from the coast (Figure 3-3); with coastal areas experiencing a daily temperature range of $7^{\circ} \mathrm{C}$ and inland areas experiencing 
diurnal temperature ranges double that of coastal regions. During the summer months, the average temperature in coastal areas can reach $24^{\circ} \mathrm{C}$, with other inland areas on the Central Plateau ranging from 4 to $17^{\circ} \mathrm{C}$. The winter months are the coldest and wettest, with coastal temperatures reaching a maximum of $12^{\circ} \mathrm{C}$ while inland regions reach $3^{\circ} \mathrm{C}$. The temperate climate of Tasmania means that seasonal temperature varies by about 6 to $7^{\circ} \mathrm{C}$ annually. 


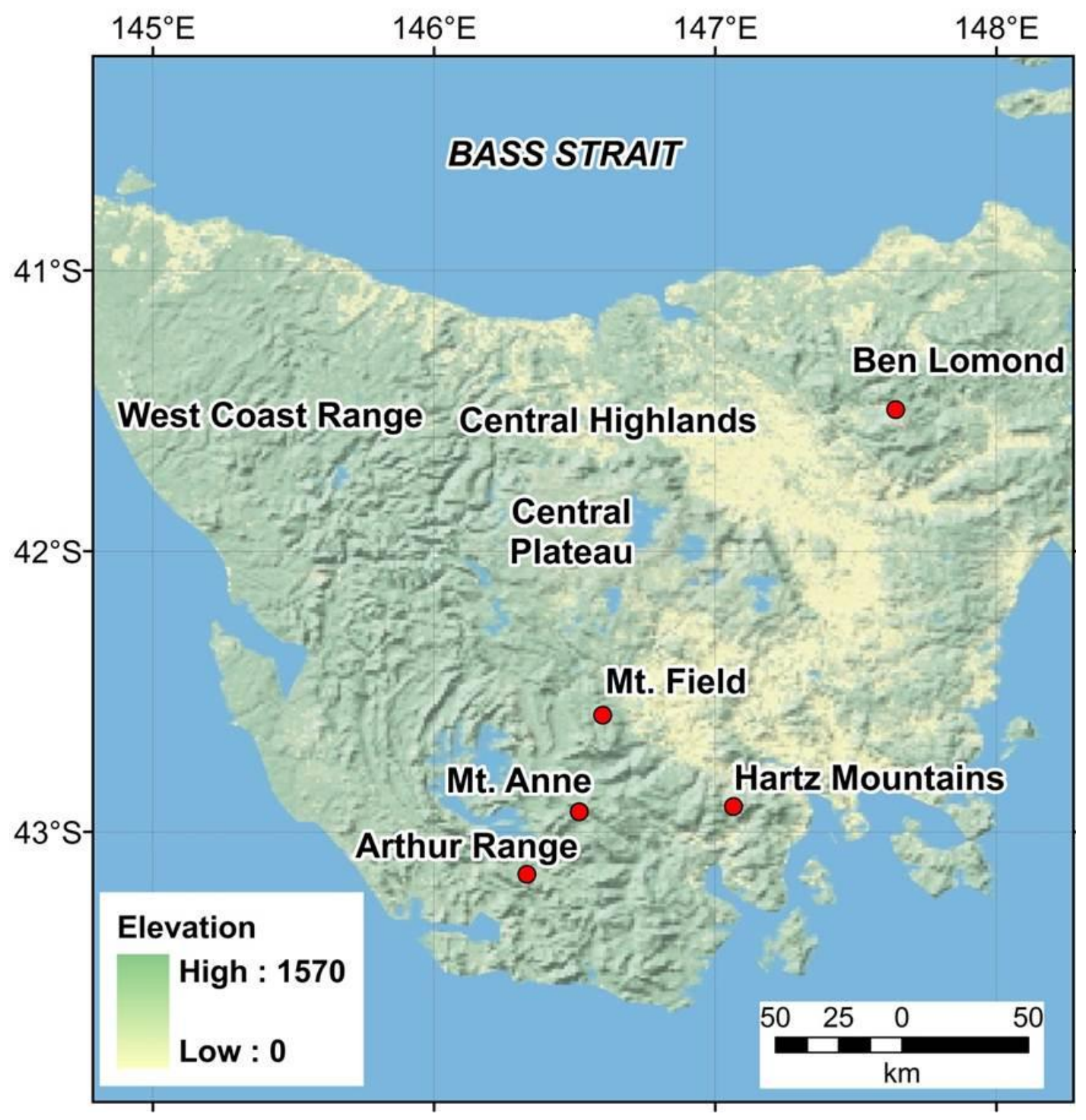

Figure 3-1: Location of Tasmania. The main areas of former Quaternary glaciation are labelled. 


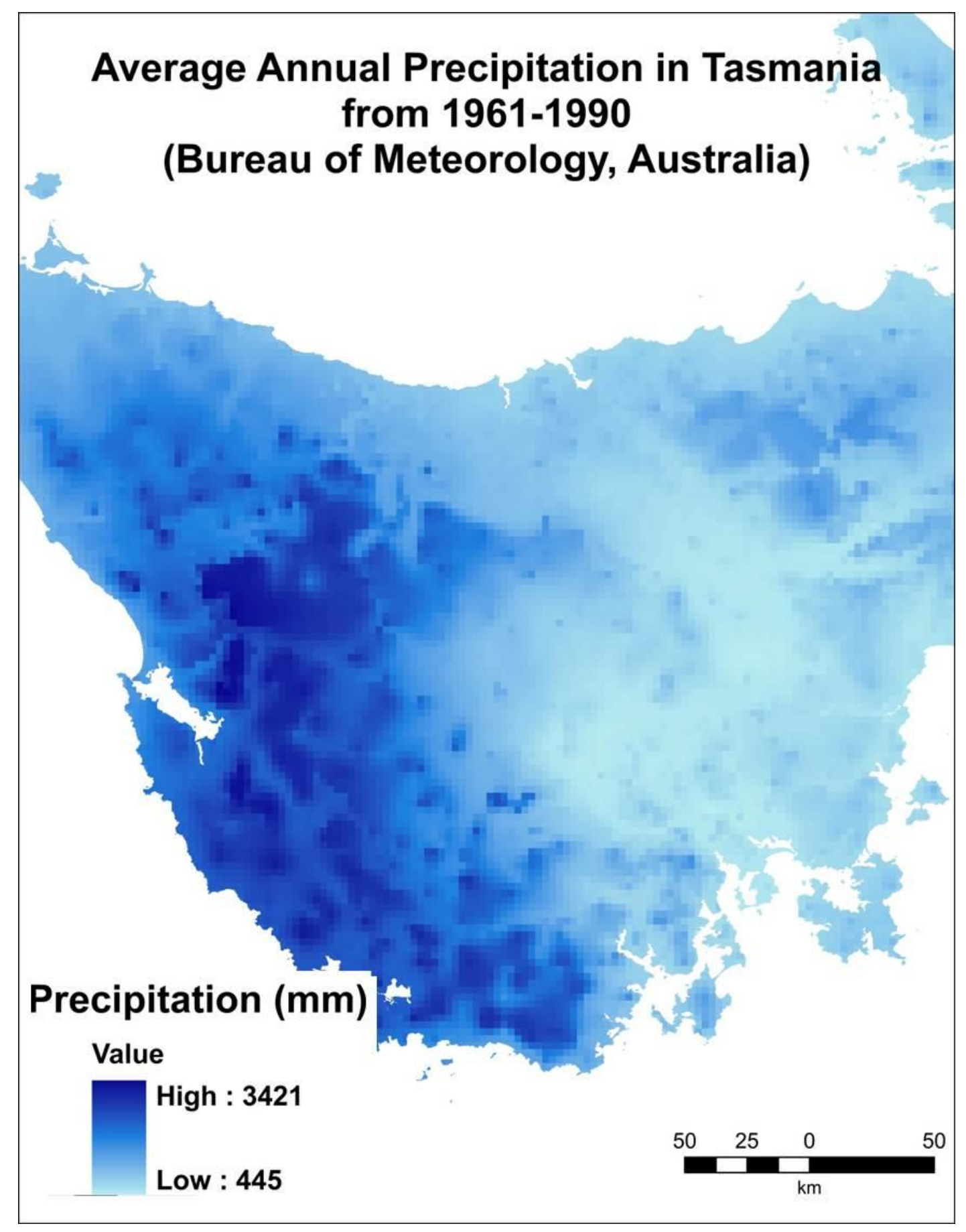

Figure 3-2: Average annual precipitation across Tasmania from the years 1961 to 1990. Sourced from the Bureau of Meteorology, Australia. 


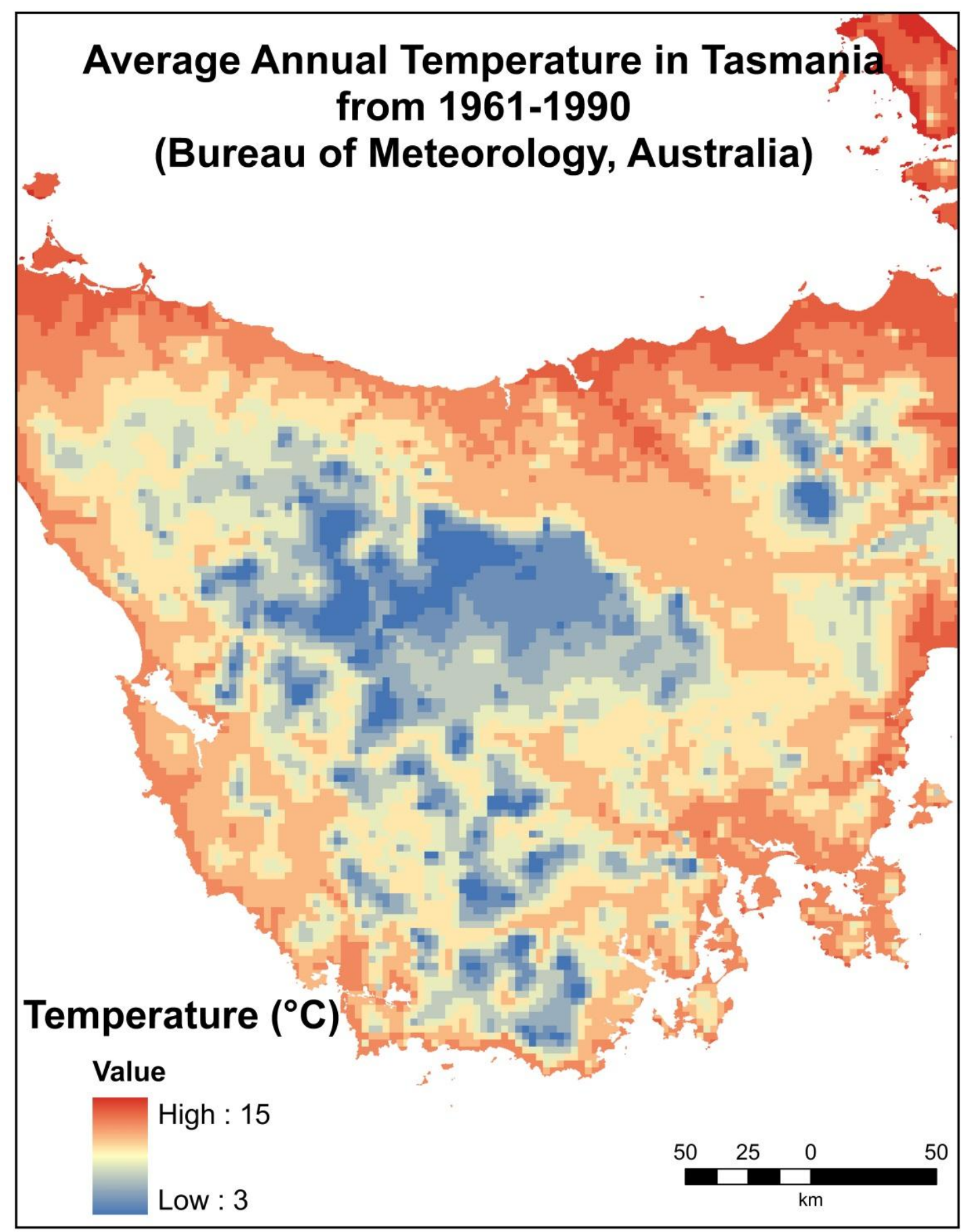

Figure 3-3: Average annual temperature across Tasmania from the years 1961 to 1990. Sourced from the Bureau of Meteorology, Australia. 


\subsection{Geology}

The geology of Tasmania is highly complex and has been extensively investigated and mapped in a number of studies (e.g. Seymour and Calver, 1995; Bottrill, et al., 1998; Stacey and Berry, 2004). Due to the complexity of the island's geology, only a simplified summary is presented here.

The West Coast Range consists of complexly faulted and folded late Cambrian to early Ordovician conglomerates, sandstones and slates flanked by intermediate volcaniclastic rocks (Corbett, 1975). Minor Cambrian granite dominates the east of the West Coast Range. To the north and northeast, the area is floored by faulted Ordovician limestone and Siluro-Devonian metasediments (Baillie and Hudspeth, 1989). The surrounding peaks and plateaus comprise Precambrian schists and quartzites and are capped by Tertiary basalts. Sills of Jurassic dolerite dominate the geology of central and eastern Tasmania, capping all of the high mountains and plateaus. The major intrusion of dolerite represents rifting from Gondwana, with similar rocks found in the Transantarctic Mountains. The dolerite overlies extensively faulted subhorizontal Triassic sandstones and Permian siltstones belonging to the Parmeener Supergroup (Burrett and Martin, 1989), which occupy the lower slopes and valley floors. The dolerite uplands formed an important high relief area for the development of glaciers.

\subsection{Previous research on glaciation in Tasmania}

Evidence alluding to the former presence of ice in Tasmania was discovered between 1850 and 1920 (Banks, et al., 1987). Early mapping by A.N. Lewis (19201945) of glacial landforms from the mountains of central and western Tasmania suggested three glacial advances occurred. Lewis assigned each of these glacial advances in order of increasing age: Margaret, Yolande and Malanna. An extensive ice cap was inferred to have developed over western Tasmania during the oldest Malanna advance, with the Yolande and Margaret advances limited to valley and cirque glaciers. However, Lewis's conclusions were based purely on erosional 
evidence and failed to consider the stratigraphic divisions present in the abundance of glacial deposits. Construction work in Tasmania increased after 1950, producing a number of new glacial and non-glacial exposures. Doubts about the validity of Lewis's theory subsequently arose after re-examination of a number of deposits by Davis (1958) and Banks and Ahmad (1959). Analysis of number of deposits at Malanna previously interpreted as glaciogenic found records of Tertiary faulting and were subsequently reassigned as being Tertiary fluvial and lacustarine deposits (Banks and Ahmad, 1959). Suggestions that this trend may occur elsewhere were confirmed when radiocarbon dating of a tree-stump of the Linda Valley moraine revealed an age of $26480 \pm 800$ years. Not only was Lewis's estimation of Pleistocene ice extent exaggerated, but his three phase advance scheme displayed significant flaws. It is not surprising that that his theory was abandoned soon after, with most glacial deposits, apart from a few erratics reassigned Last Glaciation age (Derbyshire, et al., 1965; Davis, 1967; Derbyshire, 1968; Colhoun and Peterson, 1986).

Recent studies focused on the refinement of empirical limits through improvement in the understanding of landform genesis and the introduction of advanced dating techniques. Increased land excavation in the 1960s and 1970s for dam construction purposes provided a number of key site exposures for detailed investigation. In the central and northern West Coast Range, a variety of absolute and relative dating techniques identified up to four periods of glaciation (e.g. Augustinus and Colhoun, 1986; Fitzsimons and Colhoun, 1991; Fitzsimons, et al., 1993; Augustinus, et al., 1994; Augustinus and Colhoun, 1995; Augustinus and Macphail, 1997; Augustinus, et al., 1997; Augustinus, 1999a). Three glaciations were differentiated by relative dating techniques in the Central Highlands (Kiernan, 1990b, 1992, 1999) and further north in the Mersey and Forth valleys (Hannan and Colhoun, 1987, 1991; Kiernan and Hannan, 1991). Several isolated areas of minor cirque glaciation and localized valley systems have also been investigated in some detail. Five glaciations were differentiated by weathering criteria by Kiernan (2001) in southern Tasmania at Mt Field. The two most recent advances were later dated precisely through cosmogenic dating by Barrows (2002) and Mackintosh et al. (2006). 


\subsubsection{Patterns of ice evolution}

It is evident from the pattern of ice distribution that topography was very influential in controlling ice buildup and flow. Initial studies suggested that the Central Plateau was the heart of Pleistocene glaciation in Tasmania. Given that the area is a high plateau area, with purely erosional attributes, these inferences are reasonable. However, Derbyshire (1972) reasoned that the role of precipitation was just as important as topography in determining ice distribution. With that in mind it should be expected that the greatest accumulation of ice should occur in areas that have both the highest mountains and receive the largest snowfalls. Trim line mapping showed that ice thicknesses were small over much of the Central Plateau, whereas ice was much thicker in the major troughs. As a result, principal accumulation zones were later inferred by Kiernan (1990b) to have developed over the Central Highlands and Du Cane Range (Figure 3-4). Ice descending from these accumulation areas ultimately fed numerous large valley glaciers to the north and south of the ranges. The largest of the southern glaciers flowed down the Derwent Valley, excavating a trough that is now partly occupied by Lake St Clair. Ice that flowed northwards did so down the Mersey and Forth valleys (Spry, 1958; Derbyshire, et al., 1965; Paterson, 1965, 1969; Hannan and Colhoun, 1987). Ice flowing west off the Du Cane Range flowed down the Eldon and South Eldon valleys. These valleys fed into the King Valley glacier, which at its maximum was $410 \mathrm{~m}$ thick and extended $19 \mathrm{~km}$ southwards (Kiernan, 1983; Colhoun, 1985). Ice also spilled into the King Valley from glaciers on the West Coast Range. Interestingly, little detailed investigations have been carried out in the valleys between the Du Cane Range and the West Coast Range. A number of authors (e.g. Davis, 1969; Flint, 1971; Derbyshire, 1972; Kiernan, 1990b) speculate that ice stretched continuously across these two ranges during the largest glacial advance. Kiernan (1990b) inferred this based on ice surface gradients; however, no definitive conclusions can be made in the absence of clear field evidence. Nevertheless, while the extent of the eastern flowing glaciers on the West Coast Range is uncertain, ice did flow westwards into the Yolande and Henty Valley and northeast into the lower Murchison and Pieman valleys (Colhoun, 1985). Ice limits on the easternmost area of the Central Plateau are difficult to distinguish, 
given the absence of depositional evidence. Evidence of former glaciation on the Central Plateau is expressed through zones of bedrock scour, which today are occupied by thousands of lakes. Till close to the western shoreline of Great Lake indicates that ice extended $\sim 48 \mathrm{~km}$ east of Lake St Clair (Derbyshire, 1968; Kiernan, 1983).

\subsubsection{Glacier dynamics}

Former glacier dynamics are expressed in the geomorphology of Tasmania. Western Tasmania comprises deep cirques and rock basins with large moraines, reflecting rapid mass throughput where snowfall was heaviest (Peterson, 1968; Davis, 1974; Colhoun, 1985). This contrasts with shallow and open cirques in Eastern Tasmania, indicating relatively less dynamic ice movement where accumulation was restricted. This is again reflected in the northeast rise in cirque floor elevations which largely mimics present-day precipitation patterns (Davis, 1969). Insights into the thermal regime of Tasmanian glaciers are provided from the composition of terminal moraines around Lake St Clair. The presence of $75 \%$ bedded material infers that meltwater was abundant in the terminal zones, and indicates that glaciers mostly or dominantly had a temperate thermal regime (Derbyshire, 1963). The glacier model used in this thesis includes thermodynamic components of glacier motion. This means that warm-based glaciers can be simulated with ease, however, the model also copes with ice that may have been somewhat colder. 


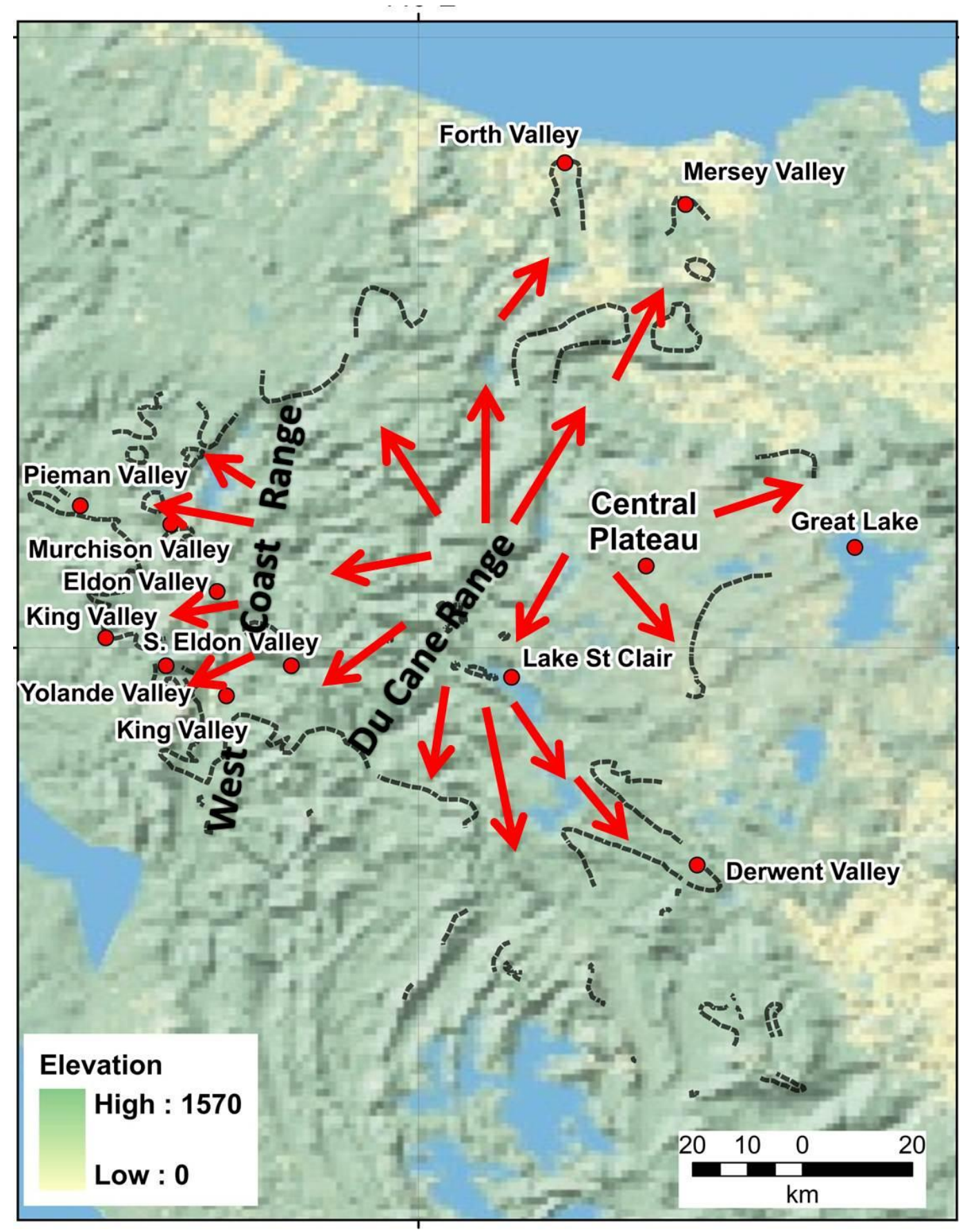

Figure 3-4: Pattern of glaciation over the Tasmanian Central Highlands with locations mentioned in text. The red arrows represent the general direction of ice flow during each glacial. The ice limits in black are from the early Pleistocene glacial, which is the largest known Quaternary advance. 


\section{Chapter 4 \\ Methodology}

\subsection{Introduction}

\subsubsection{Digital data acquisition}

Considerable research has been undertaken on both the extent and timing of Quaternary glacial advances over the Central Highlands, Central Plateau and the West Coast Range of Tasmania. However, the information is divided between numerous reports and publications which are neither favourable nor practical for visual interpretation. Therefore, a compilation of all existing field evidence, primarily constraining Quaternary ice extent was necessary.

A Geographical Information System (GIS) offers a simple means in which to collate, display and manipulate individual data sets within a single user interface. For this thesis ArcGIS, including ArcMap and ArcCatalogue, was used to store information extracted from all relevant published reports and maps. The numerical modelling component of this thesis relies heavily on ArcGIS for the visualisation of model output. File outputs produced by model runs were converted into ESRI raster format, allowing quick visualization of ice extent, velocity, temperature etc.

A compilation of geomorphological features focused on landforms constraining ice extent (moraines, nunataks, erratic and drift limits) and source areas (cirques and aerial scouring) were added to a 1:250 000 Digital Elevation Model (DEM), obtained from Geoscience Australia (GEODATA) (Figure 4-1). Data coverage varied enormously, with some areas (e.g. West Coast Range and Lake St Clair) receiving repeated attention, while other areas lacked comprehensive field investigations, mostly due to heavy forest cover and mountain access issues. The age of glacial deposits was well constrained in some areas with many studies using crosscorrelative techniques such as relative weathering criteria and $\mathrm{C}^{14}$ dating. Only the most recent papers contained cosmogenic ages, and only for the most recent glacial advances. 


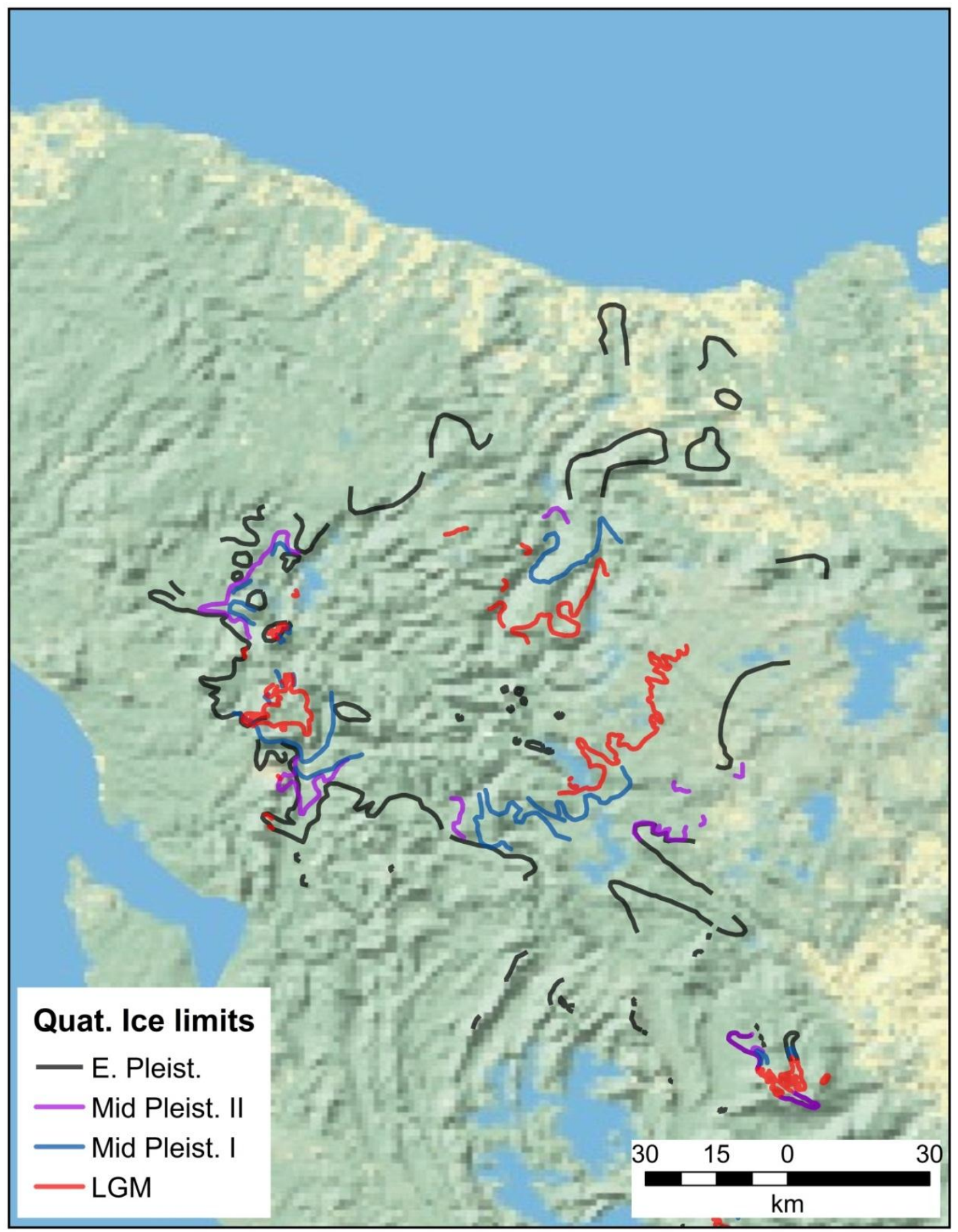

Figure 4-1: The model domain, showing Quaternary glacier limits from empirical studies. See Appendix I for source information. 
Where possible, paper maps were first georectified, and the appropriate features were then digitized. However, this procedure could only be applied to maps containing geographical information (gridlines, co-ordinate tick marks) that constrained the location of glacial landforms. More frequently, comparisons were made between data available on the maps (e.g. contours, town locations and road and river patterns) and thematic layers in order to locate and digitize glacial landforms. Different map scales and inconsistent geographical detail meant that the locations of some landforms within the GIS were slightly inaccurate. However, the spatial resolution of the model is such that minor imprecision does not matter. All layers once entered into the GIS, were registered using Australian Grid system. Layers were also attributed with a series of comments, including citations, derivation of ages, and any other relevant remarks. The GIS database is available on request from the author at becs@kenex.co.nz.

\subsection{Numerical ice-sheet modelling}

\subsubsection{Model description}

The model used for the experiments in this thesis is a three-dimensional thermomechanical ice- flow model, first developed and validated by Dr. Alun Hubbard to model the Younger Dryas ice cap and climate in Scotland (Hubbard, 1997, 1999; Golledge and Hubbard, 2005; Golledge, et al., 2008). It was also subsequently used to model the LGM ice caps in Patagonia (Hubbard, et al., 2005) and Iceland (Hubbard, et al., 2006).

The model simulates the time-dependent evolution of ice and includes both ice dynamics and climate forcing. While the mathematics behind the model is described elsewhere (Hubbard, 1997, 1999; Hubbard, et al., 2005), the fundamental equations are described in subsequent sections (4.2.1 - 4.2.4). One particular advantage of this model is its ability to operate at high spatial resolutions (grid spacing $<1 \mathrm{~km}$ ), due to the inclusion of some higher order physics. 
The model is applied to a $500 \mathrm{~m}$ grid and is used to observe the likely time-space distribution of ice during the Quaternary from initially ice-free (present day) conditions. Input specifications of basal topography (derived from the DEM) and modern temperature and precipitation data obtained from the Australian Bureau of Meteorology were required. In addition to the input specifications, the model has a parameter file (Table 4-1), which includes variables governing both ice dynamics and climate. Variables within the parameter file are able to be adjusted; meaning investigations into both internal and external glacier forcings can be explored.

\subsubsection{Model structure}

The model is driven by a simple mass-balance elevation/latitude relationship which is forced by a single-stepped relative change from present. Ice is allowed to evolve in response to climate forcing based on the continuity equation:

$$
\frac{\partial H}{\partial t}=b-\nabla \cdot(H \bar{u})
$$

$H$ is ice thickness, $t$ is time, $b$ is the net mass balance and $\overline{\mathrm{u}}$ is the vertically averaged horizontal velocity. Temporal change in ice thickness is the residual of the surface mass balance minus the vertically integrated ice flux from adjacent grid nodes $(\nabla)$.

\subsubsection{Mass balance}

Glacier mass balance $(b)$ is driven by a simple altitude-related distributed Positive Degree-Day (PDD) algorithm based on that of Laumann and Reeh (1993). The PDD method is based on the statistical assumption in that there is a high correlation between days with positive temperatures $\left(>0{ }^{\circ} \mathrm{C}\right)$ and ablation (Braithwaite and Olson, 1985). Despite the limitations and assumptions associated with simplifying 
complex processes (van der Veen, 2002), more adequately described by an Energy Balance Model (EBM), PDD schemes have been used successfully on glaciers over a broad range of climatic conditions (Braithwaite, 1984, 1995; Jóhannesson, et al., 1995).

The simplicity in the parameterization of the PDD scheme means that only two climatic variables need to be established (temperature and precipitation) for glacier surface mass balance. This provides a practical advantage when the temporal and spatial palaeo-data required for more detailed and complex EBM (e.g. wind flux, albedo, radiation, etc.) are not available. The PDD model contains a number of parameters that are poorly constrained, in particular the degree-day factor, and are based on an implicit relationship between insolation and temperature. This relationship means that PDD models demonstrate a higher sensitivity to temperature than EBMs (Oerlemans, 2001).

Values of precipitation and temperature are computated based on present day datasets from Australia's Bureau of Meteorology. Temperature is specified as a multi-regressed $\left(R^{2}>0.9\right)$ series of monthly mean values over a period of a year. Precipitation is established in much the same way as temperature, with multiregressed $\left(\mathrm{R}^{2}>0.9\right)$ monthly mean precipitation values. Precipitation can be further modified if needed by imposing north-south and west-east linear gradients over the present-day precipitation pattern. Additionally, overall global precipitation can be reduced or enhanced with the introduction of a multiplier. A degree-day factor (DDF) of $0.0055 \mathrm{~m}^{\circ} \mathrm{C}^{-1} d^{-1}$ (Laumann and Reeh, 1993; Braithwaite, 1995; Hock, 2003) is used to account for snow and ice melt. Calving, while negligible in this investigation due to ice never reaching the land-sea interface, is calculated as a function of water-depth (Brown, et al., 1982).

\subsubsection{Ice dynamics}

Total ice velocity $(\overline{\mathrm{u}})$ within the model is controlled by both internal deformation (Glen, 1955), and Weertman-type (1964) sliding when basal temperatures reach the 
pressure melting point. Ice velocity can be modified within the model's parameter file by two integer scalars; the deformation enhancement factor and the sliding factor. The deformation enhancement factor modifies the Arrhenius component of the deformation rate of ice and the sliding factor alters the Weertman-based sliding coefficient. Together, these two enhancement factors control the total velocity of ice, as well as its geometry (through the deformation rate influence). Velocity is calculated by using the zeroth-order shallow ice approximation (SIA), under the assumption that the horizontal gradient of the bedrock and surface topographies are much smaller than the vertical ones (Hutter, 1983). This assumption holds true for most places in a glacier or ice sheet with shear stresses controlling ice flow. However, in some places, unexpected changes in the velocity of glaciers or ice sheets can occur at ice divides, near shear margins and close to the ice surface. Given that the SIA cannot predict the details of glacier dynamics at these high resolutions, higher-order terms including longitudinal stresses - normal deviatoric stresses in the direction of ice flow - are required. In order to accommodate the variations in ice flow, longitudinal stresses are induced by using an empirically validated ice stretching algorithm (Hubbard, 2000). This allows for a more realistic calculation of ice velocities than what is possible using the SIA alone.

\subsubsection{Model operation and strategy}

The model was typically used to observe ice evolution through a 1500 year run starting from ice-free conditions. Output files of ice surface elevation, surface and basal velocity and temperature were produced at specified time intervals. The timestep of 0.02 years was used in order to adequately balance model stability against computing time. A variety of ice cap/glacier configurations were produced through adjustments to the models parameter file (Table 4-1). This meant that a controlled and systematic modelling approach was developed, whereby incremental adjustments to specific parameters (e.g. temperature, precipitation, sliding etc.) were imposed. Each model run was assessed in terms of how well it corresponds to the empirical limits; introducing an assumption that the mapped glacial limits are correct. 
Initial experiments sought to gain a basic understanding of the overall sensitivity of the model to a set of key parameters. This involved a considerable number of model runs and parameter iterations, commonly involving incremental changes to individual parameters. It was hoped that the influence exerted by each parameter could be isolated; however, complex feedback responses in the climate/glacier system make this difficult. Once familiarity in how the ice distribution model output was established through basic sensitivity testing, further sensitivity experiments aimed to ascertain the most realistic variable combinations that match empirical reconstructions.

A similar method was employed for the simulation of discrete glacial advances. Ideal parameter configurations determined through sensitivity testing were further refined until an optimal-fit scenario was established for each of the four Quaternary advances. Both climatic and glaciodynamic parameters were guided by palaeoenvironmental studies as far as possible (see section 2.2). This is an important component for realistically modelling former glaciations and provides a plausible range of values for parameters governing mass balance to test. 


\begin{tabular}{|c|c|c|c|}
\hline Parameter & & Value & Units \\
\hline$g$ & Gravity & 9.81 & $m s^{-2}$ \\
\hline$p$ & Density of ice & 910 & $\mathrm{kgm}^{-3}$ \\
\hline $\boldsymbol{P}_{w}$ & Density of sea water & 1028 & $\mathrm{kgm}^{-3}$ \\
\hline$n$ & Glen flow-law exponent & 3 & \\
\hline G_value & Geothermal heat flux & 70 & $W m^{-2}$ \\
\hline$d \mathbf{S L}$ & Sea level & -120 & $m$ \\
\hline A_wert & Weertman sliding parameter & $7.50 \mathrm{E}-14$ & - \\
\hline A_budd & Budd sliding parameter & $3.17 \mathrm{E}-2$ & - \\
\hline DDF & Degree-day factor & 0.0055 & $m^{\circ} \mathrm{C}^{-1} d^{-1}$ \\
\hline lapse_rate & Temp/elevation relation & -0.0065 & ${ }^{\circ} \mathrm{C} m^{-1}$ \\
\hline \multirow[t]{2}{*}{$d t$} & Time step & 0.02 & $\mathrm{a}$ \\
\hline & Cell_size & 500 & $\mathrm{~m}$ \\
\hline \multirow{4}{*}{ Domain } & X_min & 144.61125 & ${ }^{\circ}$ longitude \\
\hline & X_max & 148.36125 & ${ }^{\circ}$ longitude \\
\hline & Y_min & -43.63125 & ${ }^{\circ}$ latitude \\
\hline & Y_max & -40.63875 & ${ }^{\circ}$ latitude \\
\hline
\end{tabular}

Table 4-1: Principal parameters used in the ice sheet model, with their values and units. The model domain is defined by $\mathrm{X}$-values (latitude) and $\mathrm{Y}$-values (longitude). 


\section{Chapter 5 \\ Results}

\subsection{Introduction}

In this chapter I present results from a number of modelling experiments conducted using the processes described in the Methodology Chapter.

The first part of this chapter features a range of sensitivity experiments designed to determine the relative influence on glacier extent exerted by meteorological controls, glacier dynamics and mass-balance gradients (Experiments 1-4). In the second part of this chapter I present a collection of simulations in response to different climate forcings in which modelled ice is compared to empirical reconstructions of Quaternary glacial advances (5.6 - 5.11).

\subsection{Sensitivity experiments}

A total of four experiments are carried out in order to understand the sensitivity of the coupled mass-balance/ice-flow model to changes in key parameters. The first two experiments (5.3.1 and 5.3.2) look at the changes in modelled ice geometry associated with alterations to its internal parameters. The outcome of the first two experiments will be to ascertain best fit model parameters as well as provide an assessment of model uncertainty. The last two experiments (5.4.1 and 5.4.2) investigate the sensitivity of the model to its input data, precipitation and temperature. While other meteorological factors, namely insolation, humidity and windiness can influence glacier mass balance, the focus is on temperature and precipitation only. This is based on the assumption that the environment of Tasmania favours the development of maritime glaciers, which are shown to be primarily sensitive to changes in summer or mean annual temperature and precipitation (e.g. Kuhn, 1984; Oerlemans and Hoogendoorn, 1989; Kerr, 1990). While numerous model runs are performed using different parameter configurations (both plausible and implausible), only a key selection of modelled outputs are presented that best demonstrate the results. All experiments are compared to a datum model run, under 
present precipitation conditions, a temperature depression of $-8.5^{\circ} \mathrm{C}$, a sliding value of 0 and a lapse rate of $-6.5^{\circ} \mathrm{C} \mathrm{km}^{-1}$.

\subsection{Sensitivity of the model to its internal parameters}

\subsubsection{Experiment 1: The role of sliding}

The aim of the first experiment is to determine whether the geometry of modelled ice masses is affected by alterations to the sliding parameter. The sliding factor is an integer scalar that modifies the Weertman-based sliding coefficient. Applying modifications to the sliding parameter means that the role of both basal sliding and internal deformation can be considered. The deformation factor, which is an integer scalar that modifies the Arrhenius component of the deformation rate of ice, can also be adjusted much like the sliding factor. The control the deformation factor has over the geometry of modelled ice is similar to that of the sliding factor. Modifying the deformation factor is likely to produce superficially similar results to altering the sliding factor, and is therefore not tested during these sensitivity experiments. The deformation factor will remain at a value of 5, with typical values ranging between 1 and 10 (Greve and Blatter, 2009). Figure 5-1 illustrates ice distribution when comparing sliding values (S) between 0 and 50 . By taking $\mathrm{T}=-8.5^{\circ} \mathrm{C}$ and $\mathrm{S}=0$ as the datum model run, some interesting comparisons can be made. What is immediately noticeable is that when the sliding factor is increased, lateral spreading of the entire ice domain occurs, resulting in increased areal ice extent. This is particularly prominent in areas with outlet glaciers, where ice flows further down valley into areas of lower elevations. The same cannot be said for large ice masses situated over the Central Plateau, which remain relatively stationary throughout all model runs and are therefore independent of sliding considerations. The other major difference is that the main ice masses become thinner in conjunction with higher sliding. In Figure 5-2 it is evident that glaciers expand in zones of higher basal velocity. Figure 5-2 also shows that increasing the sliding factor appears to enhance outlet glacier basal velocity further. This results from the main ice mass being funnelled into narrow valley outlets as velocity increases. Ice driven into the valleys will subsequently thicken, raise the basal temperature, and thus facilitate sliding at 
the bed. Therefore, the patterns described above resulting from modifications to basal sliding appear to both influence and be influenced by variations in ice velocity.

In addition to variations in ice velocity, altering the sliding factor produces differences in overall modelled ice geometry. With no sliding, ice movement occurs entirely through internal deformation; dependent on temperature, thickness and surface slope. Increasing the sliding factor allows pressure melting at the glacier bed to occur, along with enhancement of driving stresses and subsequent reduction in resisting forces. The ability for ice to move freely over its bed with increased sliding inevitably leads to greater lateral expansion of modelled ice. Clearly, in Tasmania where evidence of abrasion at the bed and presence of meltwater is abundant (Colhoun, 1985), there is a need to include sliding in the model. This meant that a sliding of parameter $\leq 0$ was implausible. However, a sliding parameter of 30 produced an ice geometry with too much ice extending down into the valleys. Numerical simulations of the Younger Dryas ice cap in Scotland by Golledge et al. (2008) use a sliding value of 2.5. Given that ice in Scotland was colder and less dynamic at its base (compared to Tasmania), a sliding value of 10 was a practical choice and produces an ice geometry with the most realistic fit. This is portrayed in the glacier profile along the Lake St Clair valley in Figure 5-3, where the overall shape of ice flowing from high to low elevations appears to be realistic. 


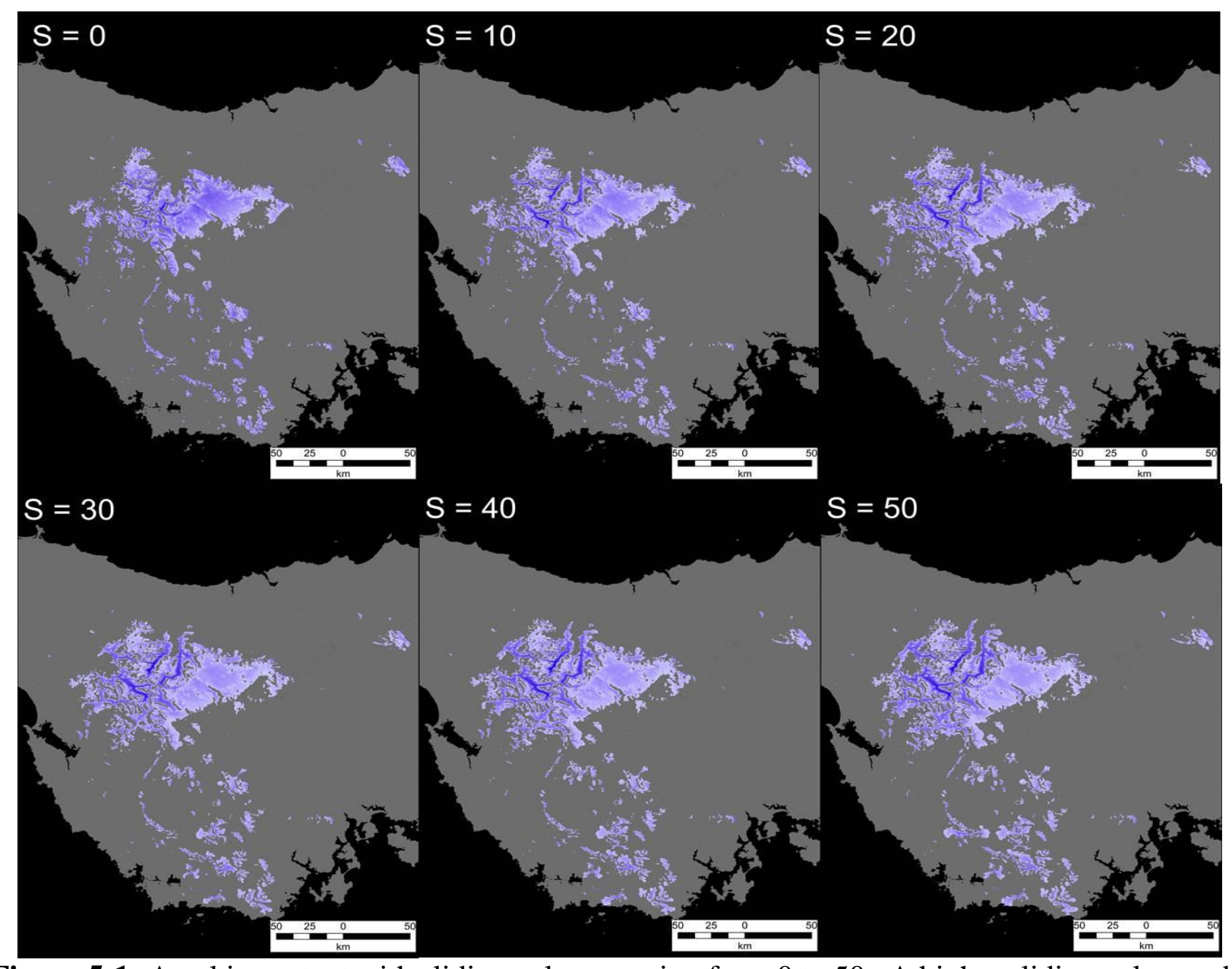

Figure 5-1: Areal ice extent with sliding values ranging from 0 to 50. A higher sliding value enables ice to move more freely over its bed (compared to a 0 value) and greater lateral spreading of ice is observed as the sliding value is increased. The datum control model for comparison has a sliding value of 0 , a lapse rate of $-6.5^{\circ} \mathrm{C} \mathrm{km}^{-1}$, present-day precipitation conditions and a temperature depression of $-8.5^{\circ} \mathrm{C}$ 


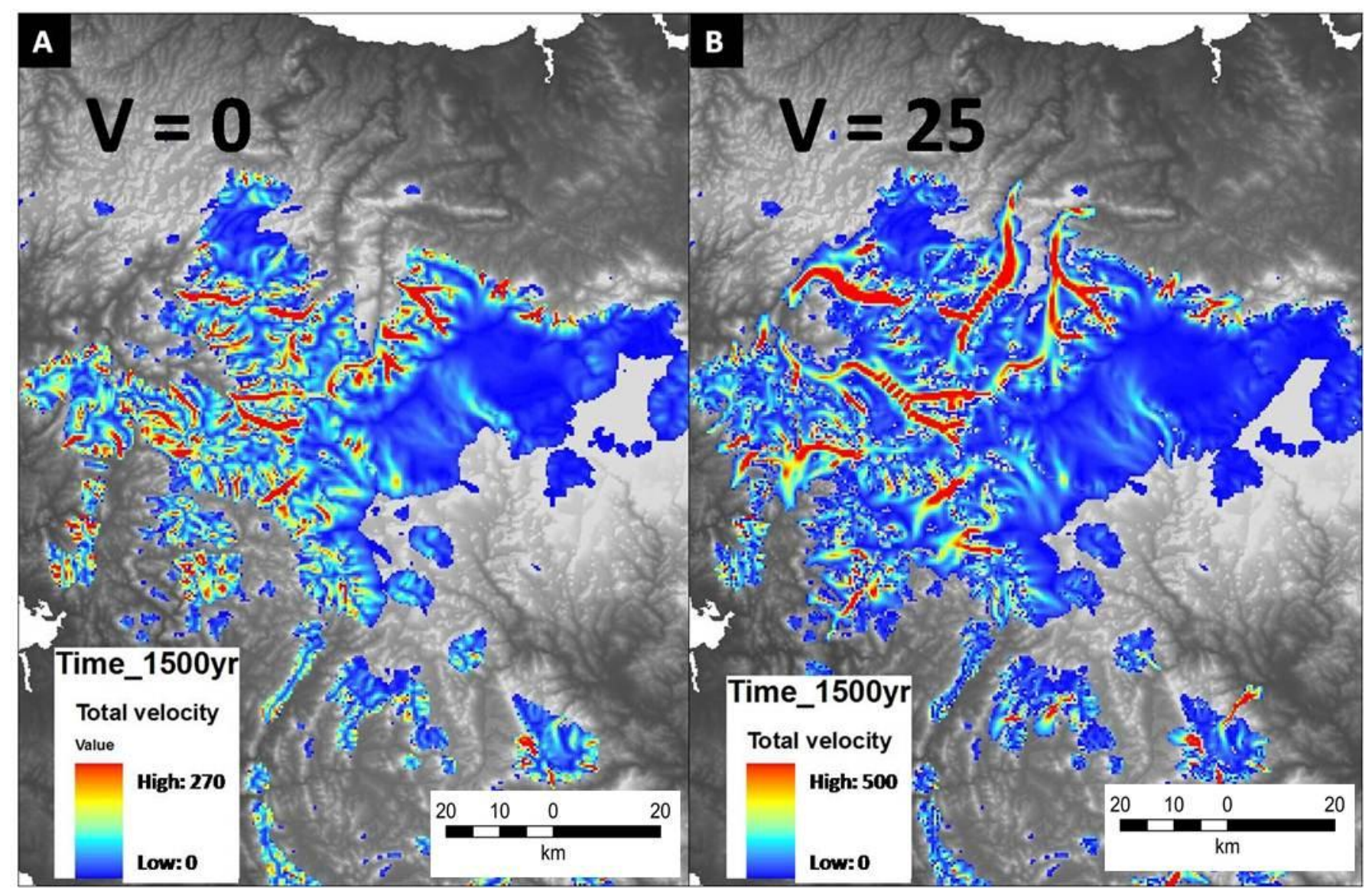

Figure 5-2: Distribution of total ice velocity under sliding values of 0 and 25 . The regional differences are far more obvious in this figure. The dynamics of former Quaternary glacier advances may have interesting linkages with the characteristics of contemporary landforms. 


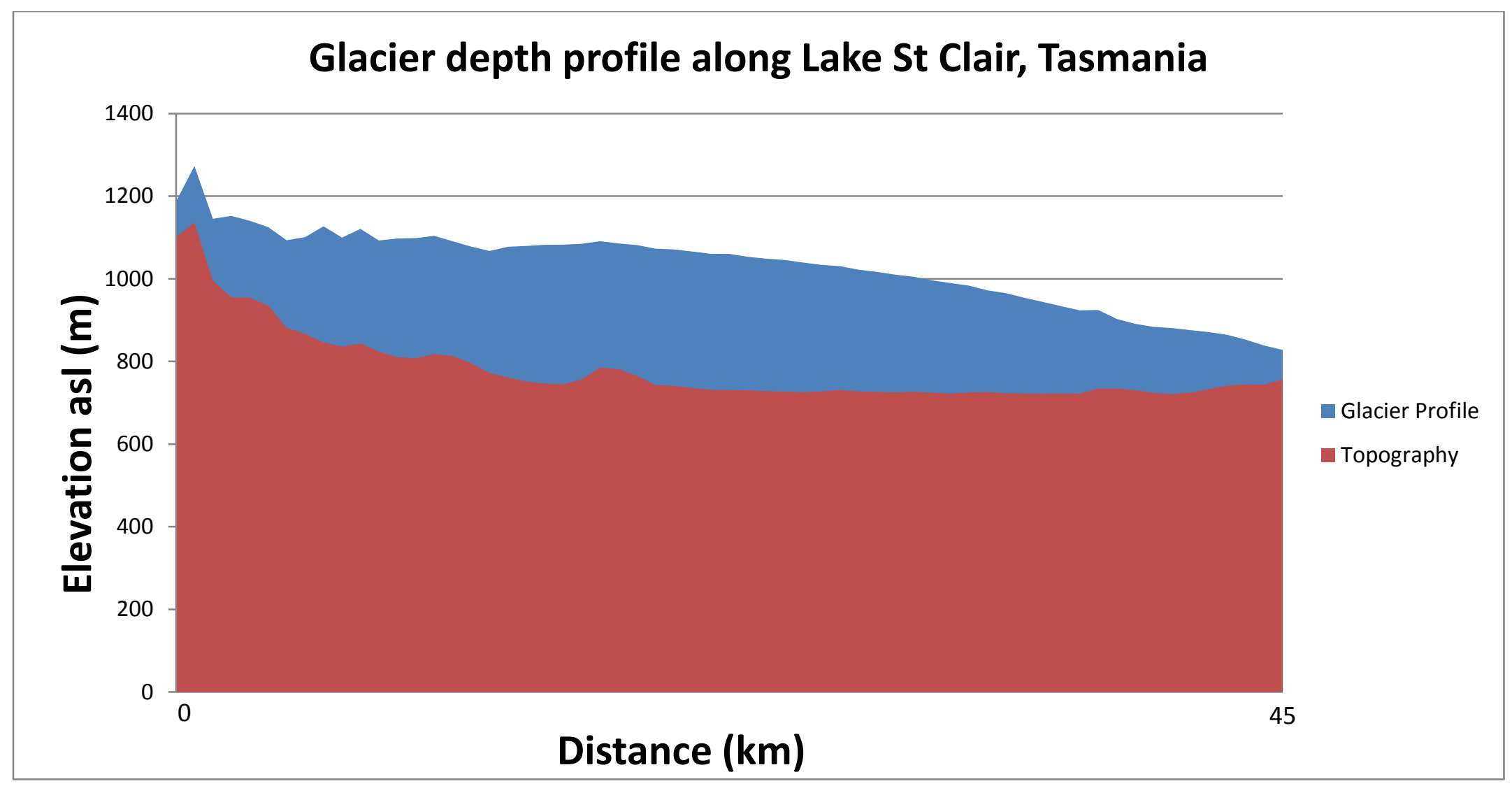

Figure 5-3: Profile view of a modelled glacier flowing down through Lake St Clair. The simulation uses a sliding value of 10 to enhance the Weertman-based sliding coefficient and produces a sensible looking valley glacier. Further modelling experiments will use a sliding value of 10 . 


\subsubsection{Experiment 2: Lapse rate}

The relationship between temperature lapse rate and ice distribution is now considered. The temperature lapse rate is an important parameter because of its effect on glacier mass balance. For example, the positive degree day (PDD) method uses the temperature lapse rate in order to calculate and determine the elevations at which ablation occurs. The temperature lapse rate also determines how much precipitation falls as snow, with snow falling when temperatures fall below $0^{\circ} \mathrm{C}$. Altering the environmental lapse rate will therefore impact the accumulation and ablation gradient, with larger lapse rates causing ablation to occur at higher elevations.

Figure 5-4 illustrates ice extent under lapse rates of $-5,-6.5$, and $-9^{\circ} \mathrm{C} \mathrm{km}^{-1}$. The differences are more subtle than in previous experiments, but trends are still present. Increasing the environmental lapse rate leads to progressive thinning and slight decreases in lateral ice extent. However, the lack variation between different simulations implies that the model is relatively insensitive to changes in the lapse rate value. Further modelling experiments use a lapse rate of $-6.5^{\circ} \mathrm{C} \mathrm{km}^{-1}$; typical of mid-latitudes (Barry, 1981). 

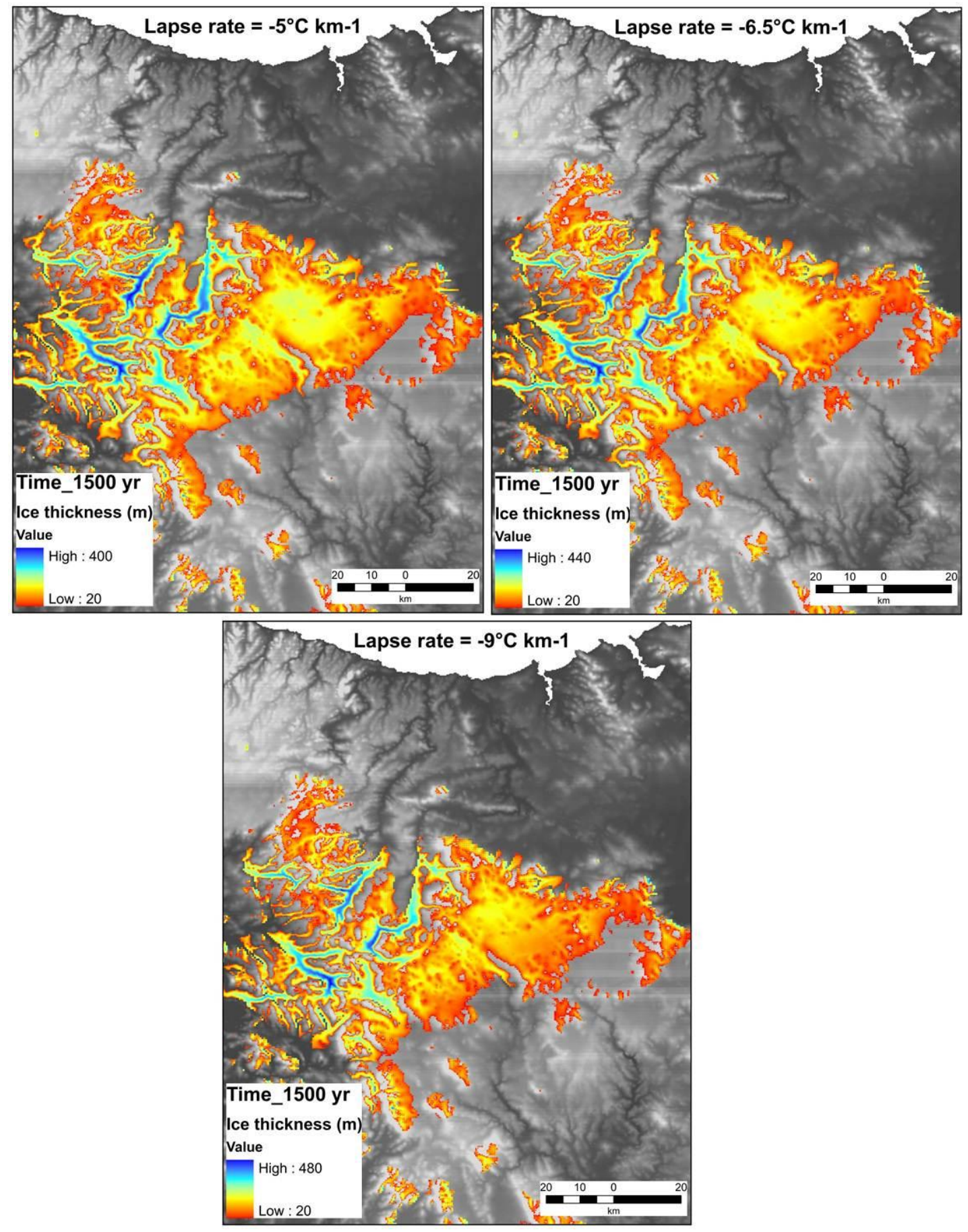

Figure 5-4: Distribution of ice under lapse rates of $-5,-6.5$ and $-9{ }^{\circ} \mathrm{C} \mathrm{km}^{-1}$. The differences between lapse rates are subtle, with slightly thicker and more expansive ice centered over the Central Plateau as the lapse rate increases. 


\subsection{Sensitivity of the model to its input data}

\subsubsection{Experiment 3: The influence of Temperature}

This experiment is designed to investigate the influence of changing temperature on ice extent. The model is forced by incrementally lowering temperature (from presentday), under contemporary precipitation conditions. A selection of modelled outputs illustrating aerial ice extent under various temperature conditions are presented in Figure 5-5. At $6^{\circ} \mathrm{C}$ of cooling, ice development is restricted to small cirque glaciers occupying the highest mountain summits. Increasing the temperature depression to $8^{\circ} \mathrm{C}$ produces a number of coalescing ice bodies, forming prominent ice masses over the Central Plateau and Central Highlands, reminiscent of Quaternary glacial maxima. Further cooling to $10^{\circ} \mathrm{C}$ results in the development of a large ice cap located over the Central Plateau and multiple coalescing glacier systems in South West Tasmania, superficially like a possible late Pliocene advance suggested by Kiernan (1990b). Tasmania develops an ice sheet with a cooling to $12^{\circ} \mathrm{C}$, with ice also reaching coastal regions in a number of areas. However, this last scenario is unrealistic and has not occurred during the late Cenozoic.

Figure 5-6 demonstrates the rate of ice volume development throughout the duration of the model run. With a $6^{\circ} \mathrm{C}$ cooling, the growth of ice at the beginning of the model run appears to be punctuated. This non-linear pattern of ice growth may reflect marginal climatic conditions, in other words, only slightly colder than the threshold required for glaciers to form. Despite this, steady-state ice conditions develop at around 200 model years, after which very slow expansion continues; discontinuing after 400 model years. Under $8^{\circ} \mathrm{C}$, substantial ice build-up occurs continuously within the first 50-150 model years, reaching equilibrium within 750800 model years. Similar trends are observed for progressively cooler temperature scenarios, with the majority of ice accumulation occurring relatively fast, followed by a period of slow increase towards equilibrium. We can conclude that significant ice build-up in Tasmania is possible in much less than 1000 years. 
As expected, the results of the experiment reveal that the model is highly sensitive to cooling. Ice growth primarily occurs in the western and central ranges where favourable combinations of altitude and precipitation occur. The model also reveals that various threshold temperature conditions need to be crossed in order to initiate ice development, emphasizing the influence of climate and topography on ice distribution. 


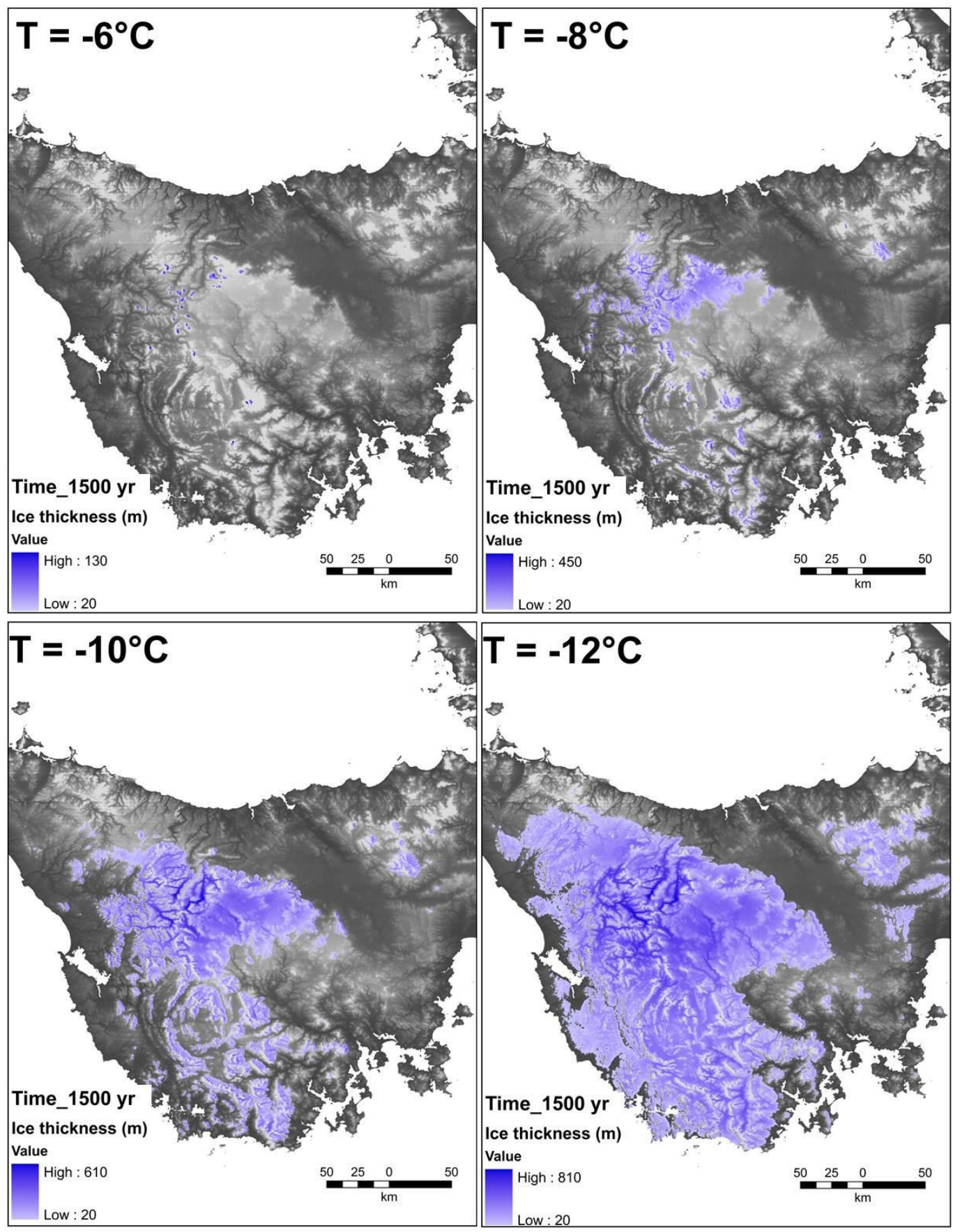

Figure 5-5: Ice extents resulting from stepped cooling of 6 to $12^{\circ} \mathrm{C}$ under present precipitation conditions. Coolings of 6 to $8^{\circ} \mathrm{C}$ superficially resemble Quaternary ice advances, whereas the ice sheet that formed in response to a $12^{\circ} \mathrm{C}$ cooling has not occurred in the late Cenozoic. 


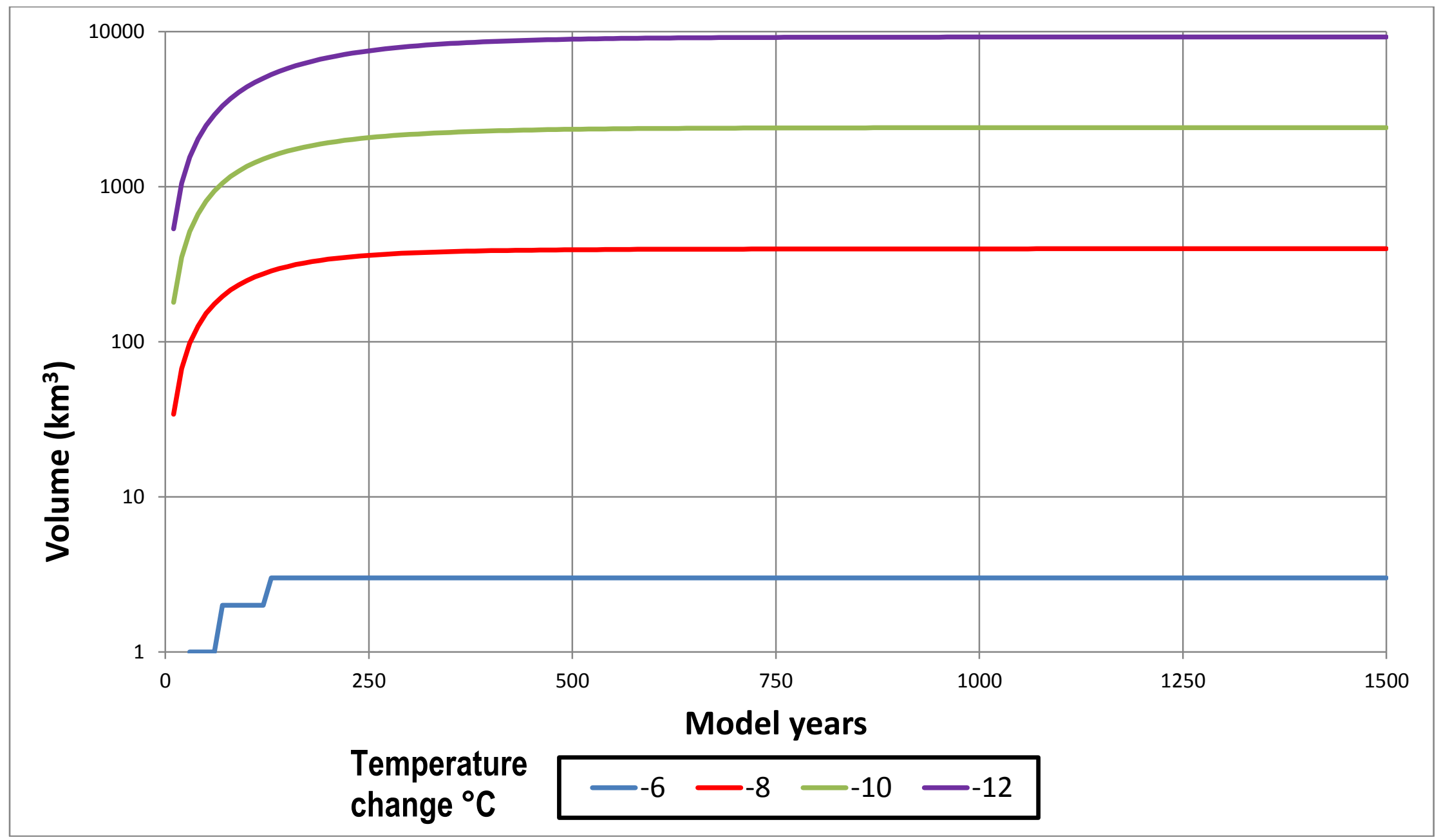

Figure 5-6: Ice volume trajectory throughout the entire model run (1500 years) resulting from coolings of 6 to $12^{\circ} \mathrm{C}$ under present precipitation conditions. Equilibrium is achieved in $\sim 800$ years. 


\subsubsection{Experiment 4: The influence of Precipitation}

I now consider the effects of precipitation over aerial ice extent and volume. In this experiment, the present-day precipitation regime is altered by systematically increasing and decreasing global precipitation. Regional precipitation was investigated as changing global precipitation may have been important for former glaciation in Tasmania. All model runs in this experiment are carried out using a temperature depression of $-8.5^{\circ} \mathrm{C}$, a sliding factor of 0 and a lapse rate of $-6.5^{\circ} \mathrm{C} \mathrm{km}$ 1. A selection of model simulations are presented in Figures 5-7, 5-8 and 5-9 comparing the datum (present-day precipitation) output with regional precipitation increases and decreases. When regional precipitation is decreased by $50 \%$, ice extent diminishes, with ice restricted to the highest mountain peaks (Figure 5-7). The reverse is true when regional precipitation is increased by 50\%, with ice extent becoming more expansive compared to the datum model run (Figure 5-8). At the extreme end of the scale, when regional precipitation is increased by $200 \%$, ice extent resembles the largest Quaternary advance (early Pleistocene) (Figure 5-9). However, this result exceeds the global precipitation maximum and is therefore an unrealistic climatic scenario.

While the influence of topography is still apparent in the pattern of ice accumulation, modifying regional precipitation appears to influence total ice volume. This is demonstrated when comparing total ice volume under between present-day conditions and modified regional precipitation (Figure 5-10). The contrasts in total ice volume are evident, with less ice development occurring when precipitation is reduced by $50 \%$, compared to when it is increased by $50 \%$ and $200 \%$. When precipitation is increased, more total snow fall is expected, resulting in a larger ice mass. In contrast, when precipitation is reduced, less total snow fall occurs and a smaller ice mass results. 


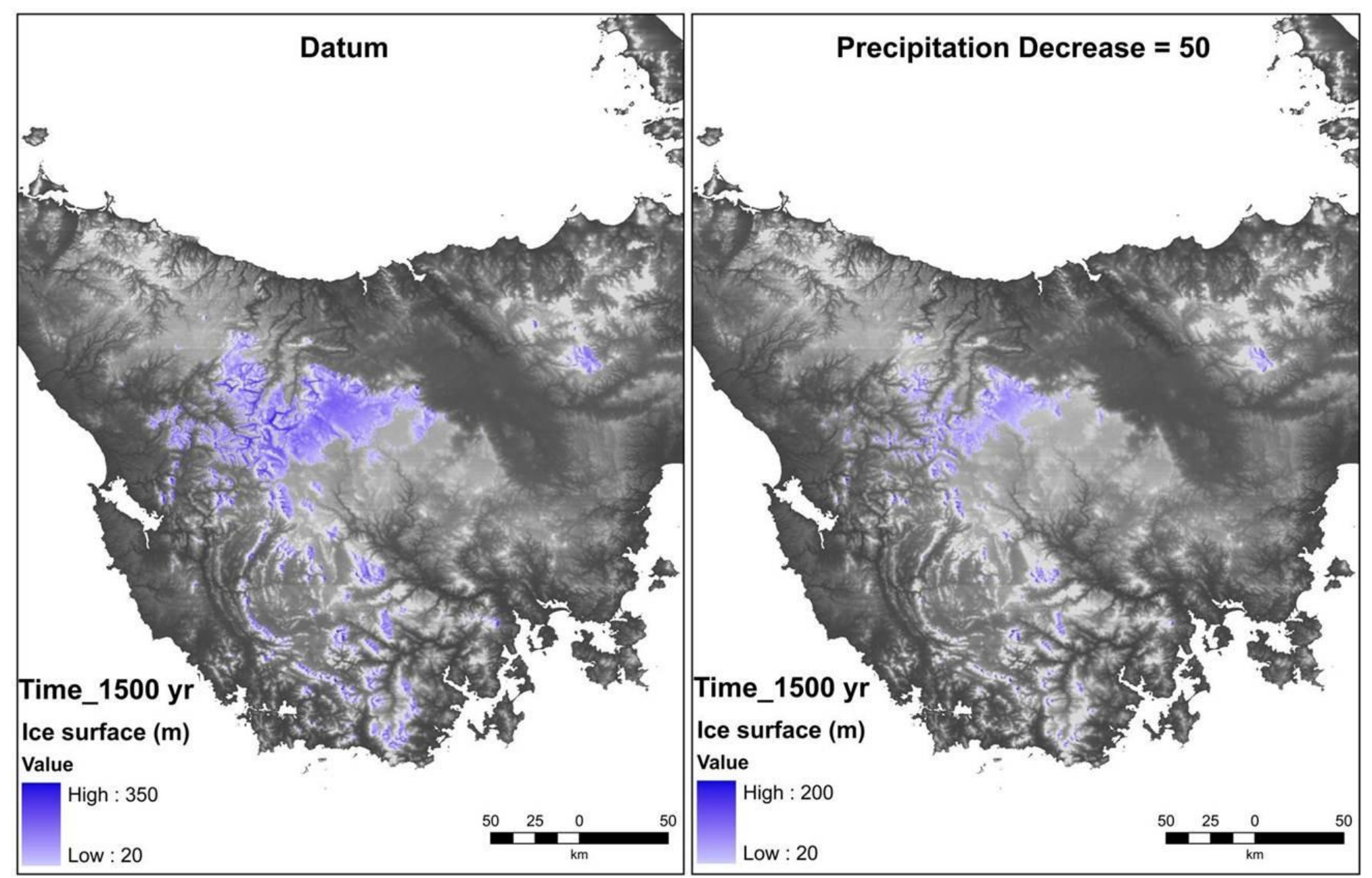

Figure 5-7: Comparison of ice extent between present-day precipitation conditions and a regional precipitation decrease of 50\%. Both simulations were carried out with a temperature depression of $-8.5^{\circ} \mathrm{C}$, a sliding value of 0 and a lapse rate of $-6.5^{\circ} \mathrm{C} \mathrm{km}^{-1}$. 


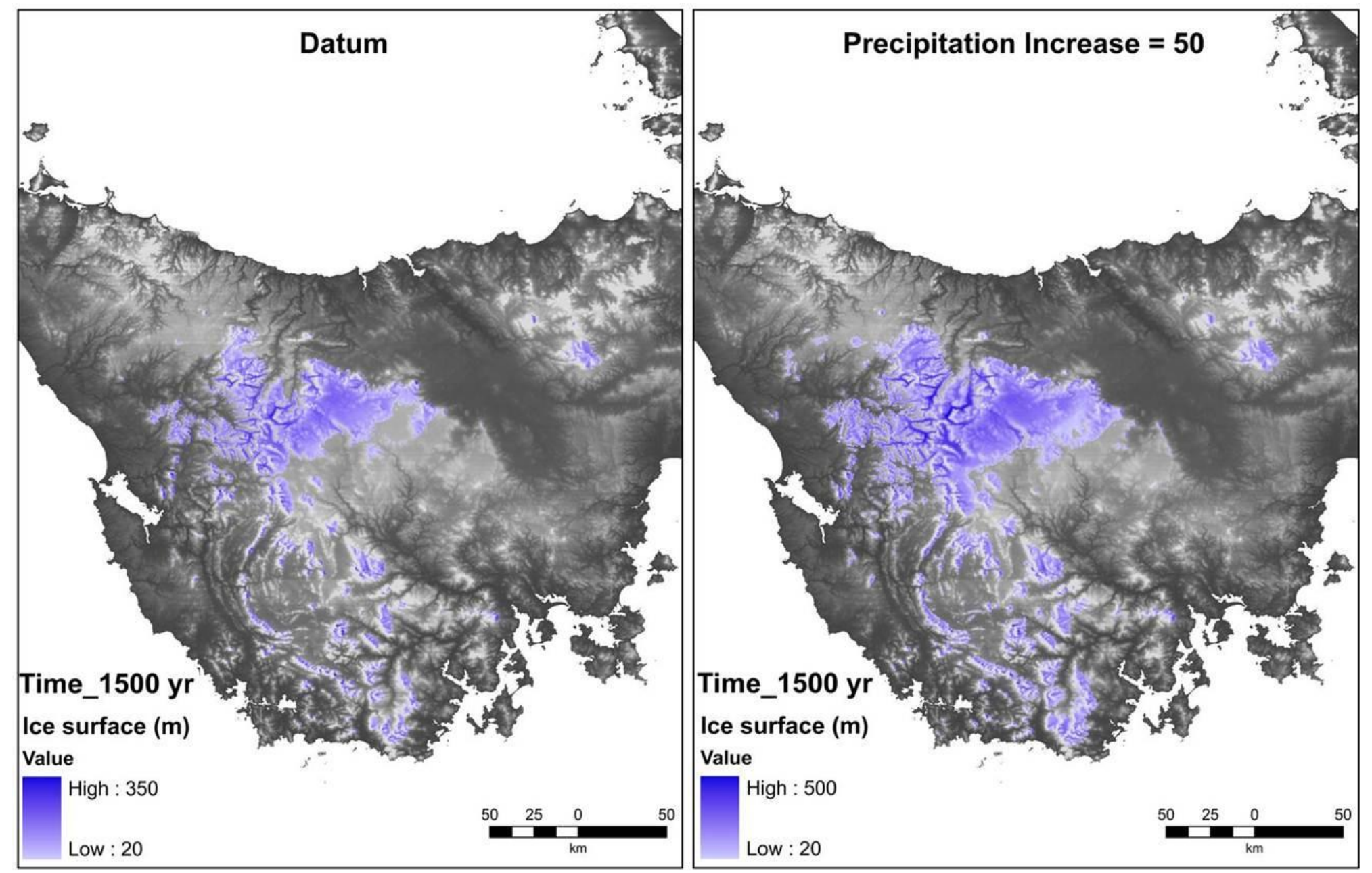

Figure 5-8: Comparison of ice extent between present-day precipitation conditions and a regional precipitation increase of 50\%. Both simulations were carried out with a temperature depression of $-8.5^{\circ} \mathrm{C}$, a sliding value of 0 and a lapse rate of $-6.5^{\circ} \mathrm{C} \mathrm{km}^{-1}$. 


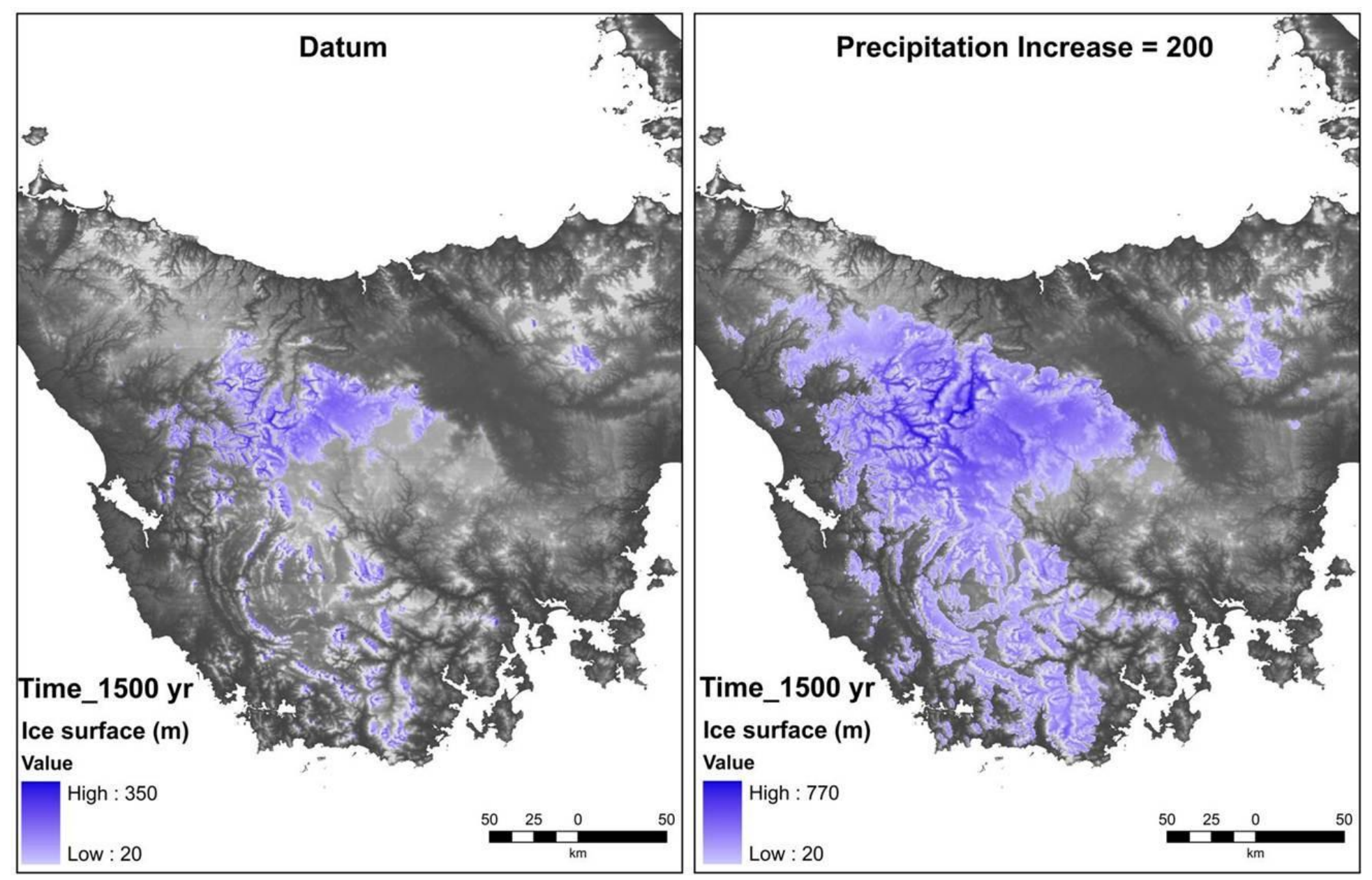

Figure 5-9: Comparison of ice extent between present-day precipitation conditions and a regional precipitation increase of $200 \%$. Both simulations were carried out with a temperature depression of $-8.5^{\circ} \mathrm{C}$, a sliding value of 0 and a lapse rate of $-6.5^{\circ} \mathrm{C} \mathrm{km}$. 


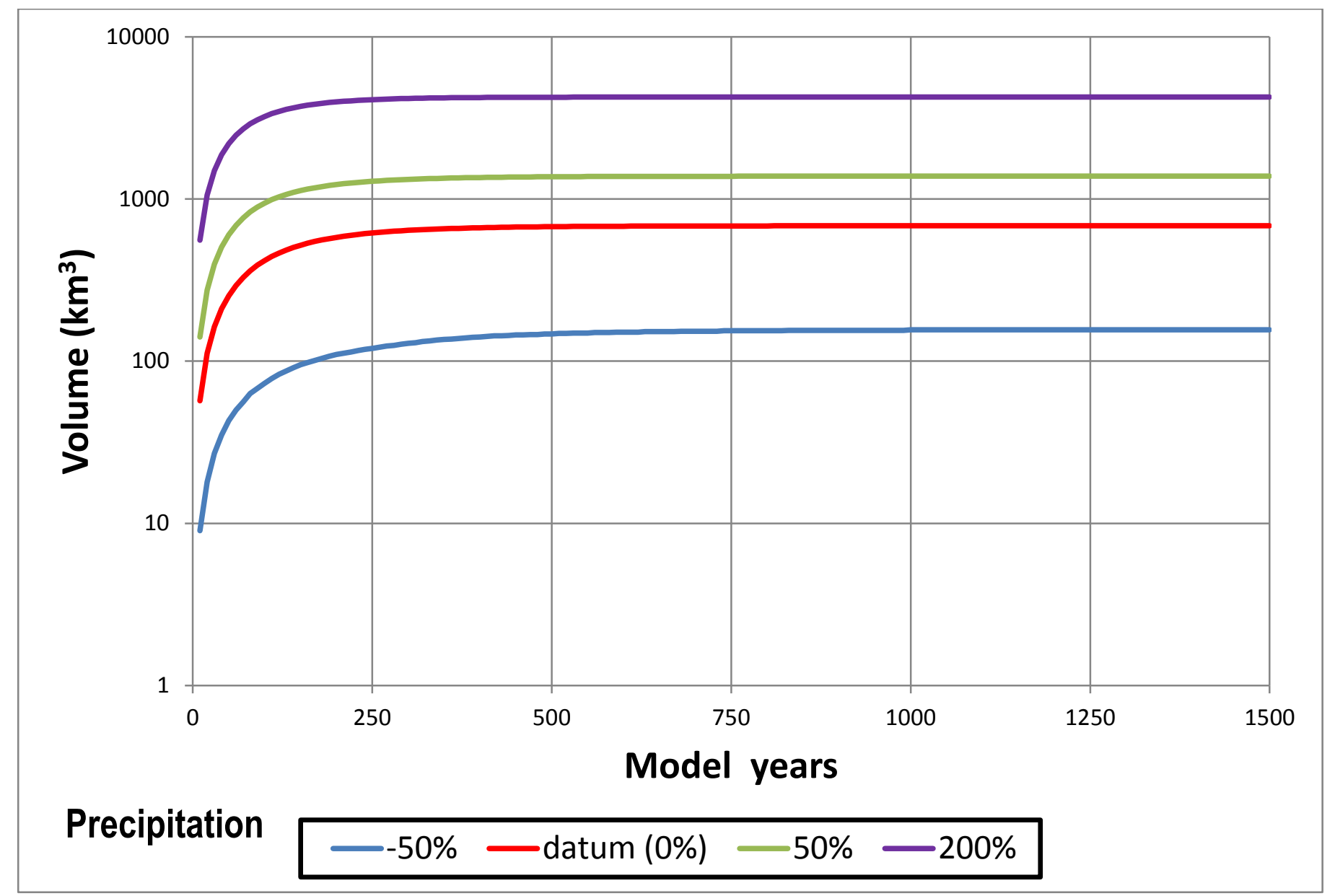

Figure 5-10: Ice volume trajectory throughout the entire model run (1500 years) under increasing and decreasing regional precipitation (compared to present-day datum conditions). All model runs were carried out using a temperature depression of $-8.5^{\circ} \mathrm{C}$, a sliding value of 0 and a lapse rate of $-6.5^{\circ} \mathrm{C} \mathrm{km}^{-1}$. Equilibrium is achieved in $\sim 800$ years. 


\subsection{Summary}

The sensitivity experiments enable understanding of the role and feedback of a number of physical processes operating within the glacier system. We have seen that the model is sensitive to both variations in the climatic and glacio-dynamic parameters tested. Nevertheless, the sensitivity tests allowed the selection of appropriate lapse rate and flow parameter values for further modelling simulations. A lapse rate value of $6.5^{\circ} \mathrm{C} \mathrm{km}^{-1}$ was chosen as this is typical of mid-latitude climate regimes and it was seen to make relatively little difference. A sliding value of 10 was chosen based the empirical evidence, other modelling investigations and how well ice was simulated in the sensitivity experiments. Further experiments now look at attaining a good match between modelled output and reconstructed glacier limits for Quaternary advances by varying temperature and precipitation conditions.

\subsection{Modelling Quaternary glacier advances}

The following experiments aim to establish an envelope of climatic configurations in which modelled ice best matches the empirical limits of the four known Quaternary glacial advances. As with the sensitivity experiments, numerous model simulations are performed, with climatic and glacio-dynamic variables systematically tuned until an envelope of best-fit scenarios is achieved.

\subsection{Last Glacial Maximum (LGM) advance}

The sensitivity experiments in the previous section enabled an envelope of temperature values to be isolated in which the total ice area proposed by Colhoun $e t$ al. (1996) for the LGM is generated. However, these temperature values depend on the parameterisation of regional precipitation (increasing or decreasing) and can have a profound effect on the ice extent generated. Additionally, the model simulations distribute ice in a way that deviates markedly from the empirical reconstructions. The spatial discrepancies allude to the need to manipulate the precipitation distribution further. A new suite of model runs based on varying the west-east and north-south precipitation gradients were performed with the aim of producing a series of temperature and precipitation scenarios that produce similar best-fit ice geometries. 


\subsubsection{Optimal-fit scenario (OFS)}

Figure 5-11 illustrates an OFS ice field and surrounding smaller ice masses at the Last Glacial Maximum after 1500 model years. The optimum-fit scenario is achieved when modelled output replicates as many of the empirical ice limits as possible. Using this approach to assess the goodness of fit only works when empirical ice limits are present. When field evidence is missing (e.g. eastern Central Plateau and valleys between Central Highlands and the West Coast Range), the model has nothing to be compared to and is therefore unconstrained. Subsequently, this leads to the generation of a range of OFS model configurations where empirical limits are replicated in some areas. Ice extent varies between each OFS configuration in areas where the model is not constrained by field evidence. Assessment on the goodness of fit is based purely on the constraining limits present, with unconstrained areas ignored as ice presence/absence is undetermined. For clarity, one example within the range of best-fit simulations is presented for each glacial reconstruction in the following sections. In order to generate an ice geometry similar to Figure 5-11, a range of temperature and regional precipitation combinations were used and are presented in Figure 5-12. A localised west-to-east increase in the precipitation gradient of 50\% and north-to-south gradient increase of $40 \%$ (compared to presentday) was also used for fine tuning. The range of temperature and regional precipitation combinations highlighted in Figure 5-12 are possible climatic scenarios that could have prevailed during the LGM. Temperature depressions between $-7^{\circ} \mathrm{C}$ and $-9^{\circ} \mathrm{C}$, with corresponding regional precipitation changes of between $+/-50 \%$ could have persisted during the LGM. The range in which an OFS is generated is very narrow; whereby small changes made to the climate variables lead to large mismatches between modelled output and empirical limits. The spatial distribution of ice extent appears to be replicating key empirical reconstructions in some areas. However, overall ice coverage is larger than areal extent predicted by Colhoun et al. (1996), with these ice areas now also thought to be an overestimate (Barrows, et al., 2002). Areal ice extent in the northern region of the main ice mass is depicted in Figure 5-13A. Ice extent follows a somewhat realistic distribution when flowing off the central ice cap and down into the Mersey and Forth valleys. However, ice 
extends beyond what the empirical data suggest, especially in the Dove Valley where ice is thought to have only occupied the eastern side of the valley. It is encouraging that the model manages to replicate the pattern of ice flow into Lake St Clair, correctly sourcing ice from the western Central Plateau and Du Cane Range and subsequently terminating in agreement with the empirical limits (Figure 5-14).

Somewhat realistic ice distributions are also simulated on isolated mountain summits and plateau regions such as Mt Field, Mt Anne, Arthur Range and Ben Lomond; well documented areas of LGM glacial advances (e.g. Caine, 1983; Kiernan, 1990a; Kiernan, et al., 2001; Kiernan, et al., 2004; Mackintosh, et al., 2006). However, the model produces an excess of ice in Ben Lomond area, possibly suggesting localised precipitation is too high in this area (Figure 5-13B). Figure 5-13C illustrates ice distribution in the western region of the model domain. The model produces continuous ice development on the mountain ranges and valleys between the Central Highlands and the West Coast Range; for example, extensive ice growth is present in the Murchison Valley. Whether ice was continuous between the central main ice mass and the West Coast Range has long been discussed (e.g. Davis, 1969; Flint, 1971; Derbyshire, 1972; Kiernan, 1990b). However, evidence indicating an LGM ice presence in this area is equivocal.

Clearly, there are areas of local mismatch between known limits and modelled output. This predominantly occurs in the West Coast Range where localised precipitation forced by the model is highest and ice extent is over predicted. However, increasing precipitation in the western region (compared to present-day) is required in order to generate sufficient ice growth in the south-western region; particularly Lake St Clair. High levels of localised precipitation result in steep mass balance gradients, subsequently increasing the sensitivity of glaciers to meteorological changes. Therefore, achieving a perfect match in the West Coast Range is difficult and can only occur at the expense of reducing ice extent from Lake St Clair. 


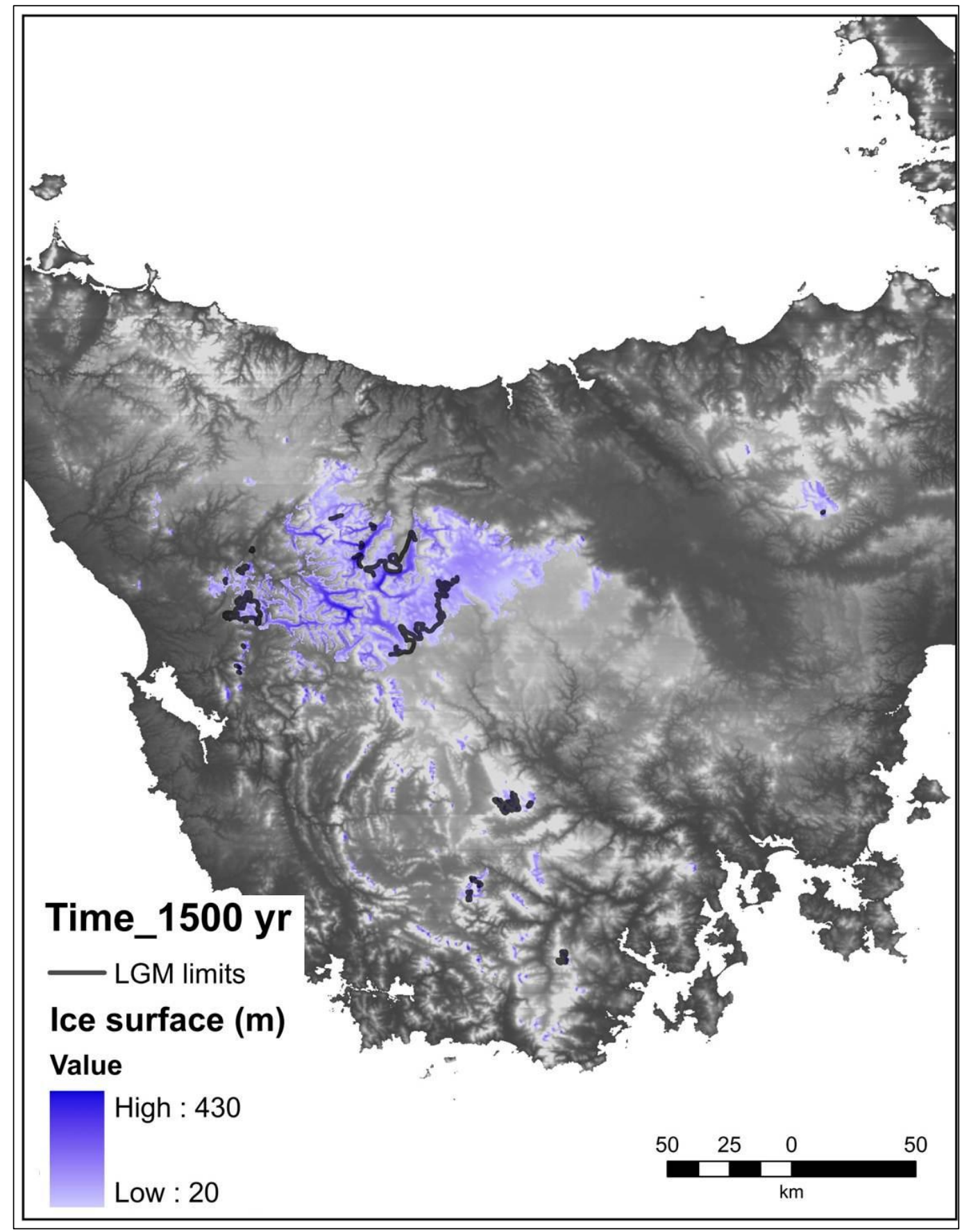

Figure 5-11: LGM ice extent and thickness over the entire model domain after 1500 model years under optimal climate parameterisation. Empirical reconstructions are shown in black outline. A good match is achieved in the southern region of the main ice mass around Lake St Clair, and in northern Tasmania down the Mersey and Forth valleys. Isolated peaks in southern Tasmania are well represented, and include: Mt Field, Mt Anne and the Arthur Range. An over-prediction of ice is simulated by the model in the West Coast Range and northeastern Tasmania. Maximum ice thickness approaches 430m in Lake St Clair, Murchison Valley, Forth Valley and Mersey Valley (dark blue). Thinner ice is simulated on the Central Plateau, in agreement with field evidence. 


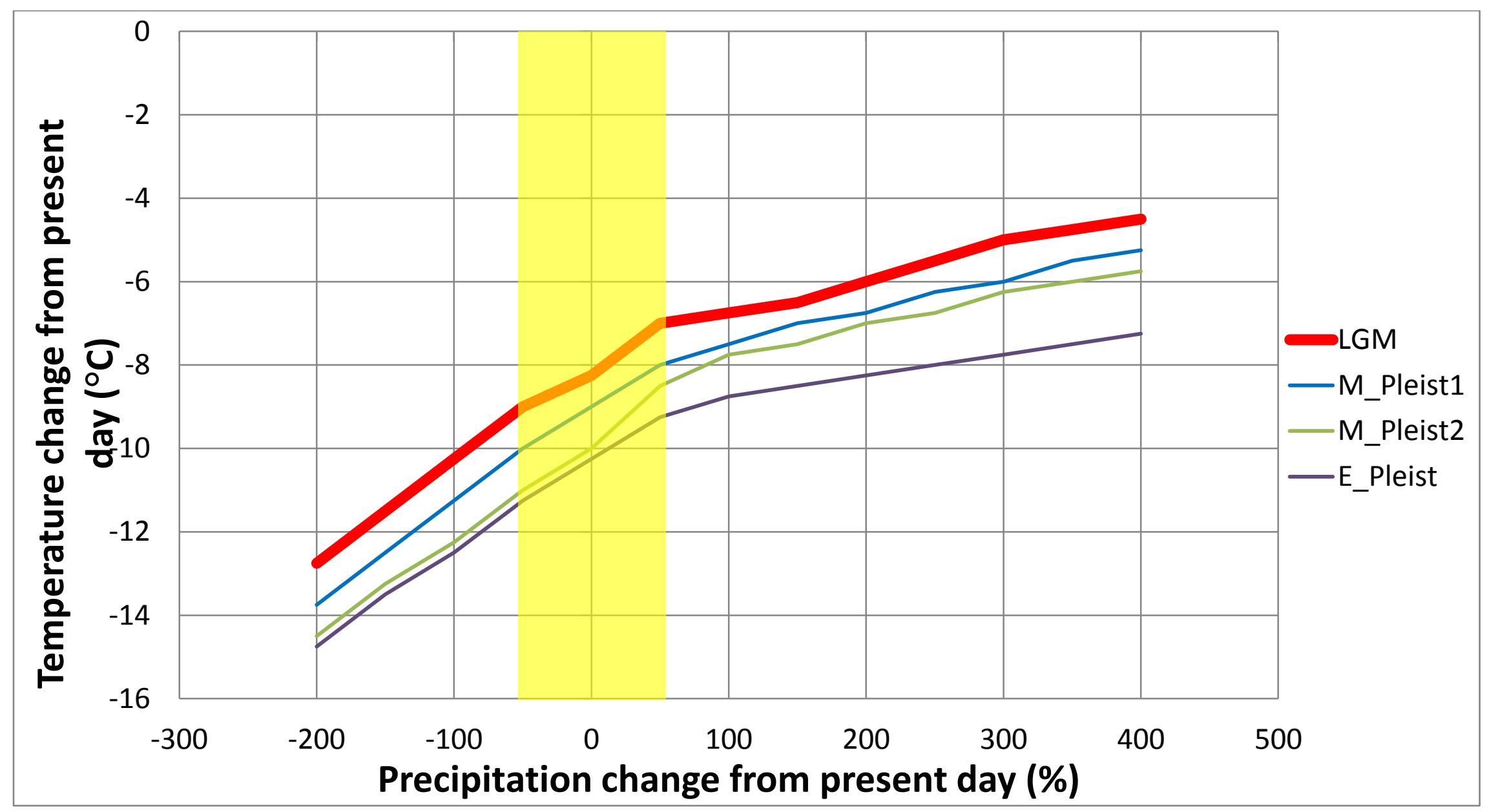

Figure 5-12: The range of temperature and precipitation conditions that produce a similar ice geometry for the LGM (red line). The three earlier Quaternary advances are also plotted for comparison (thinner lines). The yellow shading represents the range of likely combinations of temperature and precipitation required for each advance. 

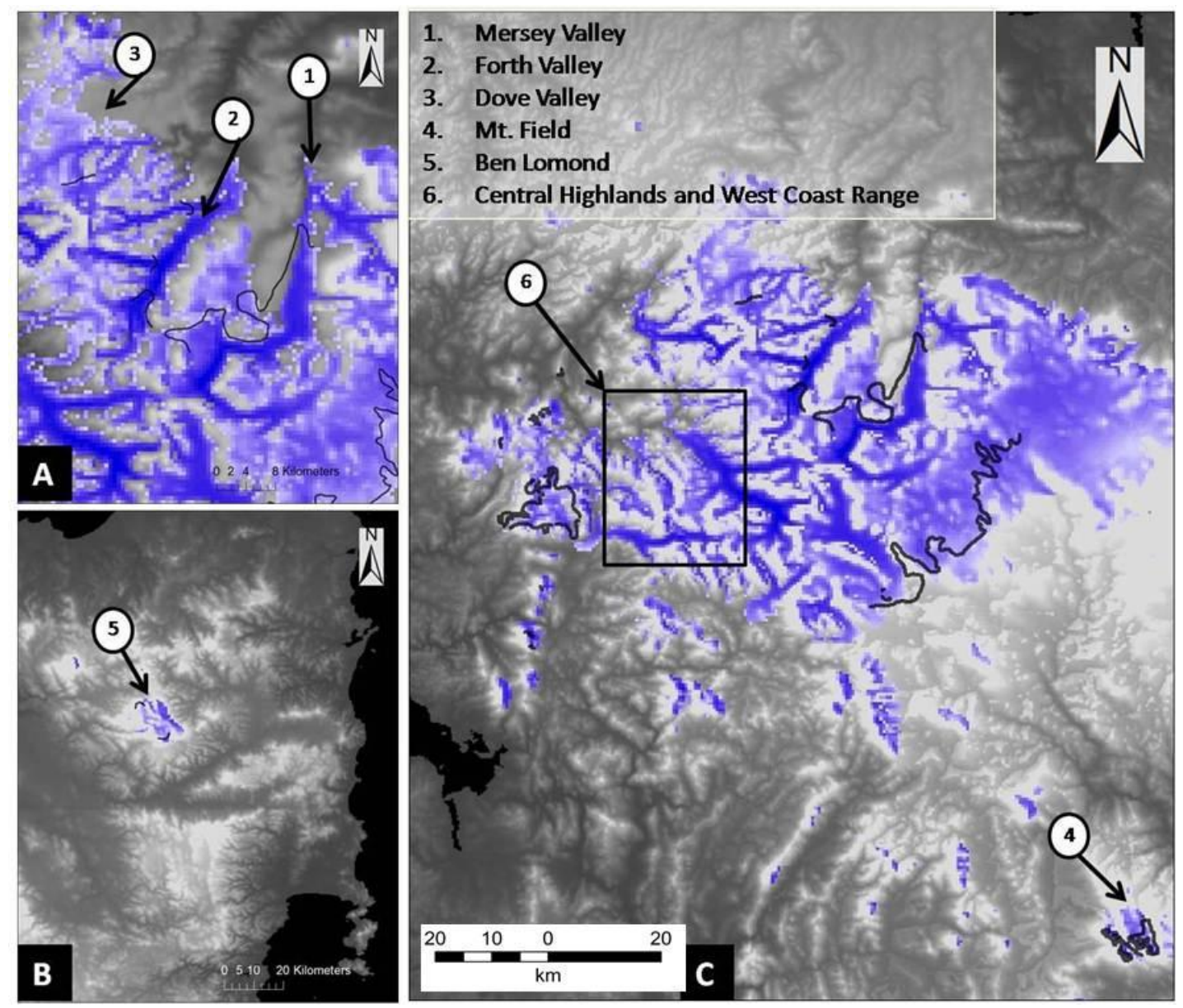

Figure 5-13: LGM simulation (A) Close up of ice distribution in the northern region of the main ice mass. (B) Ben Lomond with excess of ice compared to the empirical data. (C) Central ice mass showing detailed ice extent against the empirical limits outlined in black. Note how the overall areal coverage of ice appears to be larger than previously interpreted by Colhoun et al. (1996). This possibly suggests that cooling values between $-7^{\circ} \mathrm{C}$ and -9 are probably too high, likely due to grid resolution issues. Numbers refer to key areas mentioned in text. 

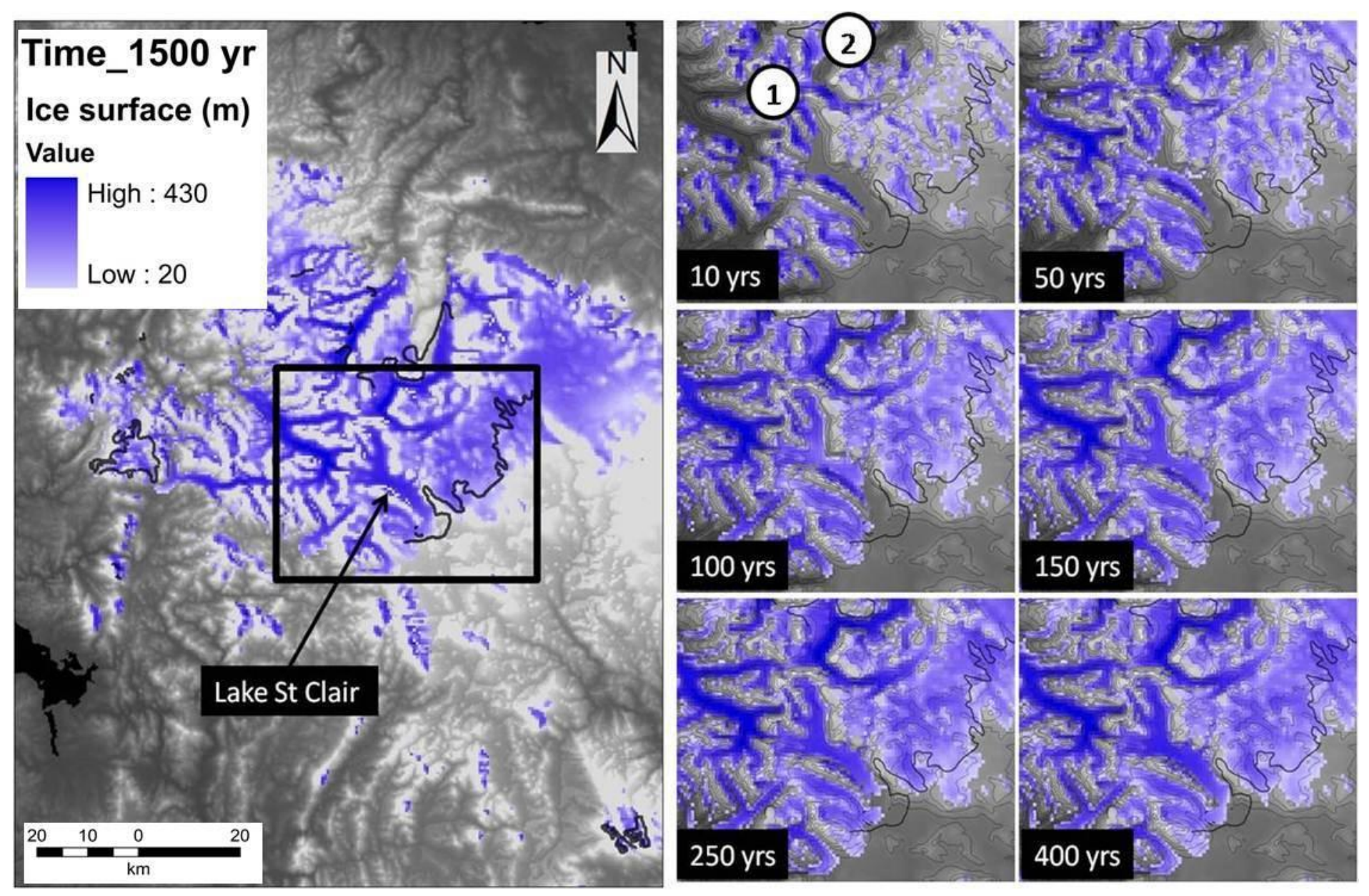

Figure 5-14: LGM time slices from the optimum model run, showing ice build-up and development in Lake St Clair. The numbers represent the main source areas of the Du Cane Range (1) and the western Central Plateau (2) 


\subsection{Pre-LGM glacial advances}

Modelling ice extent and comparing modelled output against empirical evidence prior to the Last Glacial Maximum (MIS 2) is more difficult than for the LGM simulations. Poor age control and a limited range of field data in many areas necessitate the need to divide glacial advances into broader temporal stages. However, in some instances, each division includes multiple glacial events involved. Every attempt is made to ensure that glacial advances in different regions correlate in order to keep them broadly contemporaneous. The substages in the following sections are divided up and described as:

1. Middle Pleistocene I: MIS 6 (penultimate glacial advance);

2. Middle Pleistocene II: MIS 19 (Brunhes-Matuyama reversal) to MIS 7;

3. Early Pleistocene: $0.73-2.6 \mathrm{Ma}$.

The process for determining the optimal-fit modelled ice cap/ice field is the same as described in the previous section. However, for older glacial advances depositional evidence is patchy, poorly preserved (in conjunction with increasing age) and not well-dated in some areas. Consequently, the field evidence used to assess and constrain model output is greatly reduced. This increases the number of plausible optimal-fit model scenarios; thus increasing the size of the 'optimal climatic envelope'. However, as with the previous section, only a selection of model configurations will be presented in the following sections.

\subsection{Middle Pleistocene I glacial advance}

\subsubsection{Optimal-fit scenario (OFS)}

Figure 5-15 illustrates an OFS aerial extent of ice for the middle Pleistocene I advance. Figure 5-16 presents the combination of viable temperature and regional precipitation conditions that produce an OFS. A localised precipitation pattern corresponding to a west-to-east increasing precipitation gradient of $40 \%$ and a northto-south increasing gradient of $20 \%$ (compared to present-day) is used for fine tuning. Alteration to the localised precipitation distribution is required as the LGM 
localised precipitation configuration did not produce sufficient ice in the northern West Coast Range. The range of temperature and regional precipitation combinations highlighted in Figure 5-16 are possible temperature and precipitation conditions that could have existed during middle Pleistocene I. Temperature depressions between $8^{\circ} \mathrm{C}$ and $-10^{\circ} \mathrm{C}$, with corresponding regional precipitation changes of between $+/-$ $50 \%$ could have prevailed during the middle Pleistocene I. The model generates a large ice cap focused around the key accumulation areas of the Central Highlands and Central Plateau. A good match is achieved between the OFS and empirical field evidence in the northern and southern margins of the main ice cap (Figure 5-17). Uncertainty in ice cap extent exists in the eastern region of the Central Plateau where glacier limits are unknown. Smaller ice masses are present on the Arthur range, Mount Field, Mount Anne and Ben Lomond area (Figure 5-17A). While there appears to be excess ice on Mount Anne (Kiernan, 1990a), other isolated ranges lack the equivocal evidence necessary to constrain modelled ice output.

Figure 5-17C illustrates ice development and distribution in the West Coast Range. Principal ice build-up occurs on the Tyndall Plateau and flows south into the King Valley, terminating at elevations of $\sim 300 \mathrm{~m}$ asl. Ice also develops along the South Eldon Range, and feeds into the Eldon Valley. Ice geometry is at odds with the empirical limits in the Pieman River basin, with far less ice produced by the model than the field limits suggest. In this area, ice is present on a few isolated mountain peaks, with the valleys remaining ice free. Reconstructions carried about by Colhoun (1985) suggest that a large piedmont glacier formed on the Henty peneplain, and flowed out radially into the surrounding valleys. While the model does produce ice on the Henty peneplain, accumulation is not sufficient enough to infill the surrounding valleys, even with enhanced north-to-south precipitation. Nevertheless, despite the mismatches, the range of plausible temperature values is actually quite small, and therefore, quite well constrained by the model. 


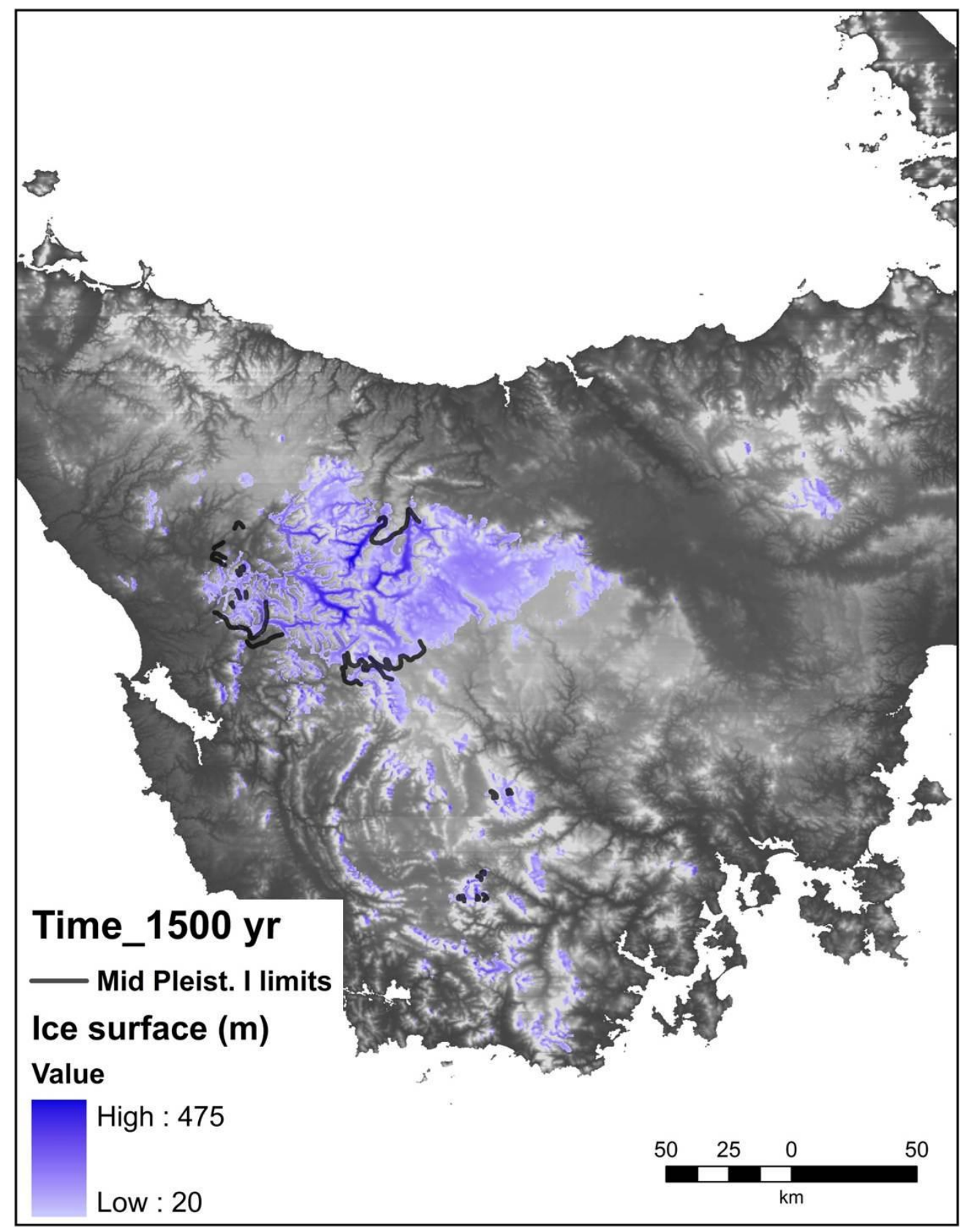

Figure 5-15: Middle Pleistocene I (MIS 6) ice extent and thickness over the entire model domain after 1500 model years under optimal climate parameterisation. A good match is achieved in northern Tasmania down the Mersey and Forth valleys, as well as in southern Tasmania around Lake St Clair, Navarre and Franklin valleys. Ice in the southern West Coast Range closely matches empirical limits, whereas the model does not produce enough ice in the northern West Coast Range. Empirical reconstructions are shown in black outline. Maximum ice thickness approaches 475 $\mathrm{m}$ in Lake St Clair, Murchison Valley, Mersey Valley and Forth Valley (dark blue). 


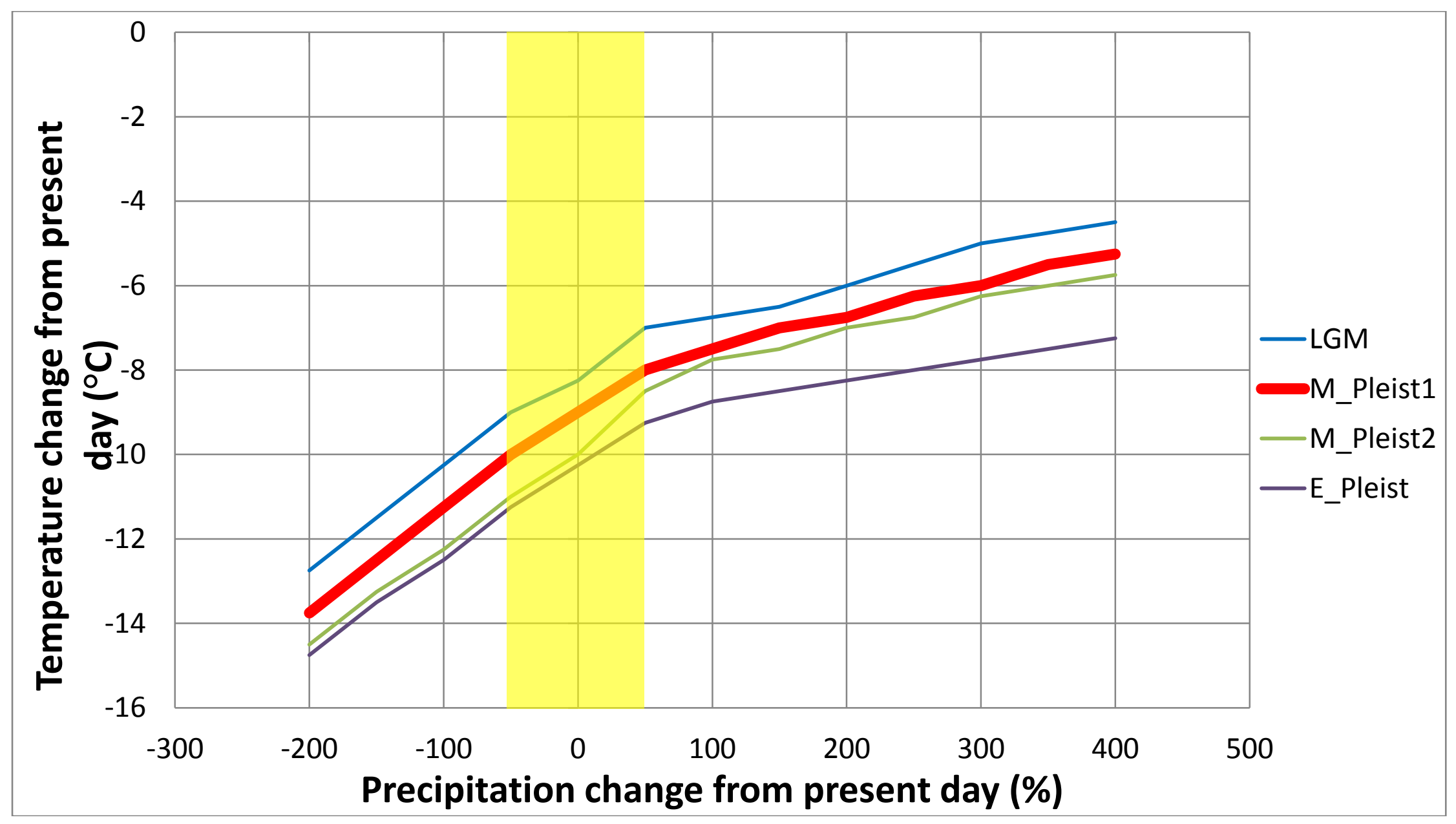

Figure 5-16. The range of temperature and precipitation conditions that produce a similar ice geometry for the middle Pleistocene I advance (red line). The three other Quaternary advances are also plotted for comparison (thinner lines). The yellow shading represents the range of likely combinations of temperature and precipitation required for each advance. 

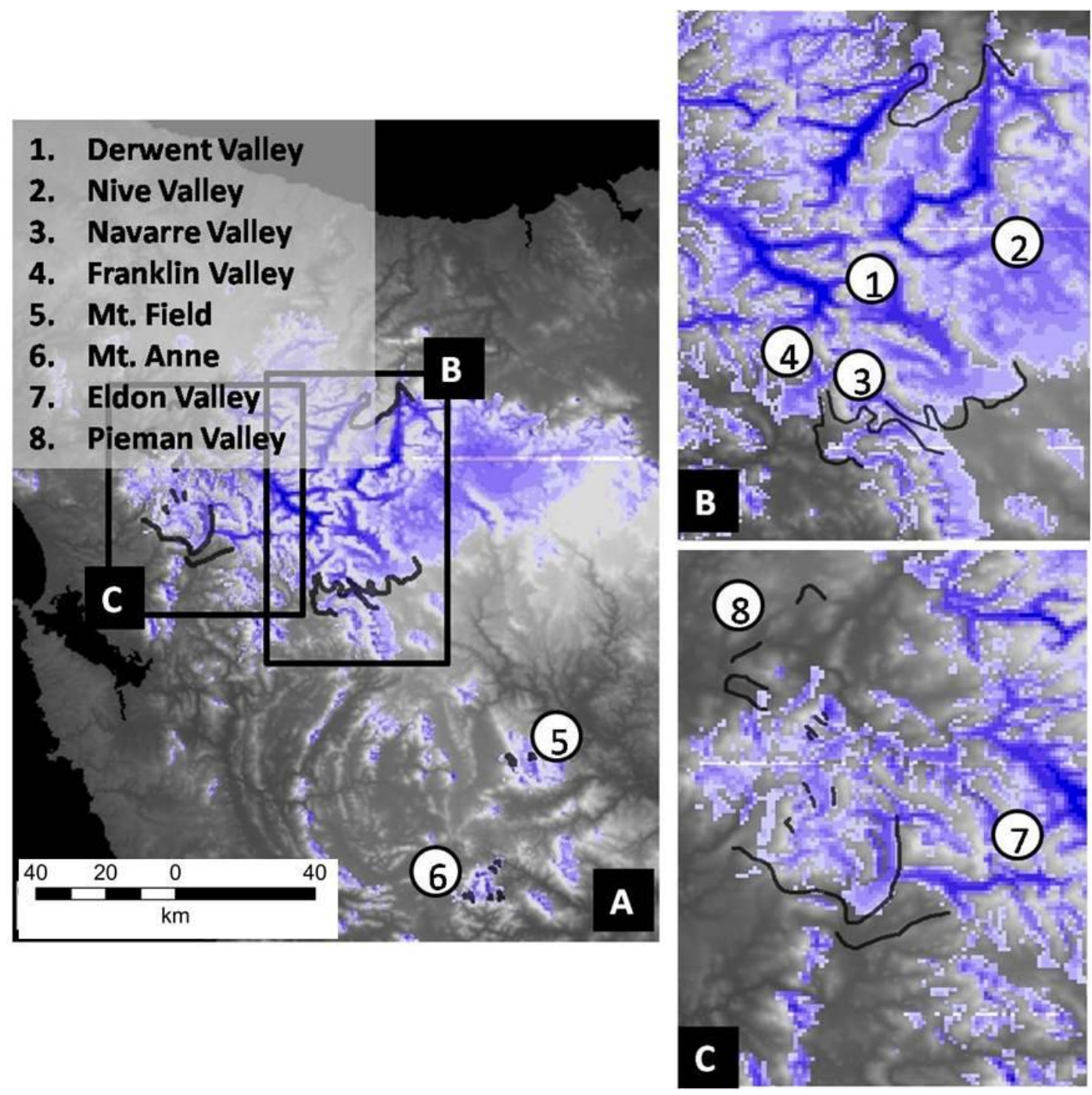

Figure 5-17: Middle Pleistocene I (MIS 6) model simulation. Close up of ice extent over the central ice mass (A). Southern region of the main ice mass (B), and the West Coast Range $(C)$. The model does a good job simulating ice to match the empirical limits in the Derwent, Nive, Navarre and Franklin valleys, as well as in the southern West Coast Range. A clear mismatch exists in the Pieman Valley, northern West Coast Range, where the model under-predicts ice extent. In each figure the black lines mark the limits of middle Pleistocene I glacial advances. 


\subsection{Middle Pleistocene II glacial advance}

\subsubsection{Optimal-fit scenario (OFS)}

Figure 5-18 illustrates ice extent for an OFS for Middle Pleistocene II glacial advances in Tasmania. The temperature and regional precipitation combinations used to produce an OFS are depicted in Figure 5-19. Temperature depressions between $8.5^{\circ} \mathrm{C}$ and $-11^{\circ} \mathrm{C}$, with corresponding regional precipitation changes of between $+/-$ $50 \%$ could have prevailed during the middle Pleistocene II. A localised west-to-east increasing precipitation gradient of $40 \%$ and a north-to-south increasing gradient of $20 \%$ (compared to present-day) is prescribed. Similarly to previous sections, the key zones of ice accumulation are situated around the Central Highlands and Central Plateau. Distributary ice flowing away from the main ice cap forms large valley glacier systems, particularly in the Derwent, Franklin, Murchison, Mersey and Forth valleys. In addition to the main ice mass, several smaller glaciers develop along the southern mountain peaks, and on the Ben Lomond range.

Modelled ice in the northern West Coast Region is shown in Figure 5-20. It is clear that ice fails to achieve an extent reminiscent of the empirical ice limits. While ice does flow into the upper reaches of the Mackintosh River, it does not flow through the Tullabardine Gap and into the Boco Valley as previous research suggests (e.g. Augustinus, 1999a). However, research into the pattern of glaciation in this region proposes two important considerations: 1) that ice flowed against the topographical gradient and 2) the ice-surface gradient was very shallow. Consequently, the northern West Coast Range relies on localised areas of topographically-induced ice thickening in order to breach high land divides; a factor not well represented by the model. Further south, ice sourced from Rolleston and Tyndall Valleys flows past the Moxon Saddle, but terminates instead of flowing further west into the Pieman River basin. 


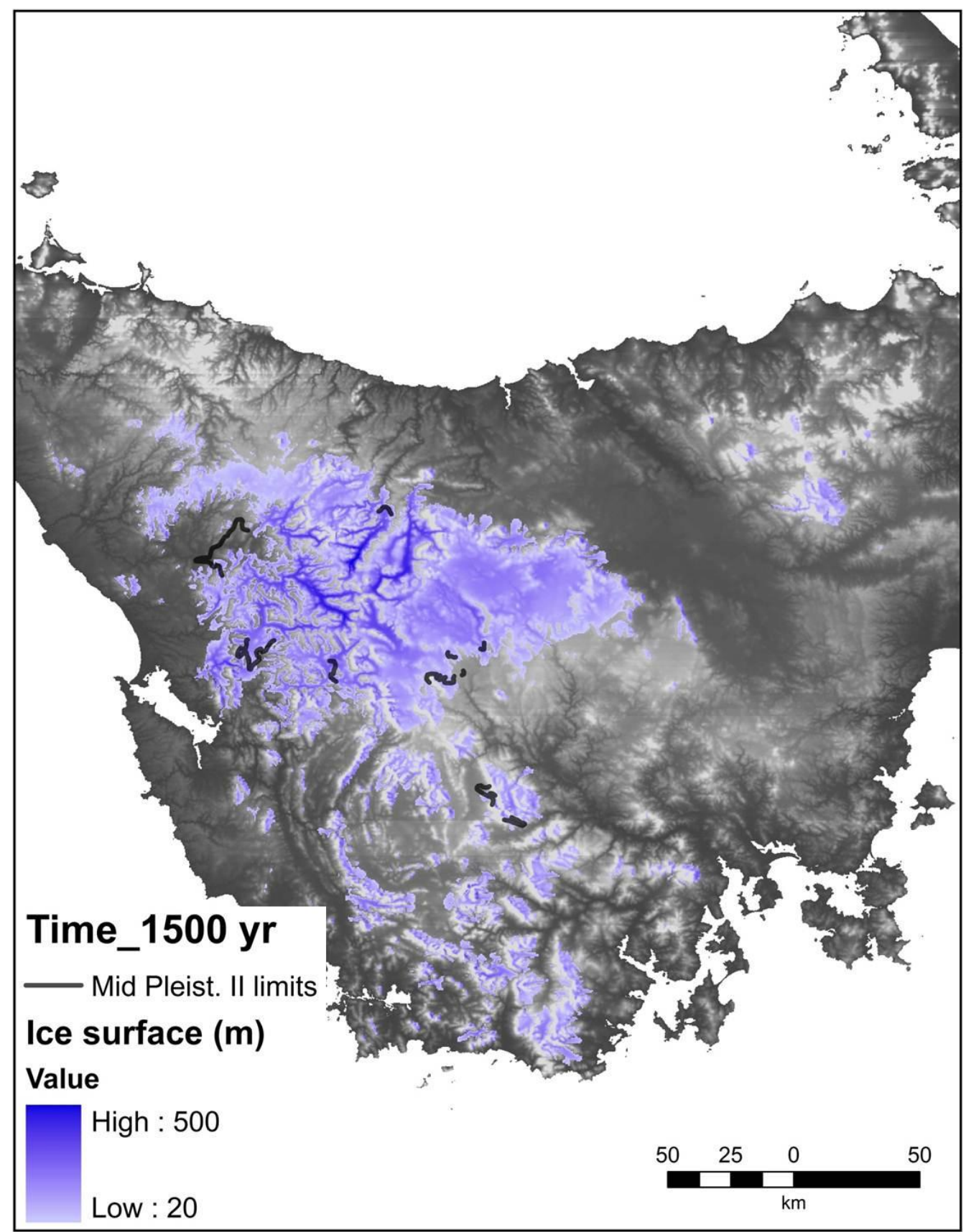

Figure 5-18: Middle Pleistocene II ice extent and thickness over the entire model domain after 1500 model years under optimal climate parameterisation. A good match is achieved between modelled ice extent and empirical limits in the Derwent Valley, southern Tasmania and the Forth Valley, northern Tasmania. In the West Coast Range excess ice is produced by the model south of the Tyndal Plateau, whereas ice is under-predicted by the model in the Pieman Valley, northern West Coast Range. Empirical reconstructions for middle Pleistocene II limits are shown in black outline. Maximum ice thickness approaches $500 \mathrm{~m}$ in Lake St Clair, Murchison Valley, Mersey Valley and Forth Valley (dark blue). 


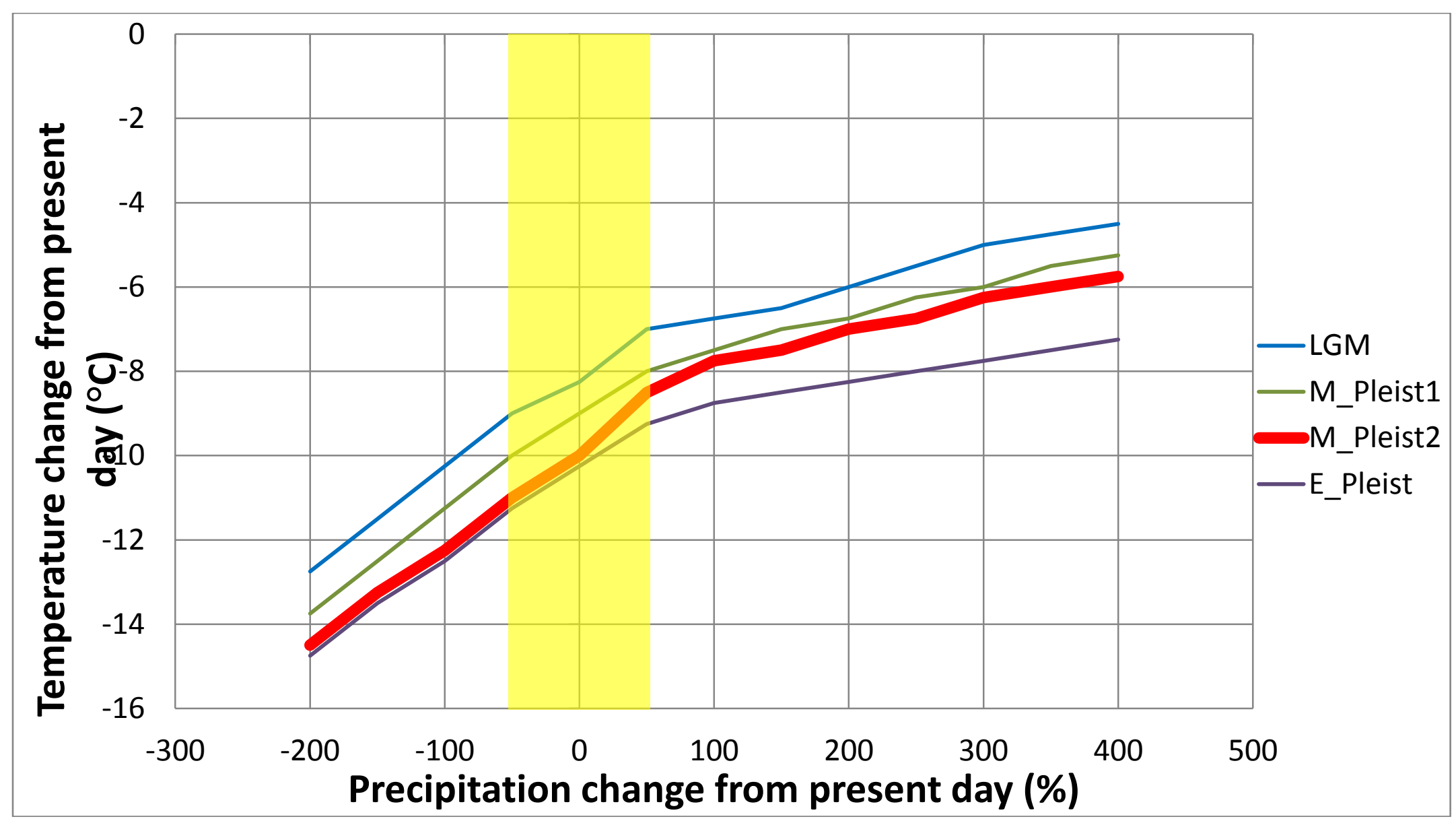

Figure 5-19: The range of temperature and precipitation conditions that produce a similar ice geometry for the middle Pleistocene II advance (red line). The three other Quaternary advances are also plotted for comparison (thinner lines). The yellow shading represents the range of likely combinations of temperature and precipitation required for each advance. 


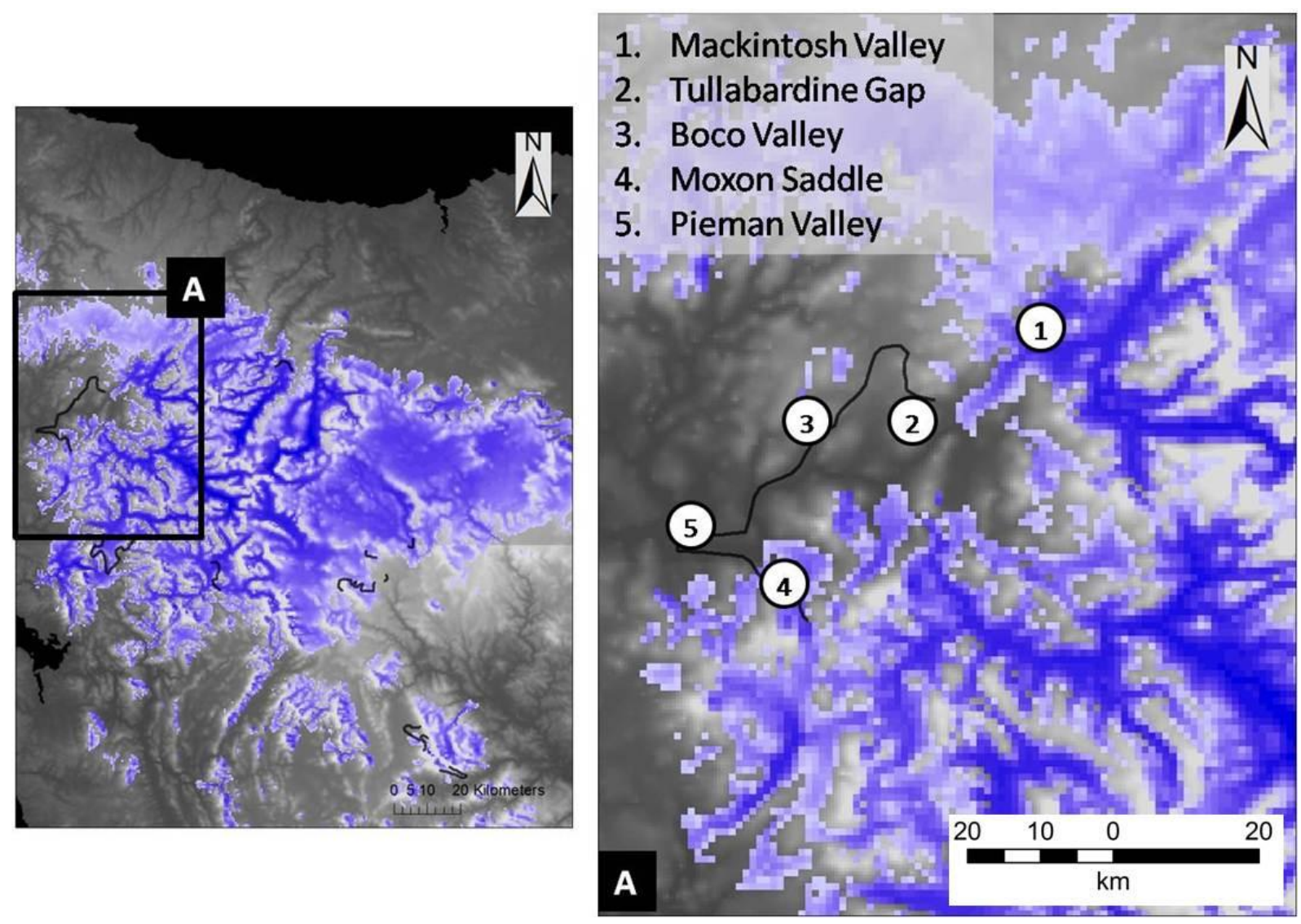

Figure 5-20: Middle Pleistocene II ice extent over the central ice mass with a close up on the northern region of the West Coast Range (A). A clear mismatch is apparent in the Boco and Pieman valleys, where modelled ice extent is under-predicted, despite increasing the north-to-south precipitation gradient. The black lines mark middle Pleistocene II empirical field limits. Key areas numbered in the figure are referred to in text in more detail. 
Figure 5-21 illustrates modelled ice extent in the southern West Coast Range region of the King Valley. Ice extent exceeds the empirical glacier limits in a number of regions. Ice flowing down the King Valley from the Tyndall Plateau becomes confluent with ice flowing off Mount Jukes and spills south past the Baxter Rivulet, breaching the Andrew Divide. Ice is also deflected west into the Queen Valley via the King Gorge. Several smaller ice masses are present on surrounding mountain peaks in the area, providing supplemental ice into the Queen Valley. Investigations into the glacial history of the King Valley by Fitzsimons and Colhoun (1991) suggest that ice did not flow south of the Andrew Divide. However, an absence of depositional evidence regarding the exact location of the former glacier terminus does raise some uncertainty. Additionally, ice is thought to have occupied the Queen Valley only during the most extensive glacial advance (early Pleistocene) and not during the middle Pleistocene II, suggesting that this is probably also an overestimate.

Ice flowing southwards off the Central Plateau becomes confluent south of Lake St Clair with ice flowing down the Clarence, Franklin and Derwent valleys (Figure 5-22). As the ice mass advances further down valley, it separates into three lobes before terminating. The model produces ice that flows and terminates in accordance with the reconstructed ice limits, with ice in the Derwent Valley terminating near the Clarence-Nive confluence.

Ice sourced from the accumulation area of the Central Highlands flows down into both the upper Forth and Mersey Valleys Figure 5-23. While, ice flowing into the Forth Valley does exceed the empirical limits, the discrepancy is not large. There is a lack of depositional evidence in the Mersey Valley from which to assess model output. However, we can speculate that ice extent in the Forth Valley might be similar to that in the Mersey Valley. Considerable ice is present in the northern valleys between Mount Cripps and Cradle Mountain, as well as east of Mount Cripps. Field evidence indicating ice presence in these areas is missing; however, it is likely that ice is simply over predicted by the model in this region. 


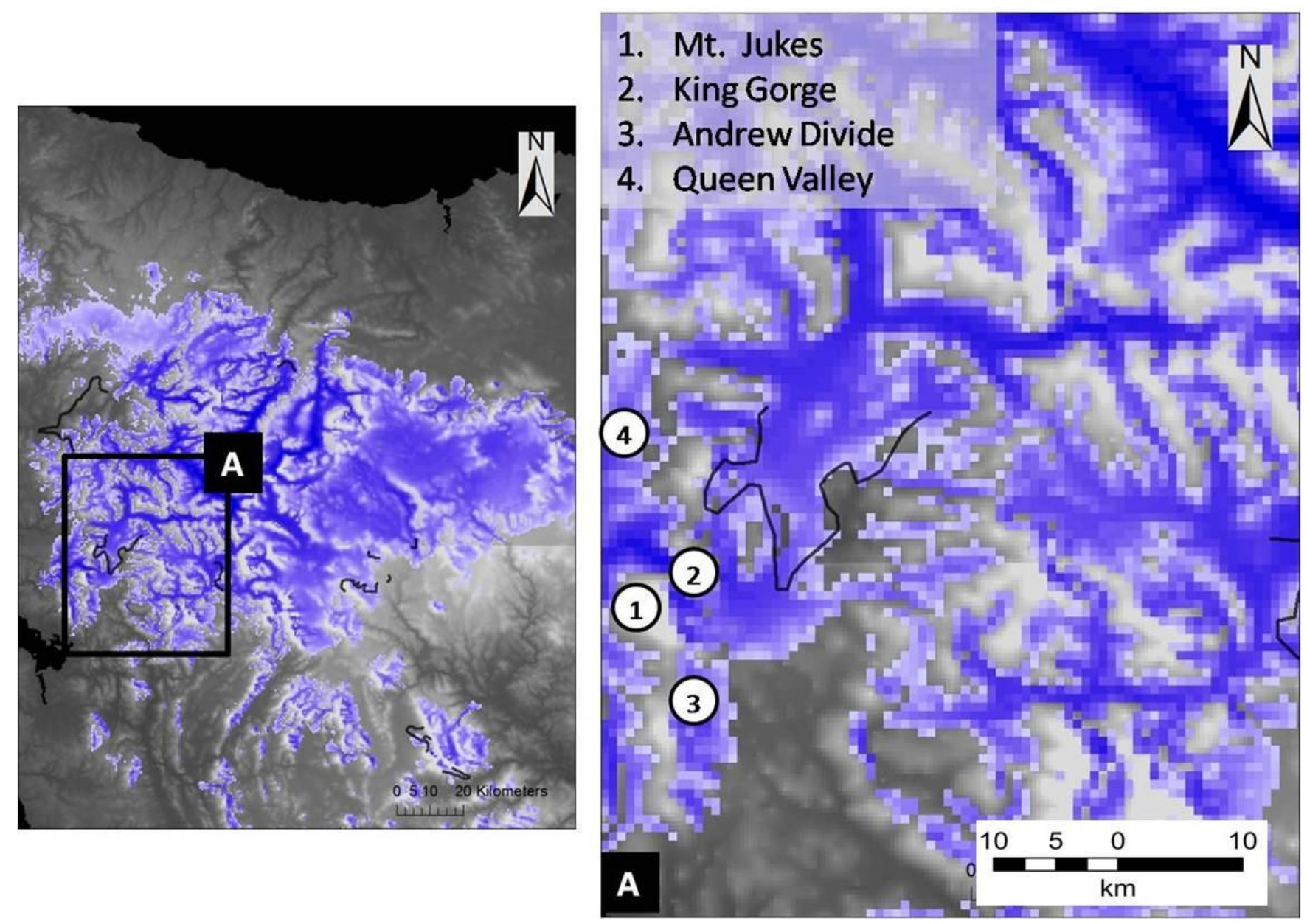

Figure 5-21: Middle Pleistocene II ice extent over the central ice mass with a close up of the southern region of the West Coast Range (A). Excess ice is produced by the model, flowing past the empirical limits. The black lines mark middle Pleistocene II empirical field limits. Key areas numbered in the above figure are referred to in text. 

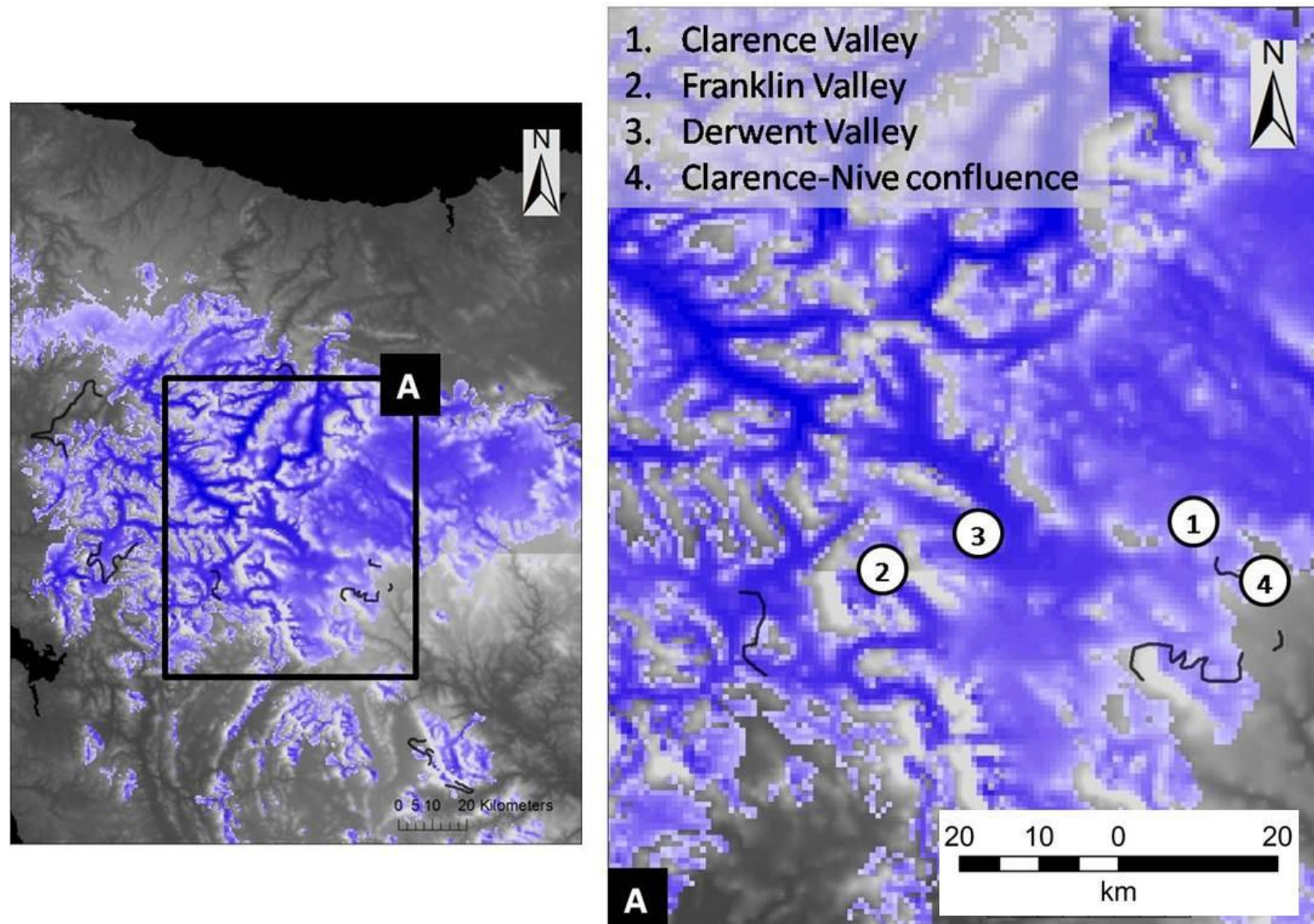

Figure 5-22: Middle Pleistocene II ice extent over the central ice mass with a close up of the southern region (A). A good match between modelled ice and empirical limits is achieved in the Franklin and Derwent valleys. Other areas lack empirical limits in which to constrain and compare modelled output. The black lines mark middle Pleistocene II empirical field limits. Key areas numbered in the figure are referred to in text. 


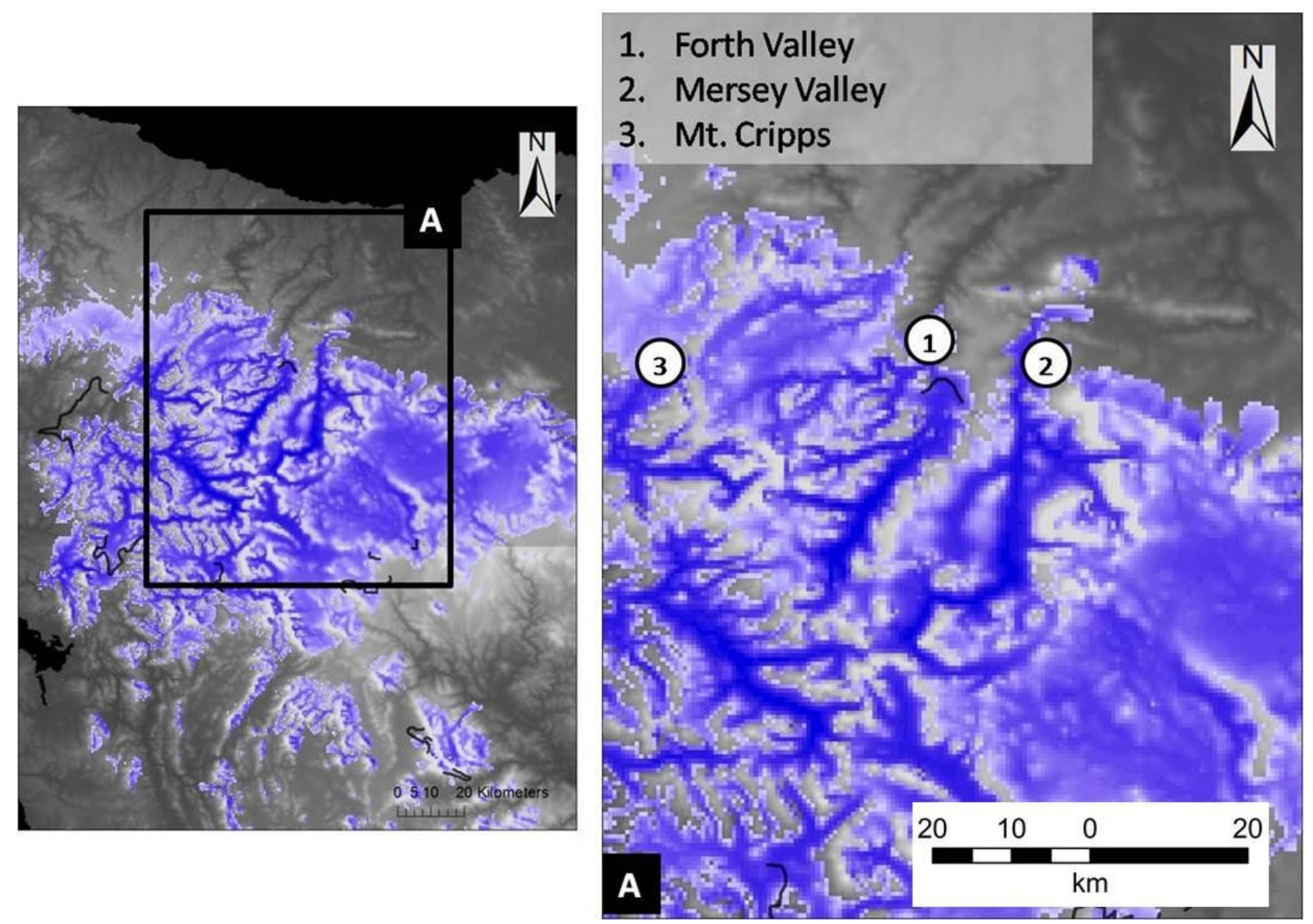

Figure 5-23: Middle Pleistocene II ice extent over the central ice mass with a close up of the northern region (A). Empirical limits are very sparse, but a good match is achieved in the Forth Valley. It is likely that excess ice is predicted by the model east of Mt Cripps, as evidence for glaciation is absent. The black lines mark middle Pleistocene II empirical field limits. Key areas numbered in the figure are referred to in text. 


\subsection{Early Pleistocene glacial advance}

\subsubsection{Optimal-fit scenario (OFS)}

Figure 5-24 shows the areal extent of modelled ice cover after 1500 model years of an OFS. The variety of feasible temperature and regional precipitation combinations are presented in Figure 5-25 that generate a model output which replicates as many of the empirical limits as possible. Temperature depressions between $-9.25^{\circ} \mathrm{C}$ and $11.25^{\circ} \mathrm{C}$, with corresponding regional precipitation changes of between $+/-50 \%$ could have prevailed during the early Pleistocene. Localised precipitation conditions corresponding to a west-to-east increasing precipitation gradient of 50\% and a northto-south increasing precipitation gradient of $20 \%$ (compared to present-day) for fine tuning. The modelled output produces the largest known Quaternary ice extent in Tasmania, with approximately $30 \%$ of the landmass being occupied by ice. The majority of ice growth is situated over the central, southern and western areas; with slightly thicker ice located west of the Du Cane Range. The main ice cap is again centered over the Central Plateau and Central Highlands, with extensive ice coverage on the southern mountain chains.

Ice extent in the southern region of the main ice mass is illustrated in Figure 5-26. Extensive valley glacier systems sourced from the Central Plateau and the Du Cane Range, are present in the Derwent, Curvier, Franklin, Clarence and Alma valleys. Much of the ice becomes confluent in these areas, particularly in the Derwent and Franklin Valley south of Mount Rufus. The glacier that formed in the Derwent Valley is shorter than the empirical evidence suggests, while in the Franklin Valley, ice flows beyond the terminal limits. However, substantially less ice is produced by the model in the Derwent Valley if precipitation restrictions, reducing ice accumulation in the Franklin Valley, are imposed.

Ice distribution in the West Coast Range is depicted in Figure 5-27. While modelled ice does extend further than the empirical limits suggest, the overall distribution is more or less correct. Ice can be seen flowing down the Eldon and South Eldon Valleys and feeding into an extensive glacier system in the King Valley. A distributary lobe from ice in the King Valley spills into the Queen Valley via a gap 
in the King Gorge. Ice from the Tyndall Plateau flows westwards into the Henty Valley, and terminates slightly further down valley of the empirical ice limits. In the northeast region of the West Coast Range, extensive ice development occurs in the Murchison Valley, flowing into the upper Pieman Valley. The Pieman Valley is also supplied by ice flowing down the Mackintosh Valley. However, as with the previous advances, the model is unable to accumulate enough ice to reach the empirical ice limits in the northern region of the West Coast Range.

Ice extent in the northern region of the main ice mass in the Central Highlands is illustrated in Figure 5-28. Outlet glaciers are located in the Mersey, Forth, Fury and Mackintosh valleys. Empirical ice limits in the Mersey Valley are in close agreement with ice produced by the model. Ice on Black Bluff, Mount Cripps and the Mackintosh Valley flow into the upper reaches of the Leven Valley. While ice exceeds terminal reconstructions carried out by Kiernan, evidence for ice entering the upper Leven Valley via Black Bluff and the Mackintosh Valley is equivocal. Ice in the north-eastern region of the Central Highlands is essentially a thin carapace, with empirical ice limits largely unknown.

Empirical ice limits on the Central Plateau are largely equivocal due to the lack of quality depositional landforms. However, the model does produce ice that extends eastwards and terminates not far from the Great Lake; in close proximity to till found on the western shoreline (Figure 5-29). Ice also flows down the upper reaches of the Mersey and Nive valleys, terminating very close to the empirical limits. 


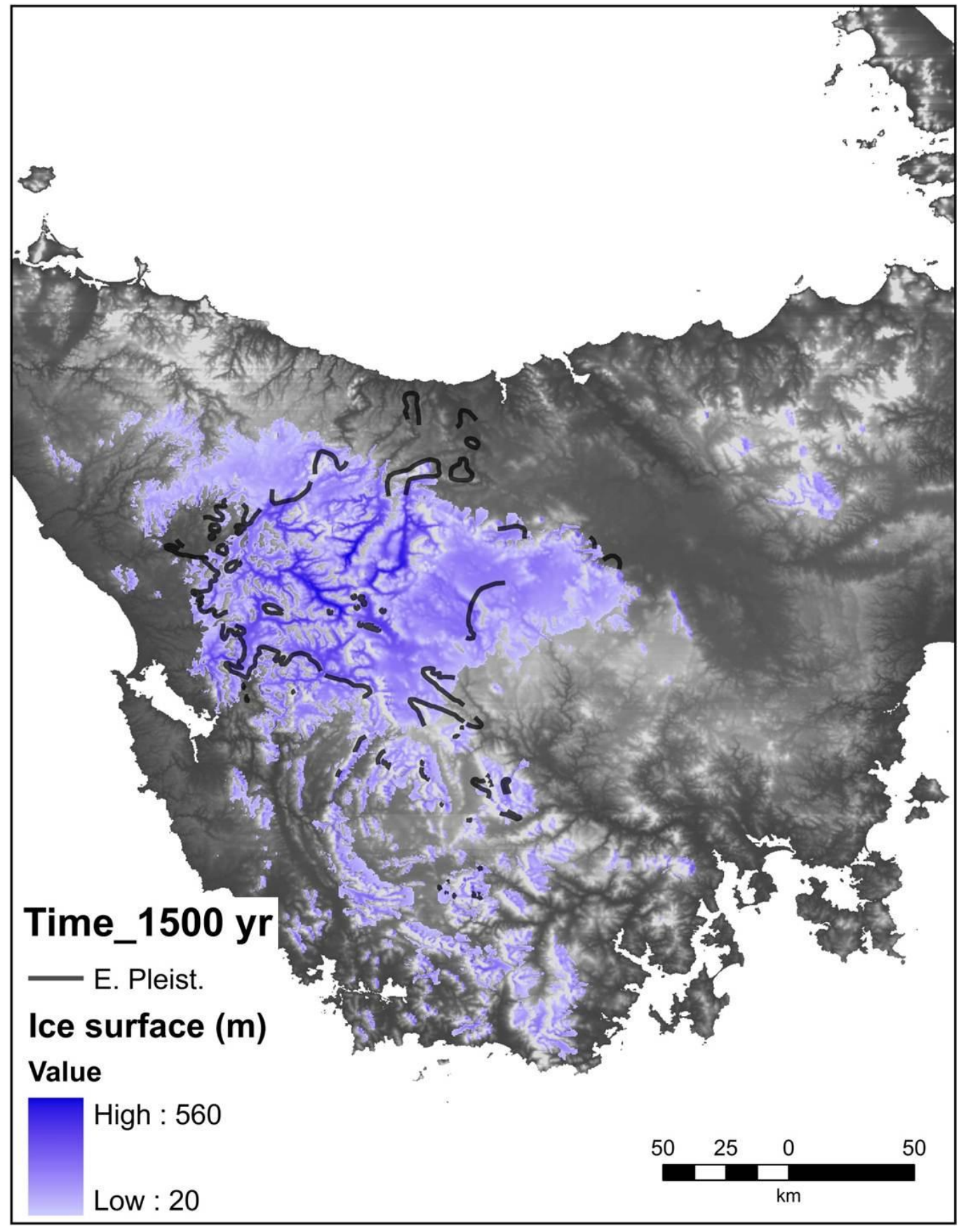

Figure 5-24: Early Pleistocene ice extent and thickness over the entire model domain after 1500 model years under optimal climate parameterisation. The overall geometry of ice simulated by the model is in agreement with the empirical limits. However, ice is over-predicted in southern and western regions of the West Coast Range, northeastern Tasmania and south of the Central Plateau. Empirical reconstructions of early Pleistocene field limits are shown in black outline. Maximum ice thickness approaches $560 \mathrm{~m}$ in Lake St Clair, Murchison Valley, Forth Valley and Mersey Valley (dark blue). 


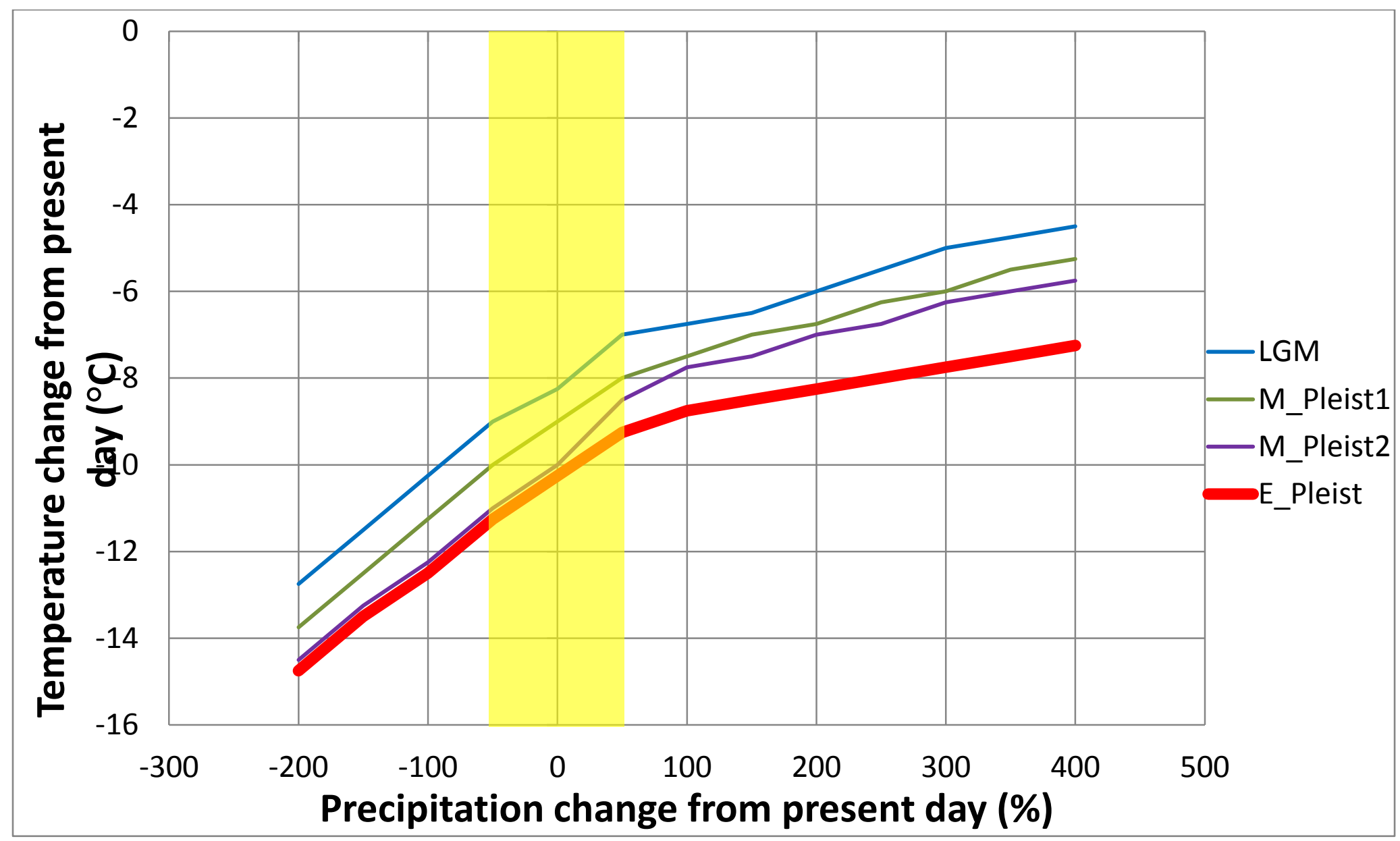

Figure 5-25: The range of temperature and precipitation conditions that produce a similar ice geometry for the early Pleistocene advance (red line). The three other Quaternary advances are also plotted for comparison (thinner lines). The yellow shading represents the range of likely combinations of temperature and precipitation required for each advance. 


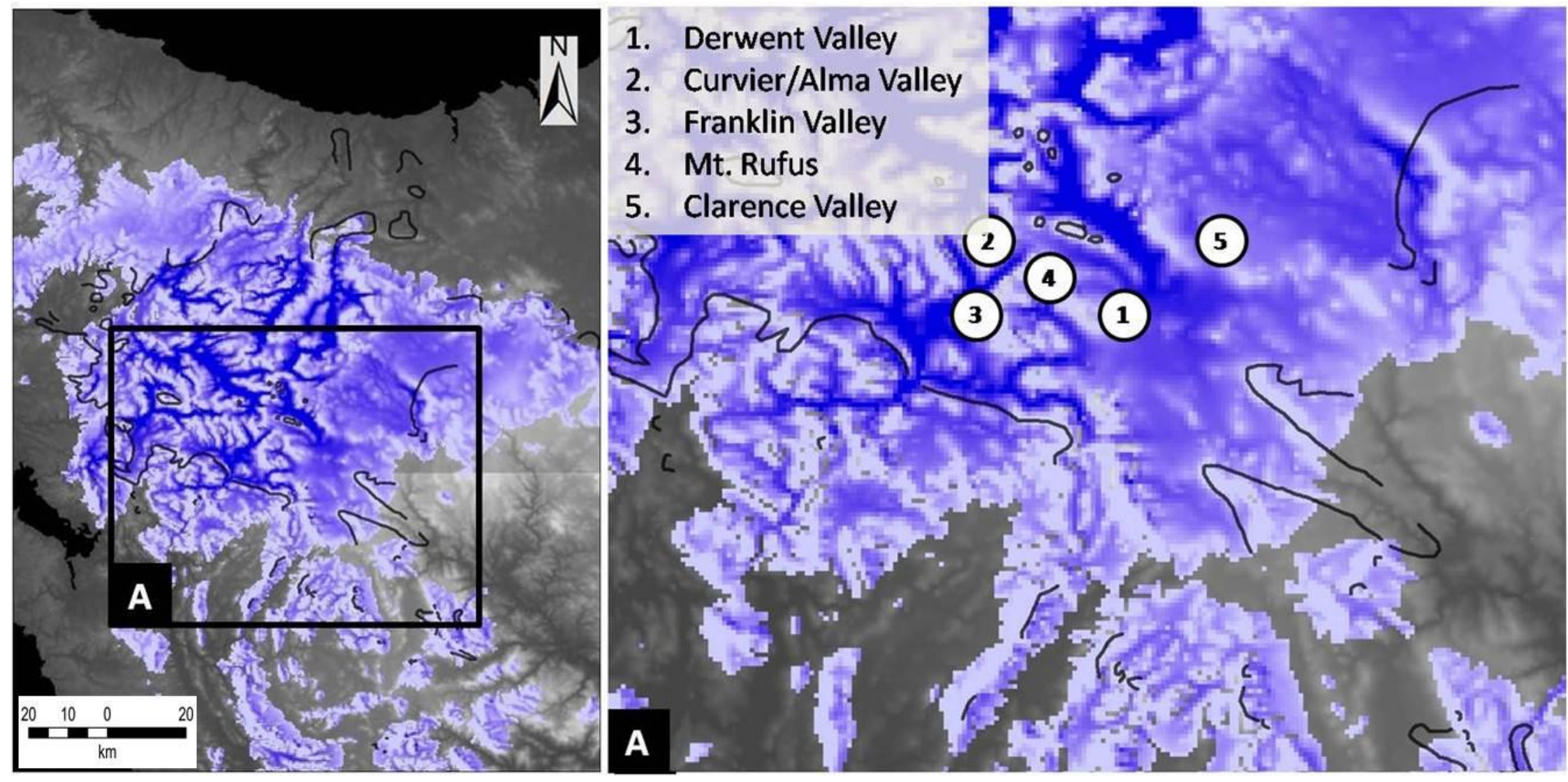

Figure 5-26: Early Pleistocene ice extent over the central ice cap with a close up of the southern region (A). The large valley glacier is not simulated by the model in the Derwent Valley. Ice is over-predicted southwest of the Franklin Valley. The black lines mark early Pleistocene empirical field limits. Key areas numbered in the figure are referred to in text. 

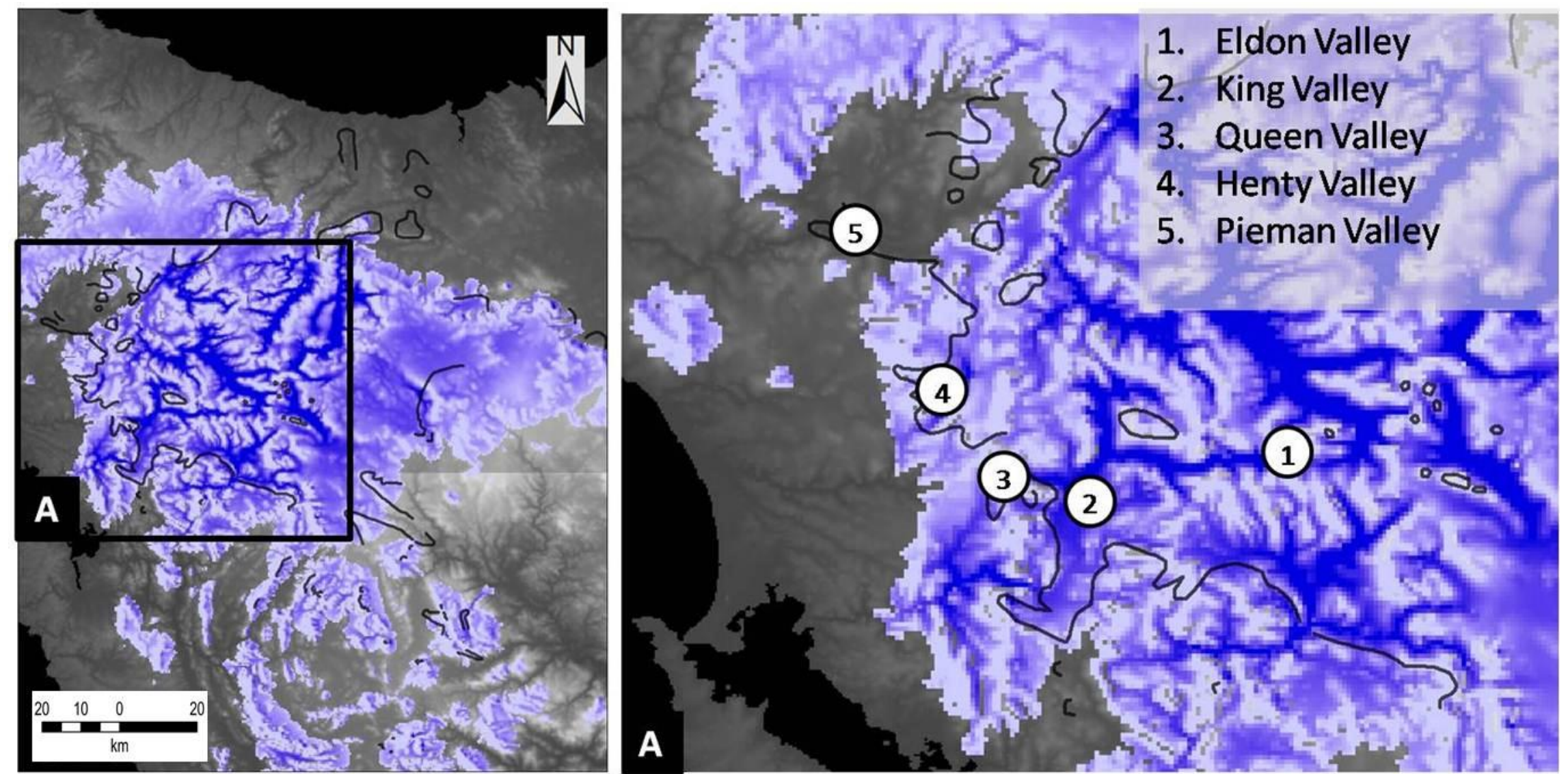

Figure 5-27: Early Pleistocene ice extent over the central ice cap with a close up of the western region (A). Ice exceeds empirical limits west of the King, Queen and Henty valleys, while ice is under-predicted in the Pieman Valley. The black lines mark early Pleistocene empirical field limits. Key areas numbered in the figure are referred to in text. 

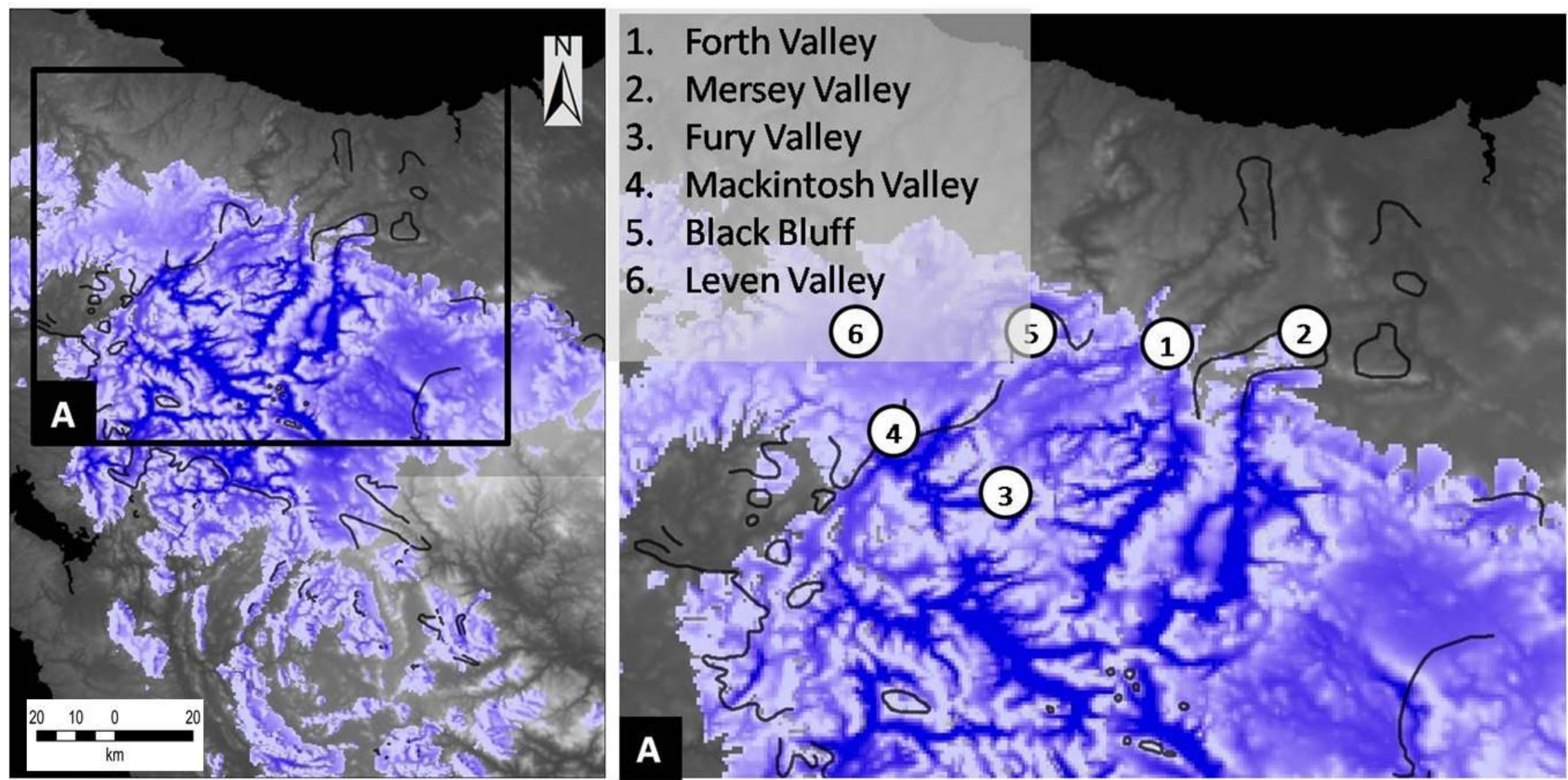

Figure 5-28: Early Pleistocene ice extent over the central ice cap with a close up of the northern region (A). A good match is achieved in the Mersey and Forth valleys. Ice is over-predicted northwest of the Mackintosh Valley. The black lines mark early Pleistocene empirical field limits. Key areas numbered in the figure are referred to in text. 

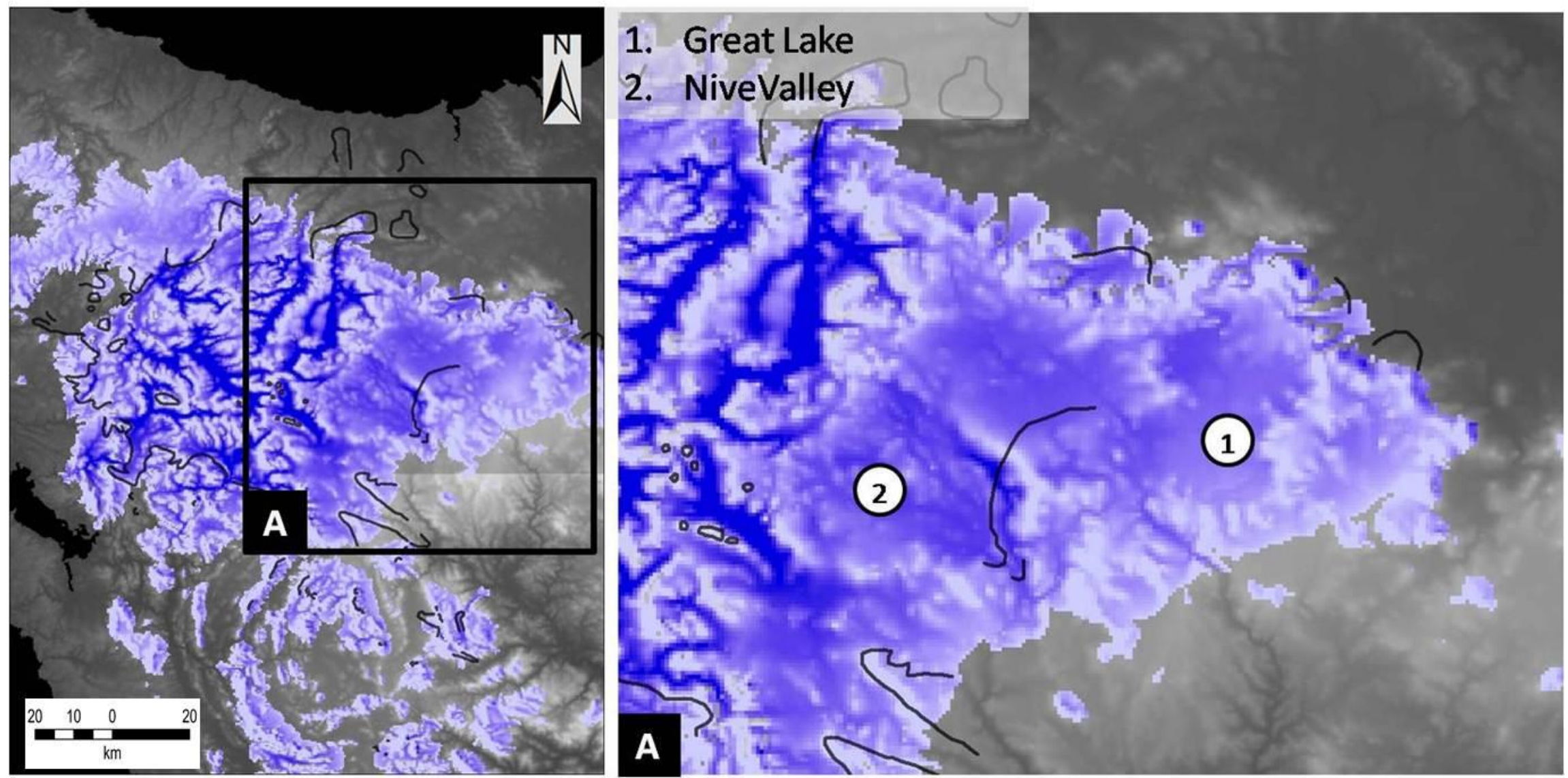

Figure 5-29: Early Pleistocene ice extent over the central ice cap with a close up of the northern region (A). A good match is achieved in the northern and eastern region of the Central Plateau. Ice is over-predicted by the model and exceeds the southern limits of the Central Plateau. The black lines mark early Pleistocene empirical field limits. Key areas numbered in the figure are referred to in text. 


\subsection{Ice dynamics}

As with the description of ice evolution, ice dynamics for all modelled glacial advances are similar. Figure 5-30 illustrates the distribution of total ice velocity under optimum conditions (middle Pleistocene II is used as an example). The differences between the western and eastern regions are marked. The western region contains many fast flowing outlet glaciers (e.g. Murchison, Fury and Forth valleys). This is contrast to the relatively slow moving eastern region. The contrasts in regional ice velocity occur due to climatological and topographic reasons. The western region is characterized by steep and highly dissected topography. This combined with an enhanced west-to-east precipitation gradient, induces large ice fluxes, resulting in highly dynamic glaciers. For example, ice flowing down the King Valley moved at 500-600 $\mathrm{ma}^{-1}$. Conversely, the eastern region has gently sloping surface topography and glaciation is constrained by moisture availability. This results in thinner ice coverage with shallow surface slopes and low mass throughput. Indeed, the majority of the Central Plateau is moving slowly, with flow values ranging from $0-50 \mathrm{ma}^{-1}$.

\subsection{Summary}

Ice geometry predicted by the model for Quaternary glacier advances simulate certain features well, especially for the LGM. Earlier glacial advances are less well replicated, partly because empirical ice limits provide less constraint. Despite mismatches with the field evidence, all model runs show some common features, meaning that the range of possible temperature and regional precipitation patterns reconstructed throughout the Quaternary still contains useful information. 


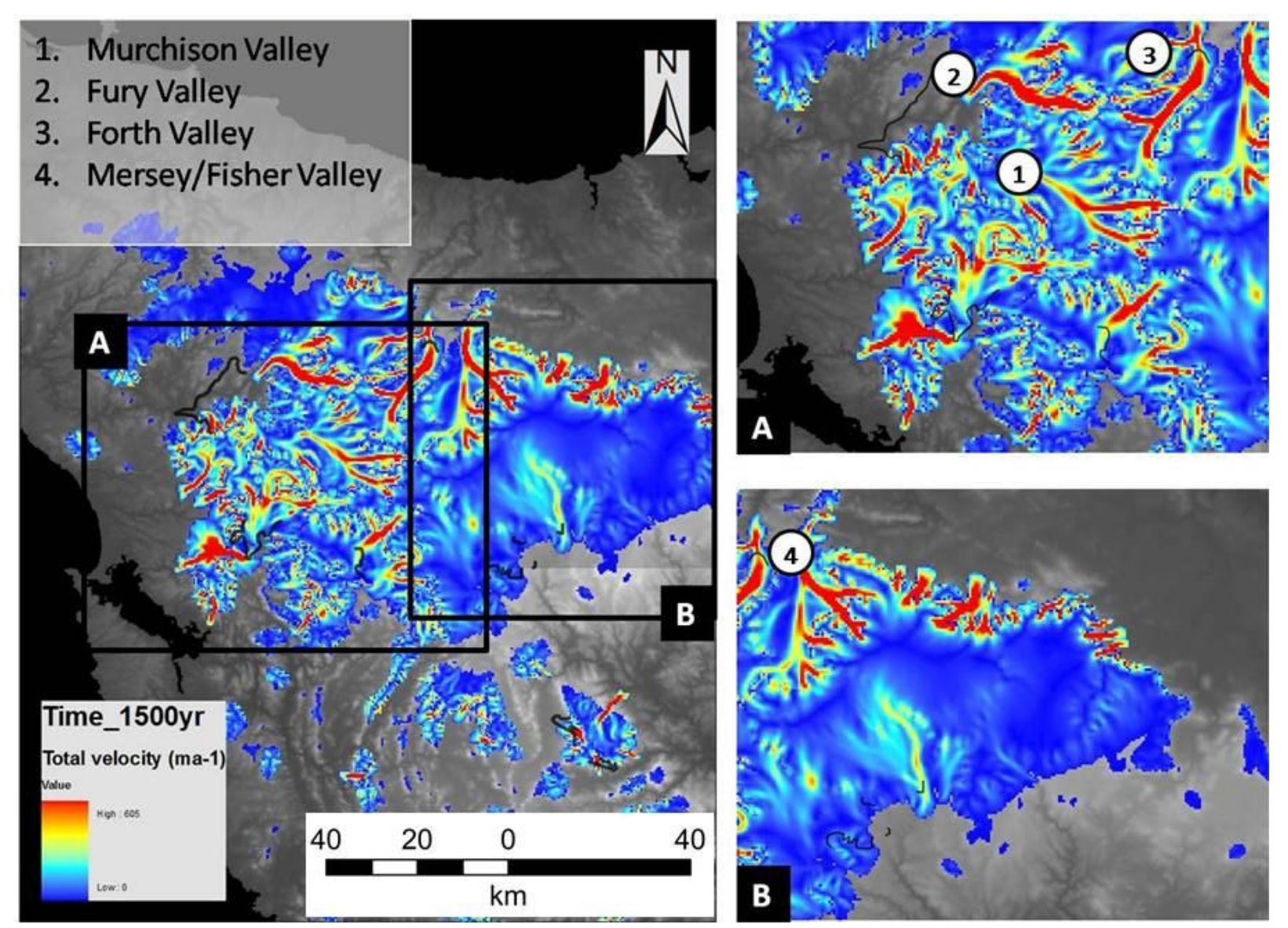

Figure 5-30: Total velocity from the optimum middle Pleistocene II run, showing zones of high and low velocity. (A) Depicts the western side of the main ice mass, with many fast flowing glaciers in red. (B) Illustrates the relatively slow moving eastern region, with some fast flowing outlet glaciers in the northern sector. Large outlet glaciers are numbered in the figure (1-4), with some referred to in text. A sliding value of 10 was used in this simulation (explained more fully in 5.4.1). 


\section{Chapter 6 \\ Discussion}

\subsection{Ice extent and thickness}

A fragmentary record of early Pleistocene-age landforms and sediments indicates that the most extensive phase of Cenozoic glaciation in Tasmania involved the development of an ice cap with outlet glacier systems in north-west Central Tasmania (Kiernan, 1990b). Subsequent glacial advances were less extensive, with ice extent largely constrained by topography (e.g. Colhoun, 1985; Augustinus and Colhoun, 1986; Colhoun and Fitzsimons, 1990; Fitzsimons and Colhoun, 1991; Kiernan, 1992). These scenarios were replicated with all modelled glacial advances by choosing appropriate temperature and precipitation combinations. Ice quickly developed on the Central Highlands and Central Plateau and coalesced to form a coherent ice mass, which in some simulations (early Pleistocene to middle Pleistocene II), coalesced with ice in the West Coast Range. These central accumulation areas fed steep outlet glaciers that drained along the main valleys around the margin of the main ice mass. Separate glacial systems produced by the model occurred in the West Coast Range (Last Glacial Maximum [LGM] only), Mount Field and Ben Lomond regions. It should be noted that during the early Pleistocene model simulation, the ice mass forming over the Central Highlands and Central Plateau resembled an ice cap with an independent dome, whereas during subsequent glacial episodes it was reminiscent of a mountain icefield.

Although the model performed well in some areas, other glaciated areas were less well simulated or lacked constraining field evidence. Distinct areas worth mentioning are: 1) the northern limits of the West Coast Range, 2) the valleys situated between the Du Cane Range and West Coast Range, and 3) the eastern limits of the Central Plateau. In the Pieman-Boco valley area in the northern West Coast Range, the optimum model simulations for early Pleistocene to mid Pleistocene I advances predicted less ice than the empirical limits suggested. The glacial history of this area represents the most securely dated Cenozoic glacial sequence in Tasmania (e.g.Colhoun, 1985; Colhoun and Fitzsimons, 1990; Kiernan, 1990b; 1999b, 1999a). 
Ice surface reconstructions for the Pieman River area carried out by Augustinus (1999b) revealed that a piedmont ice lobe developed in this region. Ice flow was restricted due to low surface slopes and the fact that ice was flowing against the topographical gradient. By contrast, the model showed that ice feeding into the Pieman Valley was insufficient to fill the valley and override topographic divides. These shortcomings occurred across a wide range of model configurations, far more than the optimally parameterised simulations presented. This discrepancy was likely due to the coarse grid resolution and topographic smoothing which may have affected the ability for glaciers to form.

The landscape record indicated that two separate ice masses developed over the Central Plateau and West Coast Range during the middle Pleistocene I and II glacials. This was simulated by the model, with additional ice located in the valleys (South Eldon, Murchison, Fury and Mackintosh) between these two ranges. While field mapping has been limited in these valleys, ice extent predicted by the model is more widespread than previously recognized. For example, little is known about the glacial geology of the Mackintosh Valley apart from the presence of large dolerite and granite boulders, at odds with the underlying geology (Sprent, 1887; Ward, 1909; Kiernan, 1990b). Colhoun and Fitzsimons (1990) provided $\mathrm{C}^{14}$ ages of outwash deposits in the lower Mackintosh Valley ( $~ 36,200$ BP) and charcoal in till at Mackintosh Dam ( >35,000 BP) suggesting ice may have occupied this valley during the middle Pleistocene II and even up to middle Pleistocene I glacial advances. Ice in the Mackintosh Valley was simulated in all modelling experiments, except for the LGM glacial advance; suggesting the possibility that the dolerite and granite boulders discovered in the valley were indeed transported by former glaciers.

The simulations also presented a testable model for areas where empirical data was either lacking or ambiguous, especially in areas where simulated ice extent was relatively insensitive to changing input parameters. For example, the model predicted the existence of large valley glaciers in the terrain between the Central Highlands and the West Coast Range for all Quaternary advances. A number of studies supported the notion of continuous ice development between the two ranges for the early 
Pleistocene glacial advance (e.g. Davis, 1969; Flint, 1971; Derbyshire, 1972; Kiernan, 1990b). This was primarily based on the reconstruction of glacier surface profiles and flow patterns. Nevertheless, the models prediction of thick ( $\sim 500 \mathrm{~m})$ and extensive ice development in the Murchison, Fury, South Eldon and Mackintosh valleys, may stimulate further palaeoglaciological research in this area.

\subsection{Basal processes and geomorphic implications}

The degree to which we understand ice flow mechanisms is important when considering variations in landform genesis. Modelling the spatial distribution of basal velocity allows the important characteristics of flow to be considered: deformation at the bed, basal sliding associated with meltwater at the bed, and the internal deformation of ice. Subsequently, the ice mass can be partitioned into discrete zones of erosion, transport and deposition and compared with landform characteristics preserved in the geomorphic record.

The model allowed differentiation between the two components of total velocity to be calculated - basal motion and internal deformation. Figure 6-1 demonstrates that by calculating the relative components of total velocity, the spatial variability of ice motion can be quantified. This enables inferences about areas subject to the greatest erosion potential to be identified and compared to the empirical landform record. Interestingly, it appears that the majority of ice simulated by the model flows by basal sliding, as opposed to internal deformation. This shows that ice is to some degree more controlled by bed slope than the slope of the ice surface. This is reflected when looking at ice accumulation on the Central Plateau. Rather than forming a domed ice cap where velocity is controlled by the slope of the ice surface, ice is instead fed into the steep surrounding valleys. The highest velocities and thus the greatest potential for erosion occur in the western region where ice from the main ice mass is funneled into topographic troughs. This is where both ice thickness and basal sliding velocities are highest (Figure 6-2). Indeed, this region is characterized with the largest moraines (Davis, 1974; Colhoun, 1985) and an abundance of deep cirques and rock basins, reflecting once vigorous ice movement. The model produces

a similar velocity distribution in all simulations, thus one could imagine that these 
mature landforms of glacial erosion developed from repeated ice erosion over multiple glaciations throughout the Quaternary.

Thinner and less dynamic ice cover was consistently predicted by the model in the Central Plateau area. The present-day landscape in this area comprises zones of areal bedrock scour, with widespread roches moutonnées, whalebacks, ice-eroded basins, meltwater channels and striae; indicative signs of glacial erosion. Purely erosional landscapes resembling the Central Plateau have previously been described by Sugden (1974), with their development occurring beneath warm-based ice, where flow is laterally extensive, as opposed to being focused into narrow channels. However, the role of preglacial weathering in the evolution of landscapes of areal scouring should not be underestimated, especially given the homogeneity in bedrock geology (Lindström, 1988).

Figure 6-3 depicts total ice velocity across the Central Plateau, with zones of fast moving ice ( $>400 \mathrm{ma}^{-1}$ ) located in the central valley, and slower ice motion around the southern fringes. From this it may be inferred that erosion of the underlying bedrock preferentially occurs where ice thickness and sliding velocities are high. When the locations of areal scouring were compared with the modelled variations of ice thickness and total velocity, an interesting relationship could be seen. Concentrated zones of glacial erosion appeared to coincide where ice thickness and basal sliding were highest (Figure 6-4 and Figure 6-5). Additionally, lake orientation in the upper part of the catchment is aligned with the modelled flow direction of valley glaciers. This suggests that the model is accurately simulating former glacier dynamics and preferential flow directions in this area. Furthermore, for each ensuing glacial advance, the same pattern of glacier dynamics is observed. This suggests that (as seen in the western region) multiple glacial episodes may have been required in order to develop the present landscape. This is not unrealistic given the high degree of preservation associated with erosional landform compared with their depositional counterparts (Sugden, 1974). 


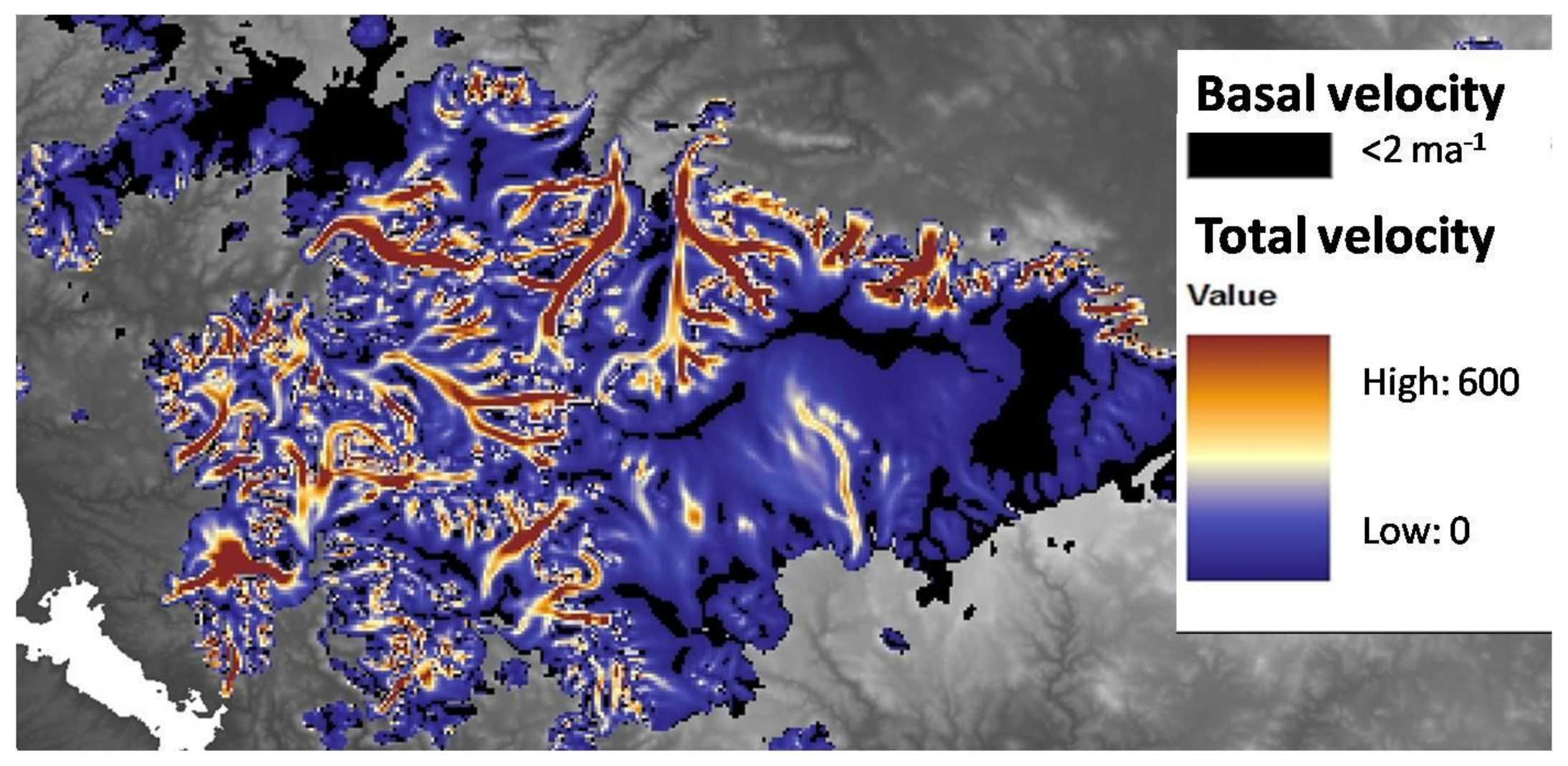

Figure 6-1: Velocity distribution of modelled ice from middle Pleistocene glacial advance. Total velocity shown in blue and red indicates that nearly all ice flows by sliding at its bed. The areas in black reflect ice movement that is less than $2 \mathrm{ma}^{-1}$ (more or less stationary), and that flows primarily through internal deformation. 
Uncertainty in former ice cap extent is greatest east of the Central Plateau where glacier limits are poorly defined. This is in contrast to the clear terminal limits in the northern, southern and western regions of the Central Plateau and Central Highlands. It is well documented that erosional landforms survive longer than depositional evidence for repeated glacial cycles. However, it is uncertain why the empirical record is not preserved in the east, especially if prominent landforms were present in other regions. It may that the less dynamic glaciers produced smaller and less distinct moraines. Additionally, the landform record in this part of Tasmania may have been preferentially removed, because clays derived from weathering of dolerite readily undergo solifluction under periglacial conditions (Kiernan, 1999). 


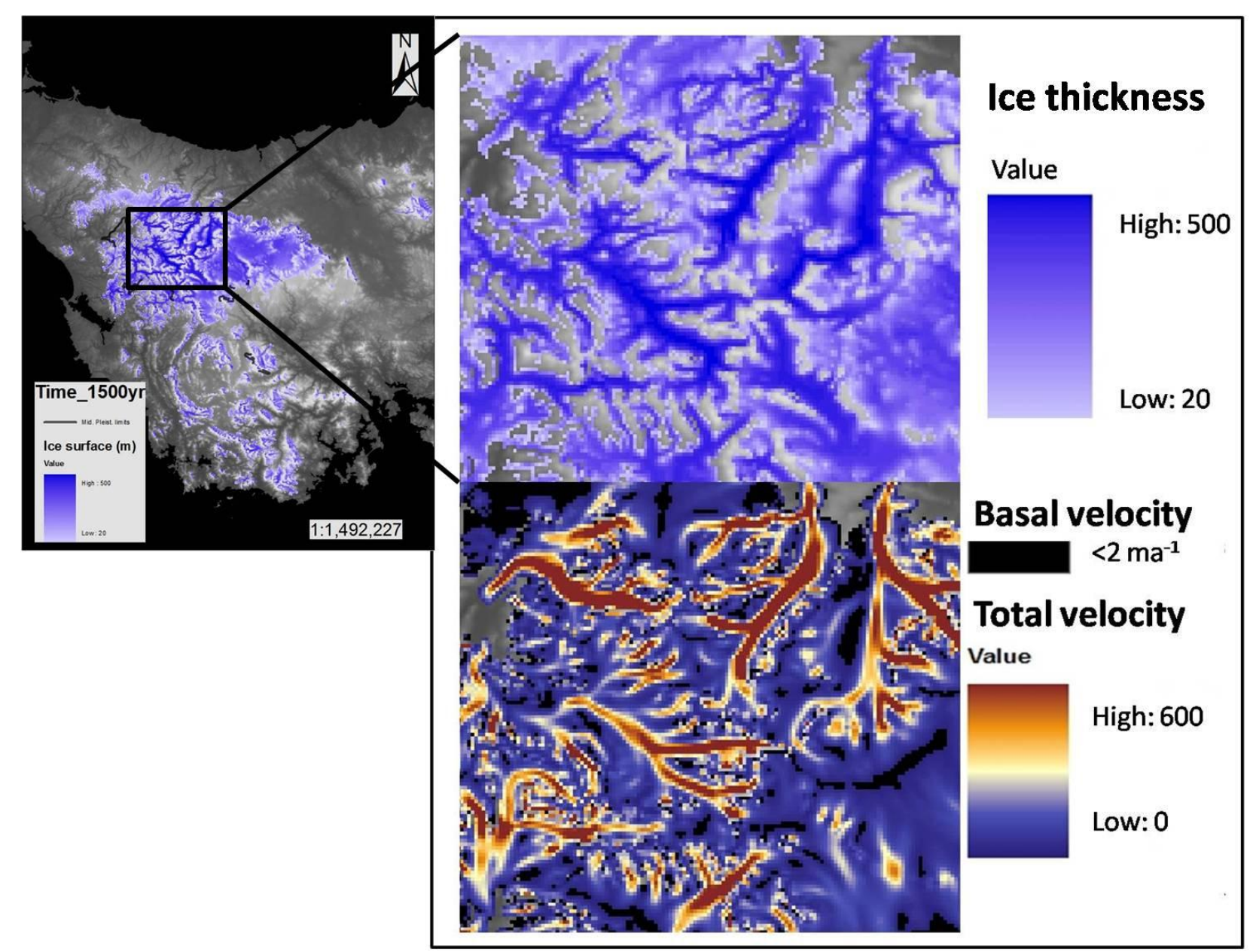

Figure 6-2: Velocity distribution and ice thickness for middle Pleistocene II model simulation. Zones of fast moving ice (400$600 \mathrm{ma}^{-1}$ ) occur in conjunction with thick ice in steep valleys. 


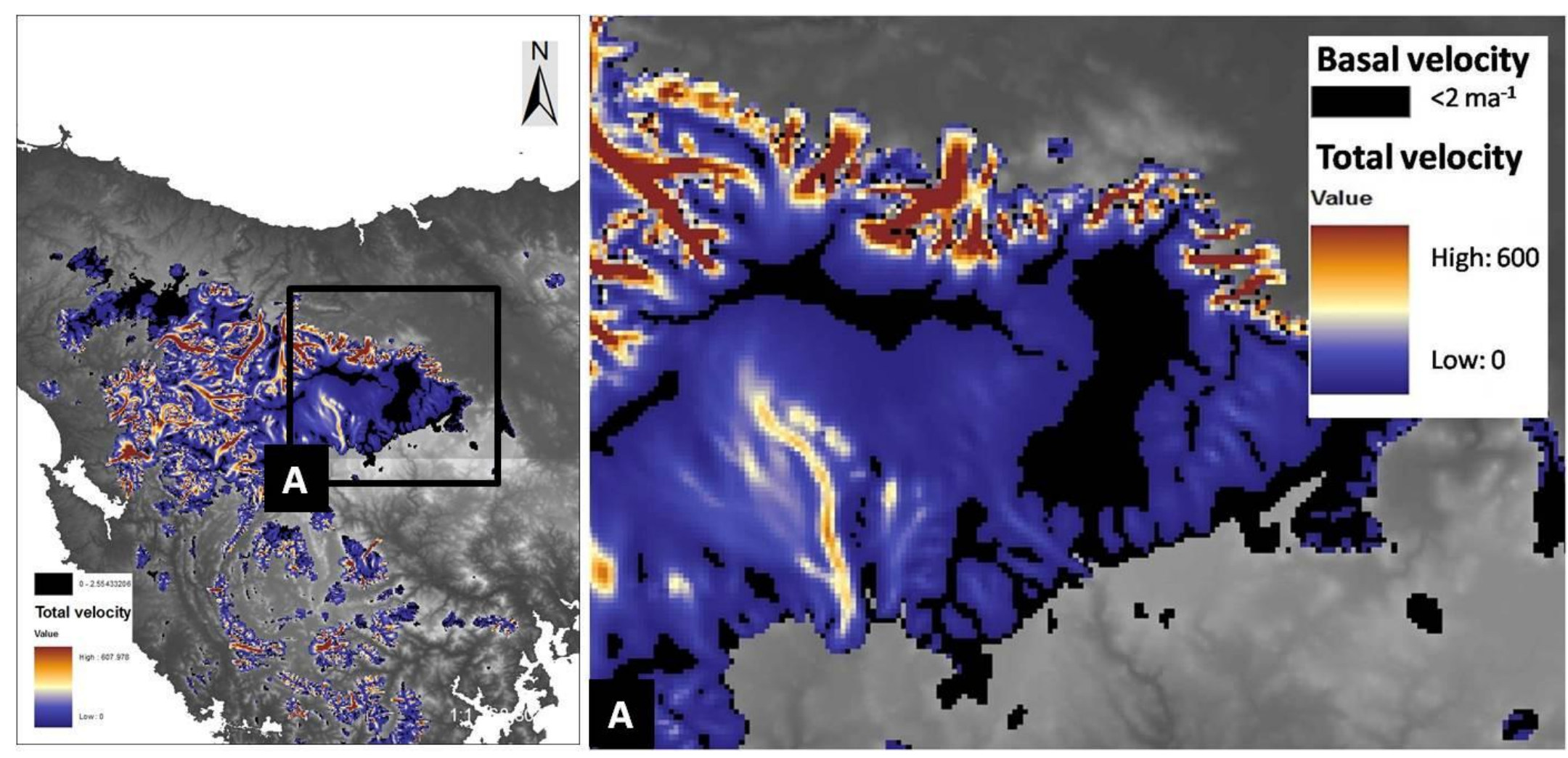

Figure 6-3: Velocity distribution over the eastern region of the Central Plateau for middle Pleistocene II advance. A large proportion of ice in this sector moves primarily through internal deformation $\left(<2 \mathrm{ma}^{-1}\right)$. There are zones of faster moving ice $\left(400-600 \mathrm{ma}^{-1}\right)$ in the central valley of this figure, however, ice along the southern fringes is more or less stationary. 


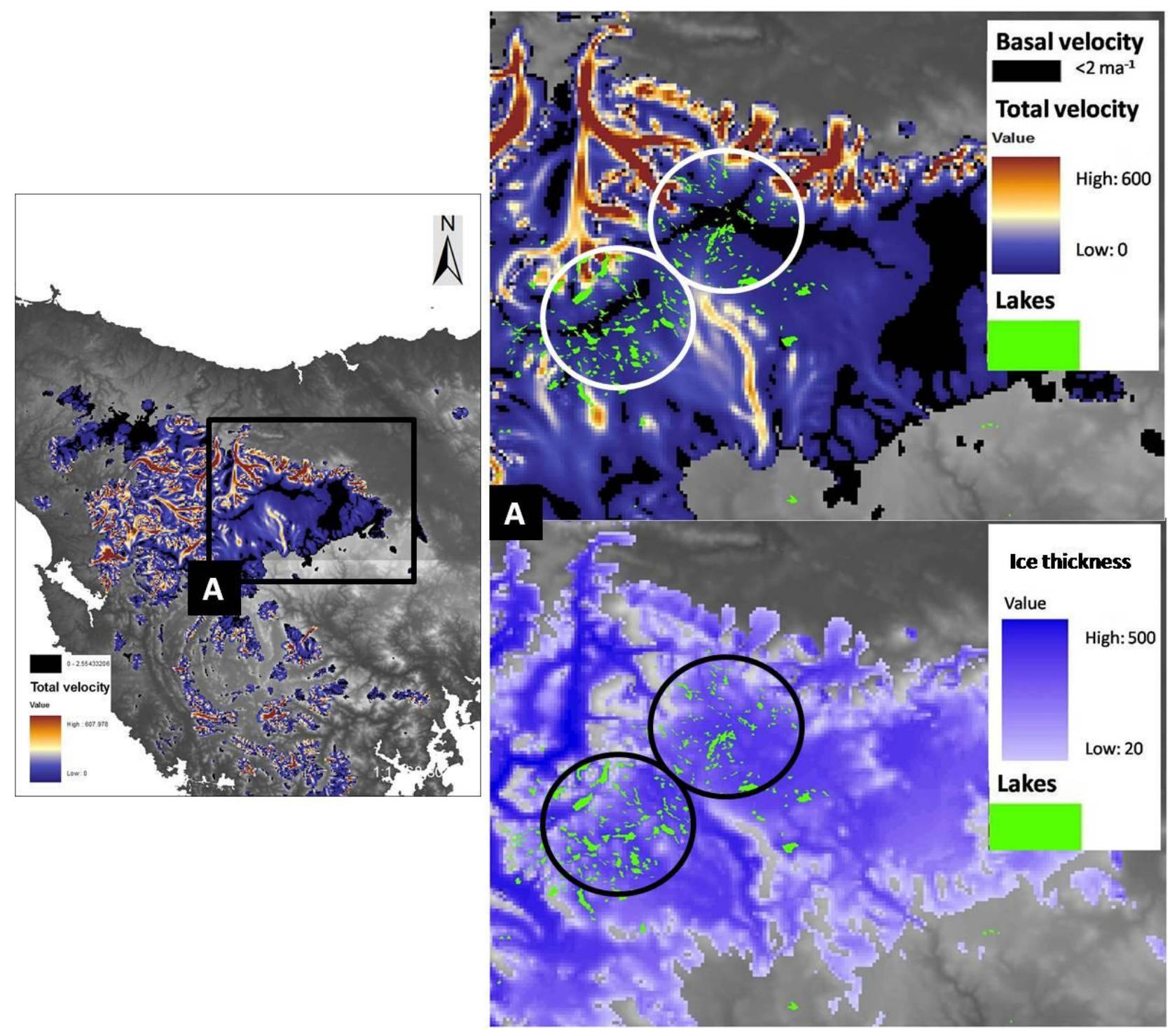

Figure 6-4: Middle Pleistocene II model simulation. Distribution of lakes representing zones of areal scouring across the eastern Central Plateau. These zones were superimposed on model predictions of ice thickness and the distribution of velocity. In general, scoured bedrock occurred where ice was slightly thicker and experiencing sliding at its bed. In the upper part of the catchment the lakes appeared to align with the flow of valley glaciers. This indicates that the model does a good job simulating former glacier dynamics in this area and long-term preferential flow directions. 


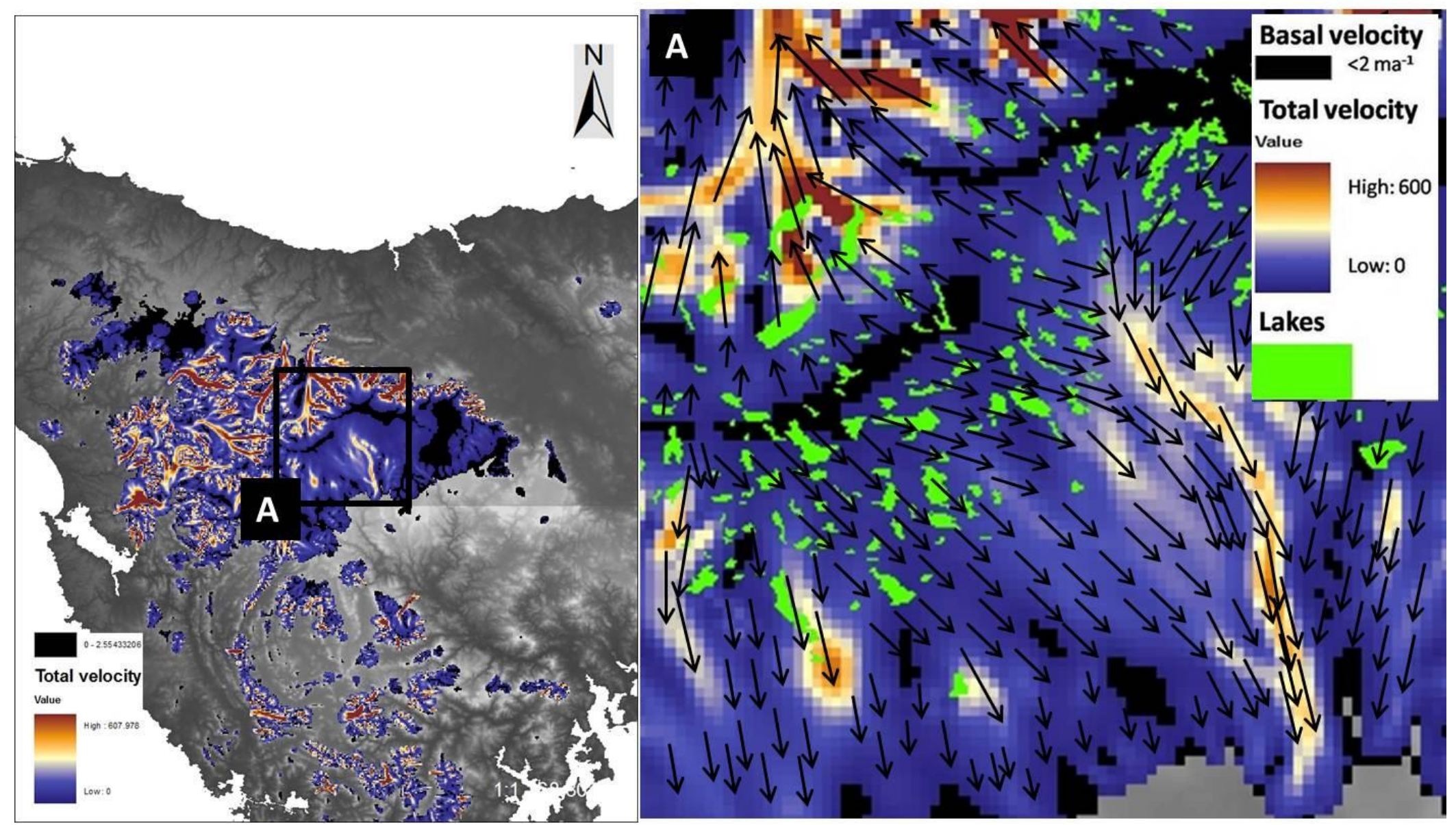

Figure 6-5: Middle Pleistocene II model simulation. Distribution of lakes representing zones of areal scouring across the eastern Central Plateau. The black arrows represent surface velocity vectors, with the arrow pointing in the direction of flow and the arrow length representing relative velocity. 


\subsection{Climatic interpretations}

Model simulations driven by a range of climatic combinations replicated the overall geometry of Quaternary glacial advances in Tasmania reasonably well. These model simulations are important as it provides a process in which glacier geometry can be translated into a semi-quantitative record of temperature and precipitation changes relative to present-day values. While numerical modelling is a useful method for palaeoclimate reconstruction, it is important to acknowledge the uncertainties and assumptions associated with this process. Errors associated with grid resolution and topographic smoothing are likely to be problematic given the $500 \mathrm{~m}$ grid resolution used. Sub-grid parameterisation can potentially reduce this error, and will possibly be employed in future modelling studies.

The value defining the degree of sliding was chosen based on the sensitivity experiments (see 5.3.1) and other modelling investigations (Golledge, 2008). While field evidence suggests sliding, it does not indicate how fast or slow ice was moving. The sliding value of 10 produced an ice geometry whose fit agreed with the empirical ice limits more so than higher or lower sliding values. It was important to remember that this value was also a potential source of error in the temperature reconstructions, as it was linked to the degree of cooling required for best-fit model simulations (i.e. more sliding meant less cooling required to reach the same empirical limits).

Equifinality is a problem in this modelling investigation. Every attempt is made to assess individual parameters in the sensitivity testing by incrementally altering each parameter in turn. Complex feedbacks with the glacier-climate system make this impossible; therefore altering one variable may produce an unknown change in another (e.g. varying sliding and its effect on temperature or altering temperature and its effect on precipitation). While this means that there is no unique condition for this model, the outcomes of the modelling experiments are to attempt to create the nearest possible match.

Climatic reconstructions were made by assuming that the glacier reached equilibrium with its climate (see 5.2). This assumption could be made with some 
assurance for ice limits marked by large terminal moraines. However, while geomorphic evidence was usually very accurate in terms of indicating former ice limits, the timing of glacial advances are sometimes not well constrained. If there are errors associated with the timing of former glacier positions, these were also carried on through to the climatic reconstructions. While an attempt was made to ensure that chronologically robust geomorphic data was used to constrain model output, evidence prior to the LGM is limited and sometimes not as well dated. Despite these shortcomings, climatic inferences drawn from the model can be compared to regional and hemispheric multi-proxy palaeoenvironmental reconstructions.

\subsubsection{Empirical model mismatches}

It became apparent in initial modelling runs that it would not be possible to achieve an exact match between numerically simulated and geologically reconstructed glacier limits. Indeed, it was difficult to achieve a good match with a number of key terminal limits without over-predicting overall ice coverage. The mismatch probably resulted from local climatic and topographic processes not being included in the model, such as the redistribution of snow by wind and shading from valley sides. These processes are known to be important in maritime ice-sheet initiation (Payne and Sugden, 1990a). Given that Tasmania was regarded as a marginal environment for glaciation during the LGM, localised climatic and topographic factors may have influenced glacier inception and subsequent ice distribution. Furthermore, limitations within the model itself, such as grid resolution, topographic smoothing or simplifications of the physics governing ice flow did not provide an environment conducive to marginal ice development at a sufficient resolution.

\subsubsection{Climatic thresholds and sensitivity}

The sensitivity experiments with the ice-sheet model indicated that glacier growth in Tasmania was affected by threshold behaviour, largely controlled by the underlying 
topography. This is important as topography is known to be a major control in glacier initiation because it influences snow and ice buildup (Ives, et al., 1975; Payne and Sugden, 1990b). Glacial inception only occurs when temperature is depressed by $6^{\circ} \mathrm{C}$, with discrete glaciers forming on high peaks and across the Central Plateau. Ice buildup initially occurred in (non-linear) steps, but for larger coolings (7 to $10^{\circ} \mathrm{C}$ ), glacier development was more progressive, with ice extent ultimately controlled by the spatial pattern of topography. Temperatures exceeding $10.5^{\circ} \mathrm{C}$ resulted in the development of an ice-sheet enveloping the majority of Tasmania and that grew independent of topography. This is a good example of glacier sensitivity, whereby small changes in temperature resulted in large and abrupt changes in ice development. In all cases, the ice mass reached equilibrium with the climate in < 1000 model years. This provides an indication of the timescale of Tasmanian glaciation. For example, it is quite possible that Tasmanian glaciers could advance and retreat in response to millennial-scale events during the Quaternary.

\subsection{Glacial palaeoclimate in Tasmania}

The best-fit Quaternary ice advances simulated by the model required a maximum temperature depression of between -7 and $-11.25^{\circ} \mathrm{C}$. These temperatures varied depending on how regional precipitation was parameterised, but realistic temperatures all fell within a realistic precipitation range $(+/-50 \%)$. There was also enhancement in orographic precipitation, with the imposition of west-to-east precipitation gradients. While palaeoclimatic inferences can be drawn from the model simulations, it is important to remember that these findings most likely contain a degree of error, considering the degree of uncertainty associated with grid resolution and topographical smoothing. Palaeoclimate records from the Andean Cordillera of South America, Australia and the Southern Alps of New Zealand, combined with modelling simulations from this study provided an opportunity to investigate climate conditions driving glacier fluctuations in the southern midlatitudes. 


\subsubsection{LGM temperature}

Palaeoenvironmental proxies and empirical glacier reconstructions indicate that temperatures were depressed by 6 to $8^{\circ} \mathrm{C}$ for the LGM.

Similar temperature reductions $\left(6\right.$ to $\left.8^{\circ} \mathrm{C}\right)$ have been inferred from pollen records and modelling of ELA reconstructions in South America (Hulton, et al., 1994; Heusser, et al., 1999; Moreno, et al., 1999; Hulton, et al., 2002; Hubbard, et al., 2005). Twice as much precipitation (compared to present-day) was thought to have occurred at 41 to $42^{\circ} \mathrm{S}$ (Lamy, et al., 1998; Heusser, et al., 1999; 1999; Moreno, et $a l ., 1999)$, with drier than normal conditions prevailing in southern Tierra del Fuego $\left(54^{\circ} \mathrm{S}\right)$ (Heusser, 1989a).

Interpretation of climate from endorheic lakes (Bowler, 1986; Nanson, et al., 1992; Chen, et al., 1993; Croke, et al., 1996, 1998; Magee, et al., 2004) and vegetation assemblages (Bowler, et al., 1976; Torgersen, et al., 1985; Torgersen, et al., 1988) in Australia indicated drier and more continental conditions prevailed during the LGM. The activation of dune fields throughout Australia supported not only drier conditions, but also suggests that the LGM was windier than present (Bowler, et al., 1976; Sprigg, 1982; Wasson, 1984). Drier conditions, especially in northern and eastern Australia may have been associated with a weakening of Walker circulation, bringing about El Niño like conditions (Beaufort, et al., 2001; Müller and Hope, 2004). Glaciers developed in the Mount Kosciuszko region in south-east Australia (Barrows, et al., 2001), with investigations suggesting that the temperature was depressed by 6 to $10^{\circ} \mathrm{C}$ (Bowler, et al., 1976; Singh, 1983; Miller, et al., 1997).

Climate deterioration in New Zealand indicated by palynologic records and reconstructed palaeo-equilibrium line altitudes indicating temperature depressions of 4.5 to $7^{\circ} \mathrm{C}$ (Porter, 1975; Alloway, et al., 1992; Newnham, et al., 1999; Bacon, et al., 2001; Shulmeister, et al., 2001). Stronger than present surface wind speeds and atmospheric drying were indicated by enhanced loess deposits and stalagmite records (Alloway, et al., 1992; McGlone, et al., 1993; Eden and Hammond, 2003; Williams, et al., 2005). A slightly larger degree of cooling of $\sim 7^{\circ} \mathrm{C}$, with a $50 \%$ reduction in 
overall precipitation was predicted by model simulations (of exactly the same kind used in this study) over the Southern Alps of New Zealand (Mackintosh and Hubbard, unpublished).

It appears that that broadly similar temperature depression of 6 to $8{ }^{\circ} \mathrm{C}$ occurred over the Southern mid-latitudes terrestrial regions during the LGM. It is difficult to reconcile this large temperature difference with classic insolation forcing in the Northern Hemisphere without some means of global amplification, for example via reduced atmospheric $\mathrm{CO}_{2}$ levels. This may be important for future climatic predictions, given the concern about rising $\mathrm{CO}_{2}$ levels and its effect on increasing global temperatures.

\subsubsection{LGM precipitation}

Indicators of past precipitation conditions in Tasmania are at best qualitative due to difficulty of separating the influences of temperature and moisture (Colhoun, et al., 1991, 1999; Jordan, et al., 1995; Hopf, et al., 2000). Despite this, an enhanced westto-east precipitation gradient (compared to present-day) has been proposed in association with cirque floor mapping (e.g. Peterson and Robinson, 1969; Caine, 1983; Colhoun, 1985) and the activation of dune sequences (Bowden, 1983) in eastern Tasmania. The temperature range for each modelled glacier advance was based on both increasing and decreasing global precipitation. However, an optimalfit for each glacier advance was also achieved without altering global precipitation. No definitive conclusions regarding the mechanisms influencing changing precipitation conditions can be drawn from this modelling investigation. However, localized enhancement of the west-to-east precipitation gradient was imposed in order to mimic increased orographic precipitation. Increased orographic rainfall could have emerged through changes in atmospheric wind strength, particularly the westerlies, influencing the intensity of orographic precipitation. The importance of the Southern Hemisphere westerlies in the global climate system is well recognised, with their position and/or strength during the LGM highly debated (Heusser, 1989a; Markgraf, 1989; Markgraf, et al., 1992; Heusser, et al., 1999) 
In South America, several studies suggested a northward shift of the westerlies to a position between 41 to $45^{\circ} \mathrm{S}$, compared to its current position of 50 to $55^{\circ} \mathrm{S}$ (Heusser, 1989b; e.g. Hulton, et al., 1994; Clapperton, et al., 1995; Singer, 2000; Heusser, 2003; Stuut and Lamy, 2004; Maldonado, et al., 2005; Toggweiler, et al., 2006). Further evidence for this is provided by LGM atmospheric reconstructions in southern Australia and Tasmania (Derbyshire, 1971), New Zealand (Shulmeister, et al., 2004) and upwelling in the Southern Ocean (Toggweiler and Russell, 2008). However, these studies also indicated that more intense westerly circulation occurred during the LGM. PMIP2 ocean-atmosphere modelling suggested less intense westerly circulation, but could not attribute this to latitudinal migration (Rojas, et al., 2009). Conversely, numerous other studies suggested less intense westerly winds but this was associated with poleward westerly migration (Wyrwoll, 1979; Markgraf, 1989; Harrison and Dodson, 1993; Kershaw, et al., 2000; Wyrwoll, et al., 2000; Grosjean, et al., 2003; Stuut, et al., 2006).

It appears that two possible scenarios representing changes in LGM atmospheric circulation may have occurred in Tasmania: 1) Strengthening of the Australian winter high pressure cell, which may have intensified westerly circulation over Tasmania, bringing about more west and north-west snow bearing winds (Figure 6-6), or 2) Weakening of the westerlies over Tasmania during the LGM, with orographic enhancement resulting from other local factors (Figure 6-7). Theoretically, both atmospheric scenarios explain the precipitation patterns observed in my LGM model simulations, although the former hypothesis is better supported by the evidence overall, and is consistent with proposed mechanisms regarding reduced $\mathrm{CO}_{2}$ levels. For example, an equatorward shift of the strongest westerlies would have reduced oceanic upwelling of $\mathrm{CO}_{2}$ in the Southern Ocean (Toggweiler, 2009), while simultaneously increasing westerly circulation over New Zealand, Patagonia and Tasmania. 


\subsubsection{Earlier Pleistocene climate reconstructions}

The model simulations in this study predicted a larger decline in air temperature for glacial advances prior to the LGM. In contrast, ice core records from Antarctica and southwest Pacific Ocean Sea Surface Temperatures (SST) indicate that middle Pleistocene glaciations were no colder than the LGM (Howard and Prell, 1992; EPICA Community Members, 2004; Pelejero, et al., 2006; Barrows et al., 2007; Crundwell, et al., 2008; Hayward, et al., 2008). It is possible that proxy records from Antarctica are simply not representative of climate variability in Tasmania. However, proxy evidence from cores off southeast Tasmania and southwest Australia should show a better match. Assuming SST temperature trends in these locations were representative of terrestrial conditions in Tasmania, why were significantly larger temperature depressions required to replicate early and middle Pleistocene glacial advances? More specifically, how can large responses in ice extent be explained by relatively minor climate fluctuations?

One possibility is that modifications to the landscape throughout the Quaternary have influenced the response of glaciers. High rates of glacial erosion (as suggested by fast velocities in model output) may have lowered the elevation of bedrock above the ELA, leading to a gradual loss of accumulation areas. Another possible reason for temperature mismatches is changing seasonality whereby annual temperatures remained the same, but longer/shorter summers significantly impact glacier mass balance. While the model took seasonality into account, it only maintained presentday seasonality patterns. Further modelling investigations could focus on glacier development and sensitivity in response to seasonality changes and/or the influence of glacial erosion. 


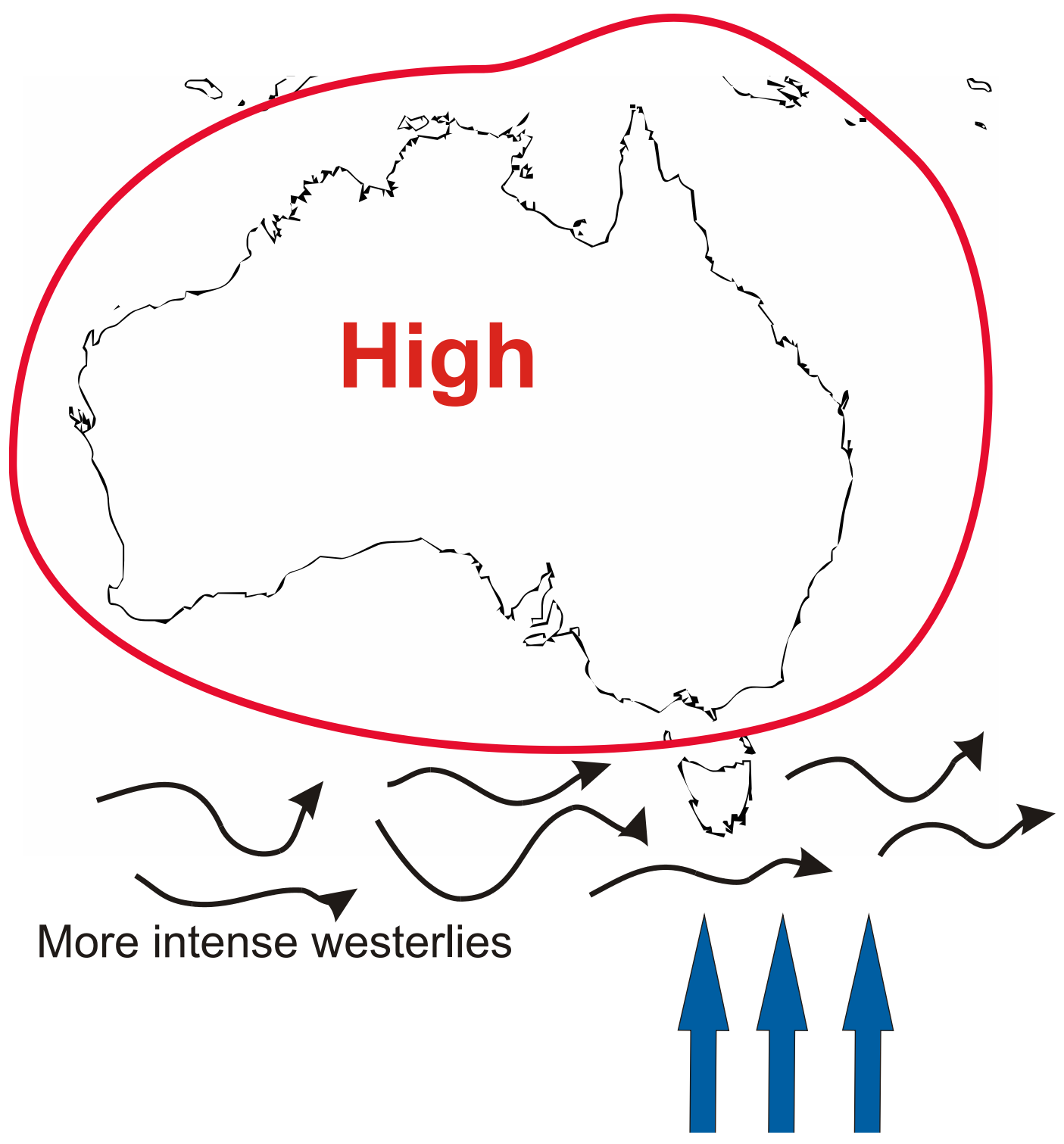

Figure 6-6: Possible atmospheric conditions operating during the LGM over Australia. During winter the high pressure cell operating over the Australian mainland is larger and more stable due to colder conditions. Intensification of the westerlies over Tasmania occurs in conjunction with an equatorward shift of westerly circulation. This is possibly in response to more northerly extent of Antarctic sea ice 


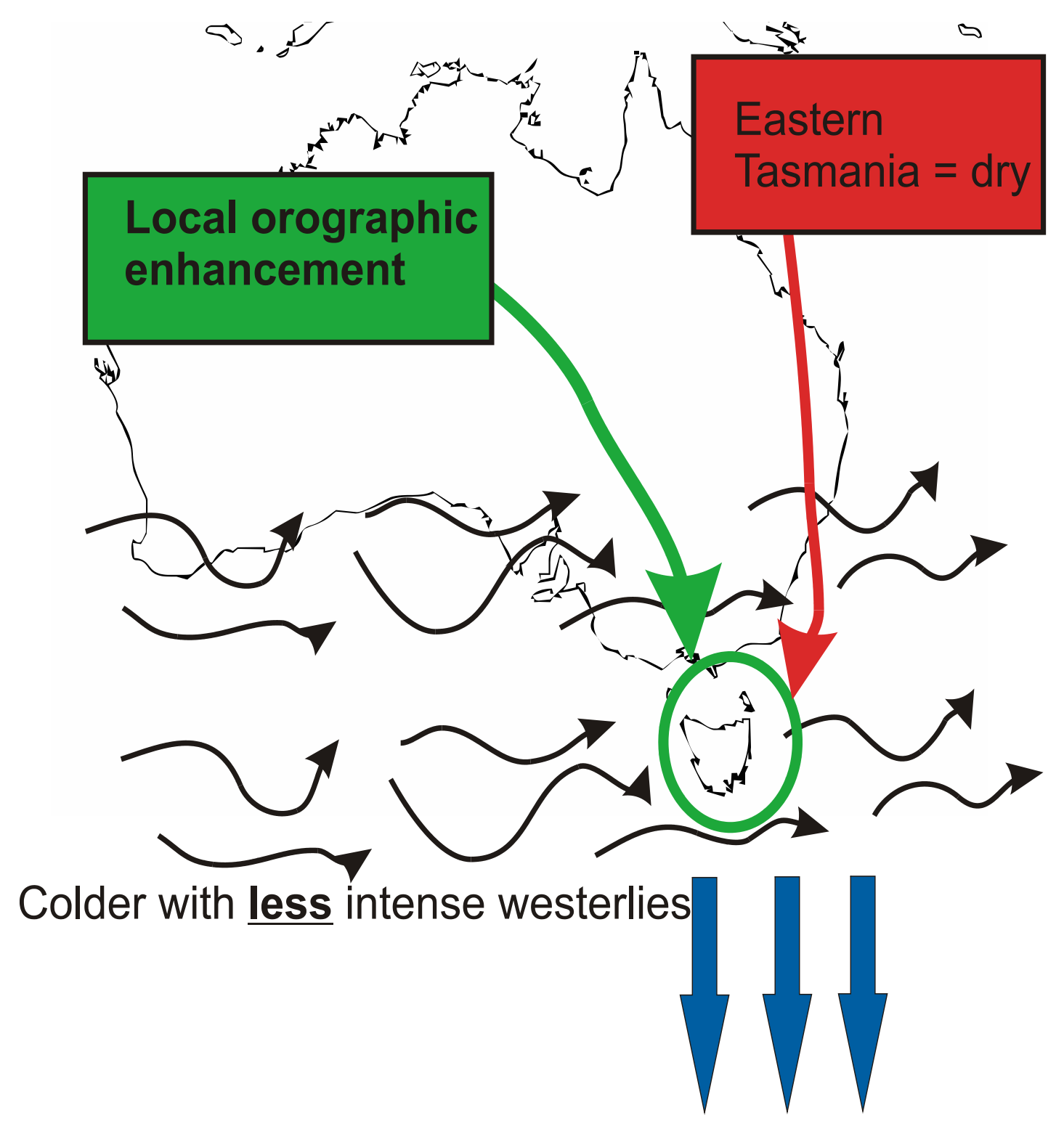

Poleward migration

Figure 6-7: Possible atmospheric conditions operating during the LGM over Australia. Weakening of westerly circulation is associated with a poleward shift of the westerly belt. Local orographic enhancement is simply a function of ice thickness increasing topographical elevation. 


\section{Chapter 7 \\ Conclusions}

A three-dimensional ice sheet model was used to investigate Quaternary glaciation in Tasmania and in particular to assess the climatic significance of glacier advances. These glacio-climatic reconstructions enable a better understanding of global climate dynamics in the Southern Hemisphere and their influence on the advance and retreat of glaciers. In particular, the model was used to address a series of key questions, in order to clarify:

1. the suitability of a numerical ice-sheet model for simulating former glacier advances,

2. the style of glaciation, and how quickly of maximum extent and thickness was achieved,

3. possible areas identified by the model suitable for further field investigation,

4. the relative components of glacier motion, and how this is depicted in the contemporary landscape, and

5. the dominant climate drivers of Tasmanian, and wider Southern Hemisphere glaciations.

The numerical simulations, when guided and constrained by empirical glacier limits represented an effective system for palaeoglaciological reconstructions. Not only were possible climate scenarios generated, but detailed insights in former glacier dynamics and preferential flow directions were identified. However, while the model managed to simulate some empirical limits well, recurrent mismatches between modelled ice and empirical glacier limits were apparent. It is obvious that refinement of model input data and more detailed field investigations will help reproduce glacier configurations with greater accuracy. However, one must start to 
consider some of the more outstanding limitations and problems with numerical simulations and the data acquired from them.

Firstly, there is considerable uncertainty in determining regional past precipitation patterns based on modelled best-fit glacier geometries. This is due to features such as former storm track variation, precipitation shadows and changing seasonality. This is important for Tasmania; especially given it was a marginal environment for glaciation at the Last Glacial Maximum (LGM). This leads to the next problem concerning small-scale glaciations, with questions regarding the spatial averaging of ice flow. This model operated at a $500 \mathrm{~m}$ grid resolution and is considered highresolution modelling (at least, for an ice-sheet model). Previous literature suggests that the areal coverage of ice in Tasmania during the LGM was only $1000 \mathrm{~km}^{2}$. How well does a model of this kind simulate small-scale ice flow, feedbacks and other processes? Is the system too small to be completely accommodated by a large-scale ice-sheet model?

\section{Can a numerical ice sheet model be used to accurately simulate ice extent for discrete glacial episodes throughout the Quaternary to match existing field evidence in Tasmania?}

The experiments with the numerical model demonstrate that is possible to simulate empirical glacier limits, but not in all areas. The narrow range of parameter values that provide best-fit simulations for each glacial advance shows that the model is sensitive to climatic forcing, especially temperature. The most difficult glacier advance to parameterize was the LGM, which highlighted the marginal environment for glaciation at this time. Recurrent inconsistencies between geologically reconstructed glacier limits and numerical simulations indicate further refinement of the model parameterization is required. This may include smaller-scale topographic and climatic factors (for example, the distribution of snow by wind and topographical shading). Mountain peaks should also be better included, and this plus other smallscale grid issues can be achieved through sub-grid parameterisation. 
2. What can the model tell us about the style of glaciation? Where were the principal accumulation areas, and how quickly did ice achieve its maximum extent and thickness?

The model simulations present a scenario where glacial inception can begin quickly, with disparate ice masses forming over the high peaks in the Central Highlands and the Central Plateau. Coherent ice masses form over the principal accumulation areas (Central Highlands and western Central Plateau) after approximately 100 model years. Glaciers attain their maximum terminal extent within 400 model years, after which the ice gradually thickens and achieves steady-state conditions after around 800 model years. During the LGM, middle Pleistocene I and middle Pleistocene II, the ice mass became an interconnected mountain ice field, with its flow largely constrained by the surrounding topography. An ice cap, more independent of topography, was numerically simulated in some areas of the Central Highlands and Central Plateau during the early Pleistocene simulation. Maximum ice thickness occurred in the outlet valleys including, the Murchison, Forth, Mersey, Fury and Derwent valleys and were fed from the central ice mass.

3. Assuming that the model can accurately simulate ice to match existing field evidence; can the model provide any information in terms of ice extent in areas where field evidence does not exist?

No detailed field investigations have been carried out in the valleys between the $\mathrm{Du}$ Cane Range and the West Coast Range. Numerical simulations suggest that ice was present in these valleys during all Quaternary glacial advances. However, ice development was restricted to mountain peaks and individual valley glacier systems during all but the early Pleistocene advance. Continuous ice development between the Du Cane Range and the West Coast Range is predicted by the numerical model for the early Pleistocene advance, supporting conclusions made by Kiernan (1990b). 
The results of the numerical simulations indicate a need for more thorough field investigations in this area.

4. Does the model reveal whether or not glaciers predominantly flowed through basal sliding, or was flow dominated by internal deformation? Is this reflected in the geomorphic record?

The numerical model simulates ice dynamics that are governed by, and consistent with, the topography of Tasmania. The modelled glaciers are significantly influenced by spatial contrasts in mass balance and topography, and are expressed through regional differences in their underlying dynamics. The western outlet glaciers are faster-flowing, with basal sliding dominating their flow mechanisms. The combined influence of ice thickness and bed geology give rise to high erosional potential and helps explain thick sediment accumulation in the western valleys. The Central Plateau is characterized by thin and relatively slow-moving ice, with some proportion of it not sliding at its bed (i.e. flowing through internal deformation). However, the western part of the plateau experienced more dynamic ice. This is the part where there is evidence of areal scouring and the model appears to do a good job of simulating former ice flow directions (as suggested by lake orientation).

\section{What do these climate reconstructions tell us about the climate drivers of} Tasmania, and wider Southern Hemisphere glaciations?

The numerical model predicted that mean annual temperatures for each Quaternary glacial phase were far colder than present. LGM temperatures $\left(7\right.$ to $9^{\circ} \mathrm{C}$ colder than present) predicted by the model were similar to regional and hemispheric palaeoclimate reconstructions. Temperature forcing was identified as the primary driver influencing the advance and retreat of glaciers. It is difficult to explain this large temperature change, and similar amounts of cooling in New Zealand and Patagonia, with traditional (northern insolation driven) Milankovitch forcing. Global amplification through changing atmospheric $\mathrm{CO}_{2}$ levels is a possible mechanism for synchronizing the northern and southern glaciations (Clark, et al., 2009). 
An enhancement of the west-to-east precipitation gradient was necessary across the model domain. This prevented the over development of ice in the eastern Central Plateau, and simulated extensive ice systems in central and western Tasmania. Changes in the strength and/or position of westerly circulation may have intensified orographic rainfall in Tasmania. Rojas et al. (2009) and Toggweiler (2009) suggest weakening westerlies at LGM, strengthening into Holocene. Conversely, Shulmeister et al. (2004) favours intensification of westerly circulation during the LGM. At this stage, the reason behind variations in former precipitation patterns cannot be identified, although the latter hypothesis is more consistent with my model results.

Palaeoclimate reconstructions from earlier glacial advances are at odds with some of the data from the palaeoclimate record (for example, ice core and benthic marine sea-surface temperature fluctuations). Substantially colder conditions were required to produce an ice geometry that fits the geological ice limits for early and middle Pleistocene advances. The reasons behind this are unknown, but it is possible that modifications to the landscape throughout the Quaternary may have influenced the response of glaciers. 


\section{Bibliography}

Adhémar, J. A. (1842). Révolutions de la Mer: Déluges Périodiques. Paris: CarilianGoeury et V. Dalmont.

Alloway, B. V., Stewart, R. B., Neall, V. E., and Vucetich, C. G. (1992). Cliate of the last glaciation in New Zealand, based on aerosolic quartz influx in an andesitic terrain. Quaternary Research, 38, 170-179.

Anderson, B. G., and Mackintosh, A. N. (2006). Temperature change is the major driver of late-glacial and Holocene glacier fluctuations in New Zealand. Geology, 34(2), 121-124.

Anderson, R. F., Ali, S., Bradtmiller, L. I., Nielsen, S. H. H., Fleisher, M. Q., Anderson, B. E., and Burckle, L. H. (2009). Wind-Driven Upwelling in the Southern Ocean and the Deglacial Rise in Atmospheric $\mathrm{CO}_{2}$. Science, 323, 1443-1448.

Augustinus, P. C. (1999a). Dating the Late Cenozoic glacial sequence, Pieman River basin, western Tasmania, Australia. Quaternary Science Reviews, 18, 13351350.

Augustinus, P. C. (1999b). Reconstruction of the Bulgobac Glacial System, Pieman River Basin, Western Tasmania. Australian Geographical Studies, 37(1), 2436.

Augustinus, P. C., and Colhoun, E. A. (1986). Glacial history of the upper Pieman and Boco valleys, western Tasmania. Australian Journal of Earth Sciences, 33, 181-191.

Augustinus, P. C., and Colhoun, E. A. (1995). Weathering and morphostratigraphic evidence for four glaciations in the Henty River basin, western Tasmania. Papers and Proceedings of the Royal Society of Tasmania, 112, 53-58.

Augustinus, P. C., and Macphail, M. K. (1997). Early Pleistocene stratigraphy and timing of the Bulgobac Glaciation, Western Tasmania, Australia.

Palaeogeography, Palaeoclimatology, Palaeoecology, 128, 253-267.

Augustinus, P. C., Short, S. A., and Colhoun, E. A. (1994). Pleistocene stratigraphy of the Boco Plain, western Tasmania. Australian Journal of Earth Sciences, 41, 581-591.

Augustinus, P. C., Short, S. A., and Heijnis, H. (1997). Uranium/thorium dating of ferricretes from mid- to late Pleistocene glacial sediments, western Tasmania, Australia. Journal of Quaternary Science, 12(4), 295-308.

Bacon, S. N., Chinn, T. J., Van Dissen, R. J., Tillinghast, S. F., Goldstein, H. L., and Burke, R. M. (2001). Paleo-equilibrium line altitude estimates from late Quaternary glacial features in the Inland Kaikoura Range, South Island, New Zealand. New Zealand Journal of Geology and Geophysics, 44, 55-67.

Baillie, P. W., and Hudspeth, J. W. (1989). West Tasmania Region. Special Publication Geological Society of Australia, 15, 361-365.

Banks, M. R., and Ahmad, N. (1959). Notes on the Cainozoic history of western Tasmania: "Malanna" Glaciation. Papers and Proceedings of the Royal Society of Tasmania, 93, 117-127.

Banks, M. R., Colhoun, E. A., and Hannan, D. G. (1987). Early discoveries of the effects of ice action in Australia. Journal of Glaciology, 33, 231-235. 
Barrows, T., Stone, J., Fifield, L., and Cresswell, R. (2002). The timing of the last glacial maximum in Australia. Quaternary Science Reviews, 21, 159-173.

Barrows, T. T., Juggins, S., De Deckker, P., Calvo, E., and Pelejero, C. (2007). Long-term sea surface temperature and climate change in the Australian-New Zealand region. Paleoceanography, 22, PA2215.

Barrows, T. T., Stone, J. O., Fifield, K., and Cresswell, R. G. (2001). Late Pleistocene glaciation of the Kosciusko Massif, Snowy Mountains, Australia. Quaternary Research, 55, 179-189.

Barrows, T. T., Stone, J. O., and Fifield, L. K. (2004). Exposure ages for Pleistocene periglacial deposits in Australia. Quaternary Science Reviews, 23, 697-708.

Barry, R. G. (1981). Mountain weather and climate. London: Methuen.

Beaufort, L., de Garidel-Thoron, T., Mix, A. C., and Pisias, N. G. (2001). ENSO-like forcing on oceanic primary production during the Late Pleistocene. Science, 293, 2440-2444.

Benn, D. I., and Evans, D. J. A. (1998). Glaciers and Glaciation. London: Arnold.

Berger, A., Li, X. S., and Loutre, M. F. (1999). Modelling northern hemisphere ice volume over the last 3 Ma. Quaternary Science Reviews, 18(1), 1-11.

Berger, A., and Wefer, G. (2003). On the dynamics of the ice ages: stage-11 Paradox, Mid-Brunhes Climate Shift, and 100-ky cycle. In A. W. Droxler, R. Z. Poore andL. H. Burckle (Eds.), Earth's climate and orbital eccentricity: the marine isotope stage 11 question (Vol. 137, pp. 41-59): American Geophysical Union Geophysical Monograph.

Bernstein, L., Bosche, P., Canziani, O., Chen, Z., Christ, R., Davidson, O., Hare, W., Huq, S., Karoly, D. J., Kattsov, V., Kundzewicz, Z., Liu, J., Lohmann, U., Manning, M., Matsuno, T., Menne, B., Metz, B., Mirza, M., Nicholls, N., Nurse, L., Pachauri, R., Palutikof, J., Parry, M., Qin, D., Ravindranath, N., Reisinger, A., Ren, J., Riahi, K., Rosenzweig, C., Rusticucci, M., Schneider, S., Sokona, Y., Solomon, S., Stott, P., Stouffer, R., Sugiyama, T., Swart, R., Tirpak, D., Vogel, C., and Yohe, G. (2007). Climate Change 2007: Synthesis Report.

Bottrill, R. S., Brown, A. V., Calver, C. R., Corbett, K. D., Green, G. R., McClenaghan, M. P., Pemberton, J., Seymour, D. B., and Taheri, J. (1998). A summary of the economic geology and mineral potential of late Proterozoic and Palaeozoic provinces in Tasmania. AGSO Journal of Australian Geology and Geophysics, 17, 123-143.

Bougamont, M., Bamber, J. L., and Greuell, W. (2005). A surface mass balance model for the Greenland Ice Sheet. Journal of Geophysical Research, 110.

Bowden, A. R. (1983). Relict terrestrial dunes: legacies of a former climate in coastal north eastern Tasmania. Zeitschrift fur Gletscherkunde und Glazialgeologie, 45, 153-174.

Bowler, J. M. (1986). Quaternary landform evolution. In D. N. Jeans (Ed.), The natural environment. Australia - A Geography (Vol. 1, pp. 117-147): Sydney University Press.

Bowler, J. M., Hope, G., Jennings, I. B., Singh, G., and Walker, D. (1976). Late Quaternary climates of Australia and New Guinea. Quaternary Research, 6, 359-394.

Bradley, R. S. (1985). Quaternary Palaeoclimatology. London: Chapman \& Hall. 
Braithwaite, R. J. (1984). Can the mass balance of a glacier be estimated from its equilibrium-line altitude? Journal of Glaciology, 30(106), 364-368.

Braithwaite, R. J. (1995). Positive degree-day factors for ablation on the Greenland Ice Sheet studied by energy-balance modelling. Journal of Glaciology, 41, 153-160.

Braithwaite, R. J., and Olson, O. B. (1985). Ice ablation in West Greenland in relation to air temperature and global radiation. Zeitschrift fur Gletscherkunde und Glazialgeologie, 20, 155-168.

Broccoli, A. J., and Manabe, S. (1987). The effects of the Laurentide ice sheet on North American climate during the last glacial maximum. Geographie Physique et Quaternaire, XLI, 291-299.

Broecker, W. S., and Denton, G. H. (1989). The role of ocean-atmosphere reorganizations in glacial cycles. Geochimica et Cosmochimica Acta, 53, 2465-2501.

Broecker, W. S., and Denton, G. H. (1990). What Drives Glacial Cycles? Scientific American, 262(1), 48-56.

Brown, C., Meier, M., and Post, A. (1982). Calving speed of Alaskan tidewater glaciers, with application to Columbia Glacier.: USGS.

Budd, W. F. (1975). A first simple model for periodically self-surging glaciers. Journal of Glaciology, 14, 3-21.

Burrett, C. F., and Martin, E. L. (1989). Geology and mineral resources of Tasmania. (Vol. 15). Brisbane: Geological Society of Australia.

Caine, T. J. (1983). The Mountains of Northeastern Tasmania: A Study of Alpine Geomorphology. Rotterdam: AA Balkema.

Chen, X. Y., Bowler, J. M., and Magee, J. W. (1993). Late Cenozoic stratigraphy and hydrologic history of Lake Amadeus, a central Australian playa. Australian Journal of Earth Sciences, 40(1), 1-14.

Clapperton, C. (1990). Quaternary glaciations in the southern hemisphere. Quaternary Science Reviews, 9, 299-304.

Clapperton, C., Sugden, D., Kaufman, D. S., and McCulloch, R. D. (1995). The last glaciation in Central Magellan Strait, southernmost Chile. Quaternary Research, 44, 133-148.

Clark, P. U., Alley, R. B., and Pollard, D. (1999). Northern Hemisphere Ice-Sheet Influences on Global Climate Change. Science, 286(5442), 1104-1111.

Clark, P. U., Dyke, A. S., Shakun, J. D., Carlson, A. E., Clark, J., Wohlfarth, B., Mitrovica, J. X., Hostetler, S. W., and McCabe, A. M. (2009). The Last Glacial Maximum. Science, 325(5941), 710-714.

Colhoun, E. A. (1985). Glaciations of the West Coast Range, Tasmania. Quaternary Research, 24, 39-59.

Colhoun, E. A. (2002). Periglacial landforms and deposits of Tasmania. South African journal of science, 98(1-2), 55-63.

Colhoun, E. A., and Fitzsimons, S. J. (1990). Late Cainozoic Glaciation in Western Tasmania, Australia. Quaternary Science Reviews, 9, 199-216.

Colhoun, E. A., Hannan, D. G., and Kiernan, K. (1996). Late Wisconsin glaciation in Tasmania. Papers and Proceedings of the Royal Society of Tasmania, 130, $33-45$. 
Colhoun, E. A., and Peterson, J. (1986). Quaternary landscape evolution and the cryosphere: research progress from Sohul to Australian Antarctica. Australian Geographical Studies, 24(1), 145-167.

Colhoun, E. A., Pola, J. S., Barton, C. E., and Heijnis, H. (1999). Late Pleistocene vegetation and climate history of Lake Selina, western Tasmania. Quaternary International, 57/58, 5-23.

Colhoun, E. A., and van de Geer, G. (1986). Holocene to Middle Last Glaciation vegetation history at Tullabardine Dam, western Tasmania. Proceedings of the Royal Society of London. Series B, Biological Sciences, 229, 177-207.

Colhoun, E. A., van de Geer, G., and Fitzsimons, S. J. (1991). Late glacial and Holocene vegetation history at Governor Bog, King Valley, western Tasmania, Australia. Journal of Quaternary Science, 6(1), 55-66.

Corbett, K. D. (1975). The Late Cambrian to Early Ordovician sequence on the Denison Range, southwest Tasmania. Papers and Proceedings of the Royal Society of Tasmania, 109, 111-120.

Croke, J., Magee, J. W., and Price, D. M. (1996). Major episodes of Quaternary activity in the lower Neales River, northwest of Lake Eyre, central Australia. Palaeogeography, Palaeoclimatology, Palaeoecology, 124, 1-15.

Croke, J., Magee, J. W., and Price, D. M. (1998). Stratigraphy and sedimentology of the lower Neales River, west Lake Eyre, Central Australia: from Palaeocene to Holocene. Palaeogeography, Palaeoclimatology, Palaeoecology, 144, 331-350.

Croll, J. (1864). On the physical cause of the change of climate during geological epochs. Philosophical Magazine, 28, 121-137.

Crundwell, M. P., Scott, G. H., Naish, T., and Carter, L. (2008). Glacial-interglacial ocean climate variability from planktonic foraminifera during the MidPleistocene transition in the temperate Southwest Pacific, ODP Site 1123. Palaeogeography, Palaeoclimatology, Palaeoecology, 260, 202-229.

Dansgaard, W., and Tauber, H. (1969). Glacier oxygen-18 content and Pleistocene ocean temperatures. Science, 166, 499-502.

Davis, J. L. (1958). The Cryoplanation of Mount Wellington. Papers and Proceedings of the Royal Society of Tasmania, 92, 151-154.

Davis, J. L. (1967). Tasmanian landforms and Quaternary climates. In J. N. Jennings andJ. A. Mabbutt (Eds.), Landform Studies from Australia and New Guinea (pp. 1-25). Canberra: ANU Press.

Davis, J. L. (1969). Landforms of Cold Climates. Canberra, Australia: ANU Press.

Davis, J. L. (1974). Geomorphology and Quaternary environments. In W. D. Williams (Ed.), Biogeography and Ecology in Tasmania (pp. 17-27). The Hague: W. Junk.

Dawson, A. G. (1992). Ice Age Earth, Late Quaternary Geology and Climate. London: Routlegde.

Denton, G. H., and Hughes, T. J. (1981). The Last Great Ice Sheets. New York: Wiley.

Derbyshire, E. (1963). Glaciation of the Lake St Clair district, west-central Tasmania. Australian Geographer, 9, 97-110.

Derbyshire, E. (1968). Two Gelifluctates near Great Lake, Central Tasmania. The Australian Journal of Science, 31(4), 154-156. 
Derbyshire, E. (1971). A synoptic approach to the atmospheric circulation of the last glacial maximum in southeastern Australia. Palaeogeography, Palaeoclimatology, Palaeoecology, 10, 103-124.

Derbyshire, E. (1972). Pleistocene glaciation of Tasmania: review and speculations. Australian Geographical Studies, 10, 79-94.

Derbyshire, E., Banks, M. R., Davies, J. L., and Jennings, J. N. (1965). A Glacial Map of Tasmania. Hobart, Tasmania.

Ding, Z., Derbyshire, E., Yang, S. L., Yu, Z. W., Xiong, S. F., and Liu, T. S. (2002). Stacked 2.6-Ma grain size record from the Chinese loess based on five sections and correlation with the deep-sea $\mathrm{d}^{18} \mathrm{O}$ record. Paleoceanography, $17(3)$.

Ding, Z., Rutter, N. W., and Liu, T. (1997). The onset of extensive loess deposition around the $\mathrm{G} / \mathrm{M}$ boundary in China and its palaeoclimatic implications. Quaternary International, 40, 53-60.

Ding, Z., Rutter, N. W., and Liu, T. S. (1993). Pedostratigraphy of Chinese loess deposits and climatic cycles in the last 2.5 Myr. Catena, 20, 73-91.

Dyurgerov, M. B., and Dwyer, J. D. (2001). The steepening of glacier mass balance gradients with northern hemisphere warming. Zeitschrift fur Gletscherkunde und Glazialgeologie, 36(2000), 107-118.

Eden, D. N., and Hammond, A. P. (2003). Dust accumulation in the New Zealand region since the last glacial maximum. Quaternary Science Reviews, 22, 2037-2052.

EPICA Community Members (2004). Eight glacial cycles from an Antarctic ice core. Nature, 429, 623-628.

Fairbanks, R. G. (1989). A 17,000 year glacio-eustatic sea level record: influence of glacial melting rates on Younger Dryas event and deep ocean circulation. Nature, 342, 637-642.

Fitzsimons, S. J., and Colhoun, E. A. (1991). Pleistocene Glaciation of the King Valley, Western Tasmania, Australia. Quaternary Research, 36, 135-156.

Fitzsimons, S. J., Colhoun, E. A., van de Geer, G., and Pollington, M. (1993). The Quaternary geology and glaciation of the King Valley. Bulletin Geological Survey Tasmania, 68, $57 \mathrm{pp}$.

Flint, R. F. (1971). Glacial and Quaternary Geology. New York: Wiley.

Gibbard, P. L., Head, M. J., and Walker, M. J. C. (2009). Formal ratification of the Quaternary System/Period and the Pleistocene Series/Epoch with a base of 2.58 Ma. Journal of Quaternary Science, 25(2), 96-102.

Gibbons, A. B., Megeath, J. D., and Kenneth, L. P. (1984). Probability of moraine survival in a succession of glacial advances. Geology, 12(6), 327-330.

Glen, J. W. (1955). The creep of polycrystalline ice. Proceedings of the Royal Society of London, Series A, 228, 519-538.

Golledge, N. R. (2008). Glacial Geology and glaciology of the Younger Dryas ice cap in Scotland. Unpublished Ph.D thesis, The University of Edinburgh, Edinburgh.

Golledge, N. R., and Hubbard, A. (2005). Evaluating Younger Dryas glacier reconstructions in part of the western Scotish Highlands: a combined empirical and theoretical approach. Boreas, 34, 274-286. 
Golledge, N. R., Hubbard, A., and Sugden, D. (2008). High-resolution numerical simulation of Younger Dryas glaciation in Scotland. Quaternary Science Reviews, 27, 888-904.

Granshaw, F. D., and Fountain, A. G. (2003). Glacier Change in the Upper Skagit River Basin.

Greve, R. (1997). Application of a Polythermal Three-Dimensional Ice Sheet Model to the Greenland Ice Sheet: Response to Steady-State and Transient Climate Scenarios. Journal of Climate, 10, 901-918.

Greve, R., and Blatter, H. (2009). Dynamics of Ice Sheets and Glaciers. Springer.

Groisman, P. Y., Karl, T. R., and Knight, R. W. (1994). Changes of Snow Cover, Temperature, and Radiative Heat Balance over the Northern Hemisphere. Journal of Climate, 7, 1633-1656.

Grosjean, M., Cartajena, I., Geyh, M. A., and Nunez, L. (2003). From proxy data to paleoclimate interpretation: the mid-Holocene paradox of the Atacama Desert, northern Chile. Palaeogeography, Palaeoclimatology, Palaeoecology, 193(1-3), 247-258.

Hannan, D. G., and Colhoun, E. A. (1987). Glacial Stratigraphy of the Upper Mersey Valley, Tasmania. Australian Geographical Studies, 25(2), 36-46.

Hannan, D. G., and Colhoun, E. A. (1991). When were the Walls of Jerusalem last glaciated? Papers and Proceedings of the Royal Society of Tasmania, 125, 16.

Harrison, S. P., and Dodson, J. R. (1993). Climates of Australia and New Guinea since 18,000 yr B.P. In H. E. Wright Jr (Ed.), Global Climates since the Last Glacial Maximum (pp. 265-293). Minneapolis: University of Minnesota Press.

Hays, J. D., Imbrie, J., and Shackleton, N. J. (1976). Variations in the earth's orbit: Pacemaker of the ice ages. Science, 194, 1121-1132.

Hayward, B. W., Scott, G. H., Crundwell, M. P., Kennett, J. P., Carter, L., Neil, H. L., Sabaa, T., Wilson, K., Rodger, J. S., Schaefer, G., Grenfell, H. R., and Li, Q. (2008). The effect of submerged plateaux on Pleistocene gyral circulation and sea-surface temperatures in the Southwest Pacific. Global and Planetary Change.

Heusser, C. J. (1989a). Polar Perspective of Late-Quaternary Climates in the Southern Hemisphere. Quaternary Research, 32, 60-71.

Heusser, C. J. (1989b). Southern westerlies during the last glacial maximum. Quaternary Research, 31, 423-425.

Heusser, C. J. (2003). Ice Age Southern Andes - A Chronicle of Paleoecological Events.: Elsevier.

Heusser, C. J., Heusser, L. E., and Lowell, T. V. (1999). Paleoecology of the southern Chilean Lake District-Isla Grande de Chiloé during middle-late Llanquihue glaciation and deglaciation. Geografiska Annaler, 81 A(2), 231-284.

Hock, R. (2003). Temperature index melt modelling in mountain areas. Journal of Hydrology, 282(1-4), 104-115.

Hopf, F. V. L., Colhoun, E. A., and Barton, C. E. (2000). Late-glacial and Holocene record of vegetation and climate from Cynthia Bay, Lake St Clair, Tasmania. Journal of Quaternary Science, 15(7), 725-732. 
Howard, W. R., and Prell, W. L. (1992). Late Quaternary surface circulation of the Southern Indian Ocean and its relationship to orbital variations. Paleoceanography, 7, 79-117.

Hubbard, A. (1997). High-resolution modeling of glaciers. Unpublished Ph.D thesis. University of Edinburgh.

Hubbard, A. (1999). High-Resolution Modeling of the Advance of the Younger Dryas Ice Sheet and Its Climate in Scotland. Quaternary Research, 52, 27-43.

Hubbard, A. (2000). The Verification and Significance of Three Approaches to Longitudinal Stresses in High-Resolution Models of Glacier Flow. Geografiska Annaler. Series A, Physical Geography, 82(4), 471-487.

Hubbard, A., Hein, A. S., Kaplan, M. R., Hulton, N. R. J., and Glasser, N. (2005). A Modelling reconstruction of the Last Glacial Maximum Ice Sheet and Its deglaciation in the vicinity of the Northern Patagonian Icefield, South America. Geografiska Annaler, 87A(2), 375-391.

Hubbard, A., Sugden, D., Dugmore, A., Norddahl, H., and Pétursson, H. G. (2006). A modelling insight into the Icelandic Last Glacial Maximum ice sheet. Quaternary Science Reviews, 25, 2283-2296.

Hulton, N. R. J., Purves, R. S., McCulloch, R. D., Sugden, D., and Bently, M. J. (2002). The Last Glacial Maximum and deglaciation in southern South America. Quaternary Science Reviews, 21, 233-241.

Hulton, N. R. J., Sugden, D., Payne, A., and Clapperton, C. (1994). Glacier Modeling and the Climate of Patagonia during the Last Glacial Maximum. Quaternary Research, 42, 1-19.

Hutter, K. (1983). Theoretical Glaciology: Material Science of Ice and the Mechanics of Glaciers and Ice-Sheets. Dordrecht: Reidel.

Huybers, P. W. (2009). Pleistocene glacial variability as a chaotic response to obliquity forcing. Climate of the Past, 5, 481-488.

Huybers, P. W., and Denton, G. H. (2008). Antarctic temperature at orbital time scales controlled by local summer duration. Nature Geoscience.

Huybers, P. W., and Wunsch, C. (2005). Obliquity pacing of the Late Pleistocene glacial terminations. Nature, 434, 491-494.

Imbrie, J., Berger, A., Bogle, S., Clemens, S., Duffy, A., Howard, W. R., Kukla, G., Kutzbach, J., Martinson, D. G., McIntyre, A., Mir, A., Molfino, B., Morley, J., Peterson, L., Pisias, N. G., Prell, W. L., Raymo, M. E., Shackleton, N. J., and Toggweiler, J. R. (1993). On the structure and origin of major glaciation cycles. 2 . The 100,000 year cycle. Paleoceanography, 8, 699-735.

Imbrie, J., and Imbrie, J. Z. (1980). Modelling the climatic response to orbital variations. Science, 207, 943-953.

Ives, J. D., Andrews, J. T., and Barry, R. G. (1975). Growth and decay of the Laurentide ice sheet and comparisons with Fenno-Scandinavia. Die Naturwiss, 62, 118-125.

Jansen, J. H. F., and Kuijpers, A. (1986). A mid-Brunhes climatic event: Long-term changes in global atmosphere and ocean circulation. Science, 232, 619-622.

Jóhannesson, T., Sigurdsson, O., Laumann, T., and Kennett, M. (1995). Degree-day glacier mass balance modelling with applications to glaciers in Iceland, Norway and Greenland. Journal of Glaciology, 41, 624-629. 
Jordan, G. J., Macphail, M. K., Barnes, R., and Hill, R. S. (1995). An Early to Middle Pleistocene Flora of Subalpine Affinities in Lowland Western Tasmania. Australian Journal of Botany, 43, 231-242.

Jouzel, J., Lorius, C., Petit, J. R., Genthon, C., Barkov, N. I., Kotlyakov, V. M., and Petrov, V. M. (1987). Vostok ice core: a continuous isotope temperature record over the last climatic cycle (160,000 yr). Nature, 329, 403-408.

Jouzel, J., Masson-Delmotte, V., Cattani, O., Dreyfus, G., Falourd, S., Hoffmann, G., Minster, B., Nouet, J., Barnola, J. M., Chappel-laz, J., Fischer, H., Gallet, J. C., Johnsen, S., Leuenberger, M., Lulergue, L., Luethi, D., Oerter, H., Parrenin, F., Raisbeck, G., Raynaud, D., Schilt, A., Schwander, J., Selmo, E., Souchez, R., Spahni, R., Stauffer, B., Steffensen, J. P., Stenni, B., Stocker, T. F., Tison, J. L., Werner, M., and Wolff, E. W. (2007). Orbital and millennial Antarctic climate variability over the last 800000 years. Science, 317, 793796.

Justino, F., Souza, E., Amorim, M. C., Silva Dias, P. L., and Lemos, C. F. (2008). Influence of boundary conditions on the Southern Hemisphere atmospheric circulation during the last glacial maximum. Revista Brasileira de Meteorologia, 23(4), 490-500.

Karl, T. R., Groisman, P. Y., Knight, R. W., and Heim, R. R. (1993a). Recent variations of snow cover and snowfall in North America and their relation to precipitation and temperature variations. Journal of Climate, 6, 1327-1344.

Karl, T. R., Jones, P. D., Knight, R. W., Kukla, G., Plummer, N., Razuvaec, V., Gallo, K. P., Lindseay, J., Charlson, R. J., and Peterson, T. C. (1993b). A new perspective on recent global warming: Asymmetric trends of daily maximum and minimum temperature. Bulletin of the American Meteorological Society, 74, 1007-1023.

Kerr, A. (1990). The initiation of Maritime Ice Sheets. Zeitschrift fur Gletscherkunde und Glazialgeologie, 26(1), 69-79.

Kershaw, P., Quilty, P. G., David, B., Van Huet, S., and McMinn, A. (2000). Palaeobiogeography of the Quaternary of Australasia. Memoir of the Association of the Australasian Palaeontologists, 23, 471-516.

Kiernan, K. (1983). Relationship of cave fills to glaciation in the Nelson River Valley, central western Tasmania. Australian Geographer, 15, 367-375.

Kiernan, K. (1990a). The alpine geomorphology of the Mt. Anne massif, southwestern Tasmania. Australian Geographer, 21(2), 113-125.

Kiernan, K. (1990b). The Extent of Late Cenozoic Glaciation in the Central Highlands of Tasmania, Australia. Arctic and Alpine Research, 22(4), 341354.

Kiernan, K. (1992). Mountain Geomorphology and the Last Glaciation at Lake St Clair. Papers and Proceedings of the Royal Society of Tasmania, 126, 47-56.

Kiernan, K. (1999). The southern margin of the Late Cainozoic ice cap on the Central Plateau of Tasmania. Australian Geographer, 30, 5-33.

Kiernan, K., Fifield, L. K., and Chappell, J. (2004). Cosmogenic nuclide ages for Last Glacial Maximum moraine at Schnells Ridge, Southwest Tasmania. Quaternary Research, 61, 335-338.

Kiernan, K., and Hannan, D. G. (1991). Glaciation of the Upper Forth River Catchment, Tasmania. Australian Geographical Studies, 29(1), 155-173. 
Kiernan, K., Lauritzen, S.-E., and Duhig, N. (2001). Glaciation and cave sediment aggradation around the margins of the Mt Field Plateau, Tasmania. Australian Journal of Earth Sciences, 48, 251-263.

Kuhn, M. (1984). Mass budget imbalances as a criterion for a climatic classification of glaciers. Geografiska Annaler, 81A(4), 659-670.

Lamy, F., Hebbeln, D., and Wefer, G. (1998). Late Quaternary precessional cycles of terrigenous sediment input off the Norte Chico, Chile (27.5 degrees S) and palaeoclimatic implications. Palaeogeography, Palaeoclimatology, Palaeoecology, 140, 233-244.

Lamy, F., Hebbeln, D., and Wefer, G. (1999). High-resolution marine record of climatic change in mid-latitude Chile during the last 28,000 years based on terrigenous sediment parameters. Quaternary Research, 51, 83-93.

Laumann, T., and Reeh, N. (1993). Sensitivity to climate change of the mass balance of glaciers in southern Norway. Journal of Glaciology, 39, 656-663.

Lear, C. H., Elderfield, H., and Wilson, P. A. (2000). Cenozoic Deep-sea Temperatures and Global Ice Volumes from $\mathrm{Mg} / \mathrm{Ca}$ in Benthic Foraminiferal Calcite. Science, 287(5451), 269-272.

Lindström, E. (1988). Are roches moutonnées mainly preglacial forms? Geografiska Annaler, 70 (A), 323-331.

Lisiecki, L. E., and Raymo, M. E. (2005). A Pliocene-Pleistocene stack of 57 globally distributed benthic $\delta^{18} \mathrm{O}$ records. Paleoceanography, 20, PA1003.

Lourens, L. J., and Hilgen, F. J. (1997). Long-periodic variations in the Earth's obliquity and their relation to third-order eustatic cycles and Late Neogene glaciation. Quaternary International, 40, 43-52.

Mackintosh, A., Barrows, T., Colhoun, E., and Fifield, K. (2006). Exposure dating and glacial reconstruction at Mt. Field, Tasmania, Australia, identifies MIS 3 and MIS 2 glacial advances and climatic variability Journal of Quaternary Science, 21(4), 363-376.

Magee, J. W., Miller, G. H., Spooner, N. A., and Questiaux, D. G. (2004). Continuous 150 k.y. monsoon record from Lake Eyre, Australia: Insolation forcing implications and unexpected Holocene failure. Geology, 32, 885-888.

Maldonado, A., Betancourt, J. L., Latorre, C., and Villagrán, C. (2005). Pollen analyses from a 50 000-yr rodent midden series in the southern Atacama Desert. Journal of Quaternary Science, 20(5), 493-507.

Manabe, S., and Broccoli, A. J. (1985). The influence of continental ice sheets on the climate of an ice age. Journal of Geophysical Research, 90, 2167-2190.

Markgraf, V. (1989). Reply to C.J. Heusser's 'Southern Westerlies' during the Last Glacial Maximum. Quaternary Research, 31, 426-432.

Markgraf, V., Dodson, J. R., Kershaw, A. P., McGlone, M. S., and Nicholls, N. (1992). Evolution of late Pleistocene and Holocene climates in the circumSouth Pacific land areas. Climate Dynamics, 6, 193-211.

Martinez-Garcia, A., Rosell-Mele, A., and McClymont, E. L. (2006). Drivers of the Middle Pleistocene Transition: the Role of the Southern Ocean in Modulating Changes in $\mathrm{CO}_{2}$ and the Transition to the $100 \mathrm{ky}$ World. Paper presented at the American Geophysical Union, Fall Meeting 2006.

McGlone, M. S., Salinger, J., and Moar, N. T. (1993). Paleovegetation studies of New Zealand's climate since the Last Glacial Maximum. In H. E. Wright Jr, 
J. Kutzbach, I. Webb, T., W. F. Ruddiman, F. A. Street-Pettott andP. J. Bartlein (Eds.), Global Climates Since The Last Glacial Maximum.

Meierding, T. (1982). Late Pleistocene glacial equilibrium-line altitudes in the Colorado Front Range: A comparison of methods. Quaternary Research, 18, 289-310.

Mercer, J. H. (1984). Simultaneous climate in both hemispheres and similar bipolar interglacial warming: Evidence and implications. In H. Hansen andT. Takahashi (Eds.), Climate Processes and Climate Sensitivity (pp. 307-313): American Geophysical Union.

Milankovitch, M. M. (1941). Canon of Insolation and the Ice-Age Problem. Beograd: Koniglich Serbische Akademie.

Miller, G. H., Magee, J. W., and Jull, A. J. T. (1997). Low latitude glacial cooling in the Southern Hemisphere from amino-acid racemization in emu eggshells. Nature, 385, 241-244.

Moreno, P. I., Lowell, T. V., Jacobson Jr, G. L., and Denton, G. H. (1999). Abrupt vegetation and climate changes during the last glacial maximum and last termination in the Chilean Lake District: a case study from Canal de la Puntilla (41 $\left.{ }^{\circ} \mathrm{S}\right)$. Geografiska Annaler, 81 A(2), 285-311.

Mudelsee, M., and Schulz, M. (1997). The Mid-Pleistocene climate transition: onset of $100 \mathrm{ka}$ cycle lags ice volume build-up by $280 \mathrm{ka}$. Earth and Planetary Science Letters, 151, 117-123.

Müller, A., and Hope, P. (2004). An El Niño-like climate mean state during the Last Glacial Maximum. Paper presented at the Proceedings of International Conference on Storms.

Munro, D., and Davies, J. L. (1978). On fitting the log-linear model to wind speed and temperature profiles over a melting glacier. Boundary Layer Meteorology, 15, 423-437.

Naish, T., Abbott, S. T., Alloway, B. V., Beu, A. G., Carter, R. M., Edwards, A. R., Journeaux, T. D., Kamp, P. J. J., Pillans, B. J., Saul, G., and Woolfe, K. J. (1998). Astronomical calibration of a Southern Hemisphere Plio-Pleistocene reference section, Wanganui Basin, New Zealand. Quaternary Science Reviews, 17, 695-710.

Nanson, G. C., Price, D. M., and Short, S. A. (1992). Wetting and drying of Australia over the past $300 \mathrm{ka}$. Geology, 20, 791-794.

Newnham, R. W., Lowe, D. J., and Williams, P. W. (1999). Quaternary environmental change in New Zealand; a review. Progress in Physical Geography, 23, 567-610.

Oerlemans, J. (1980). Modelling of Pleistocene European ice sheets: some experiments with simple mass-balance parameterizations. Quaternary Research, 15, 77-85.

Oerlemans, J. (1982). A model of the Antarctic Ice Sheet. Nature, 297, 550-553.

Oerlemans, J. (1992). Climate sensitivity of glaciers in southern Norway: Application of an energy-balance model to Nigardsbreen, Hellstugubreen and Alftobreen. Journal of Glaciology, 38, 223-243.

Oerlemans, J. (2001). Glaciers and Climate Change. Taylor \& Francis.

Oerlemans, J., Andersen, B. G., Hubbard, A., Huybrechts, P., Hannesson, T., Knap, W., Schmeits, M., Stroeven, A. P., van de Wal, R. W. S., Wallinga, J., and 
Zuo, Z. (1998). Modelling the response of glaciers to climate warming. Climate Dynamics, 14, 267-274.

Oerlemans, J., and Fortuin, J. (1992). Sensitivity of glaciers and small ice caps to greenhouse warming. Science, 258, 115-117.

Oerlemans, J., and Hoogendoorn, N. C. (1989). Mass-balance gradients and climate change. Journal of Glaciology, 35(121), 399-405.

Oerlemans, J., and Vugts, H. F. (1993). A meteorological experiment in the melting zone of the Greenland ice sheet. Bulletin of the American Meteorological Society, 71, 355-365.

Ohmura, A. (2001). Physical basis for the temperature-based melt-index method. Journal of Applied Meteorology, 40, 753-761.

Paillard, D. (1998). The timing of Pleistocene glaciations from a simple multiplestate climate model. Nature, 361, 378-381.

Paterson, S. J. (1965). Pleistocene drift in the Mersey and Forth valleys: Probability of two glacial stages. Papers and Proceedings of the Royal Society of Tasmania, 99, 115-124.

Paterson, S. J. (1969). Pleistocene deposits at Parangana dam site in the Mersey Valley: Results of excavation and construction drilling. Papers and Proceedings of the Royal Society of Tasmania, 103, 57-61.

Paterson, W. S. B. (1994). The Physics of Glaciers. (3rd Edition ed.). Oxford: Pergamon.

Payne, A., and Sugden, D. (1990a). Climate and the initiation of maritime ice sheets. Annals of Glaciology, 14, 232-237.

Payne, A., and Sugden, D. (1990b). Topography and ice sheet growth. Earth Surface Processes and Landforms, 15, 628-639.

Pelejero, C., Calvo, E., Barrows, T. T., Logan, G. A., and De Deckker, P. (2006). South Tasman Sea alkenone palaeothermometry over the last four glacial/interglacial cycles. Marine Geology, 230, 73-86.

Peterson, J. (1968). Cirque morphology and Pleistocene ice formation conditions in southeastern Australia. Australian Geographical Studies, 6, 67.

Peterson, J., and Robinson, G. (1969). Trend surface mapping of cirque floor levels. Nature, 222, 75-76.

Petit, J. R., Jouzel, J., Raynaud, D., Barkov, N. I., Barnola, J. M., Basile, I., Bender, M., Chappellaz, J., Davis, J. L., Delaygue, G., Delmotte, M., Kotlyakov, V. M., Legrand, M., Lipenkov, V., Lorius, C., Pépin, L., Ritz, C., Saltzman, E., and Stievenard, M. (1999). Climate and atmospheric history of the past 420,000 years from the Vostok ice core, Antarctica. Nature, 399, 429-436.

Pollard, D. (1978). An investigation of the astronomical theory of the ice ages using a simple climate-ice sheet model. Nature, 272, 233-235.

Pollard, D., and DeConto, R. M. (2009). Modelling West Antarctic ice sheet growth and collapse through the past five million years. Nature, 458, 329-332.

Porter, S. C. (1975). Equilibrium-Line Altitudes of Late Quaternary Glaciers in the Southern Alps, New Zealand. Quaternary Research, 5, 27-47.

Ravelo, A. C., Andreasen, D. H., Lyle, M., Lyle, A. O., and Wara, M. W. (2004). Regional climate shifts caused by gradual global cooling in the Pliocene epoch. Science, 429, 263-267. 
Raymo, M. E. (1997b). The timing of major climate transitions. Paleoceanography, $12,577-585$.

Raymo, M. E., Oppo, D. W., and Curry, W. (1997a). The mid-Pleistocene climate transition: a deep sea carbon isotope perspective. Paleoceanography, 12, 546559.

Rojas, M., Moreno, P. I., Kageyama, M., Crucifix, M., Hewitt, C., Abe-Ouchi, A., Ohgaito, R., Brady, C., and Hope, P. (2009). The Southern Westerlies during the last glacial maximum in PMIP2 simulations. Climate Dynamics, 32, 525548.

Rutter, N. W., Ding, Z., Evans, T. E., and Liu, T. S. (1991). Baoji-type pedostratigraphic section, Loess Plateau north-central China. Quaternary Science Reviews, 10, 1-22.

Saltzman, B., and Maasch, K. A. (1991). A first-order gobal model of late Cenozoic climate change II: a simplifcation of $\mathrm{CO}_{2}$ dynamics. Climate Dynamics, 5 , 201-210.

Schaefer, J., Denton, G. H., Barrell, D. J. A., Ivy-Ochs, S., Kubik, P. W., Andersen, B. G., Phillips, F. M., Lowell, T. V., and Schlüchter, C. (2006). NearSynchronous Interhemispheric Termination of the Last Glacial Maximum in Mid-Latitudes. Science, 312, 1510-1513.

Seymour, D. B., and Calver, C. R. (1995). Explanatory notes for the Time-Space Diagram and Stratotectonic Elements Map of Tasmania. Record Tasmanian Geological Survey, 1995/01.

Shackleton, N. J., and Opdyke, N. D. (1977). Oxygen isotope and paleomagnetic evidence for early Northern Hemisphere glaciation. Nature, 270, 216-219.

Shulmeister, J., Goodwin, I., Renwick, J., Harle, K., Armand, L., McGlone, M. S., Cook, E., Dodson, J. R., Hesse, P. P., Mayewski, P., and Curran, M. (2004). The Southern Hemisphere westerlies in the Australasian sector over the last glacial cycle: a synthesis. Quaternary International, 118-119, 23-53.

Shulmeister, J., Shane, P., Lian, O. B., Carter, J. A., Harper, M., Dickinson, W. W., Augustinus, P. C., and Heijnis, H. (2001). A long late-Quaternary record from Lake Poukawa, Hawkes Bay, New Zealand. Palaeogeography, Palaeoclimatology, Palaeoecology, 176, 81-107.

Sigman, D. M., and Boyle, E. A. (2000). Glacial/interglacial variations in atmospheric carbon dioxide. Nature, 407, 859-869.

Sikes, E. L., Howard, W. R., Samson, C. R., Mahan, T. S., Robertson, L. G., and Volkman, J. K. (2009). Southern Ocean seasonal temperatures and Subtropical Front movement on the South Tasman Rise in the late Quaternary. Paleoceanography, 24, PA2201.

Singer, B. (2000). 40Ar/39Ar evidence for early deglaciation of the central Chilenian Andes. Geophysical Research Letters, 27(11), 1663-1666.

Singh, G. (1983). Late Quaternary vegetation and lake level record from Lake George, N.S.W., $18+/-2$ ka. In J. Chappell andA. Grindrod (Eds.), Proceedings of the First CLIMANZ Conference, 1981 (pp. 66): Australian National University.

Sissons, J. B., and Sutherland, D. G. (1976). Climatic inferences from former glaciers in the southeast Grampian Highlands, Scotland. Journal of Glaciology, 17, 325-346. 
Sprent, C. P. (1887). Recent Explorations on the West Coast of Tasmania. Transactions and Proceedings of the Royal Geographical Society of Australia. Victoria Branch, 3, 58-72.

Sprigg, R. C. (1982). Alternating wind cycles of the Quaternary era and their influence in and around the dune deserts of southeastern Australia. In R. J. Wasson (Ed.), Quaternary Dust Mantles of China, New Zealand, and Australia (pp. 211-240). Canberra: ANU Press.

Spry, A. H. (1958). Precambrian rocks of Tasmania, Part III - Mersey-Forth area. Papers and Proceedings of the Royal Society of Tasmania, 92, 117-137.

Stacey, A. R., and Berry, R. F. (2004). The structural history of Tasmania: a review for petroleum explorers. PESA Eastern Australian Basins Symposium II, Adelaide.

Stephens, B. B., and Keeling, R. F. (2000). The influence of Antarctic sea ice on glacial-interglacial $\mathrm{CO}_{2}$ variations. Nature, 404, 171-174.

Stuut, J. B. W., and Lamy, F. (2004). Climate variability at the southern boundaries of the Namib (south-western Africa) and Atacama (northern Chile) coastal deserts during the last 120,000 yr. Quaternary Research, 62(3), 301-309.

Stuut, J. B. W., Marchant, D. R., Kaiser, J., Lamy, F., Mohtadi, M., Romero, O. E., and Hebbeln, D. (2006). The Late Quaternary paleoenvironment of Chile as seen from marine archives. Geographica Helvetica, 61, 135-151.

Sugden, D. (1974). Landscapes of glacial erosion in Greenland and their relationship to ice, topographic and bedrock conditions. In E. H. Brown andR. S. Waters (Eds.), Progress in Geomorphology: Papers in Honour of D.L. Linton (Vol. 7, pp. 177-195): Institute of British Geographers Special Publication.

Suggate, R. P. (1990). Late Pliocene and Quaternary glaciations of New Zealand. Quaternary Science Reviews, 9(2-3), 175-197.

Toggweiler, J. R. (2008). Origin of the 100,000-year timescale in Antarctic temperatures and atmospheric $\mathrm{CO}_{2}$. Paleoceanography, 23, PA2211.

Toggweiler, J. R. (2009). Climate Change: Shifting Westerlies. Science, 323(5920), 1434-1435.

Toggweiler, J. R., and Russell, J. (2008). Ocean circulation in a warming climate. Nature, 451, 286-288.

Toggweiler, J. R., Russell, J. L., and Carson, S. R. (2006). Midlatitude westerlies, Atmospheric $\mathrm{CO}_{2}$, and climate change during the ice ages. Paleoceanography, 21, PA2005.

Torgersen, T., Jones, M. R., Stephens, A. W., Searle, D. E., and Ullman, W. J. (1985). Late Quaternary hydrological changes in the Gulf of Carpentaria. Nature, 313, 785-787.

Torgersen, T., Luly, J., De Deckker, P., Jones, M. R., Searle, D. E., Chivas, A. R., and Ullman, W. J. (1988). Late Quaternary Environments of the Carpentaria Basin, Australia. Palaeogeography, Palaeoclimatology, Palaeoecology, 67, 245-261.

Torsnes, I., Rye, N., and Nesje, A. (1993). Modern and Little Ice Age equilibriumline altitudes on outlet valley glaciers from Jostedalsbreen, Western Norway: an evaluation of different approaches to their calculation. Arctic and Alpine Research, 25, 106-116. 
Tziperman, E., and Gildor, H. (2003). On the mid-Pleistocene transition to 100-kyr glacial cycles and the asymmetry between glaciation and deglaciation times. Paleoceanography, 18.

van de Geer, G., Heusser, L. E., Lynch-Stieglitz, J., and Charles, C. D. (1994). Palaeoenvironments of Tasmania inferred from a 5-75 ka marine pollen record. Palynology, 18, 33-40.

van de Wal, R. W. S., Oerlemans, J., and van der Hage, J. (1991). A study of ablation variations on the tongue of Hintereisferner, Austria. Journal of Glaciology, 38, 319-324.

van der Veen, C. J. (2002). Polar ice sheets and global sea-level: how well can we predict the future? Global and Planetary Change, 32, 165-194.

Ward, L. K. (1909). The Mt. Farrell mining field. Report of the Secretary of Mines, Tasmania, 1908, 1-120.

Wasson, R. J. (1984). Late Quaternary paleoenvironments in the desert dunefields of Australia. In J. C. Vogel (Ed.), Late Cainozoic Paleoclimates of the Southern Hemisphere (pp. 419-432): A. A. Balkema.

Weertman, J. (1964). The theory of glacier sliding. Journal of Glaciology, 5, 287303.

Williams, P. W., King, D. N. T., Zhao, J., -X., and Collerson, K. D. (2005). Late Pleistocene to Holocene composite speleothem ${ }^{18} \mathrm{O}$ and ${ }^{13} \mathrm{C}$ chronologies from South Island, New Zealand - did a global Younger Dryas really exist? Earth and Planetary Science Letters, 230, 301-317.

Wyrwoll, K. H. (1979). Late Quaternary climates of Western Australia: Evidence and mechanisms. Journal of the Royal Society of Western Australia, 62, 129142.

Wyrwoll, K. H., Dong, B., and Valdes, P. (2000). On the position of southern hemisphere westerlies at the Last Glacial Maximum: An outline of AGCM simulation results and evaluation of their implications. Quaternary Science Reviews, 19, 881-888.

Yokoyama, Y., Lambeck, K., De Deckker, P., Johnston, P. J., and Fifield, L. K. (2000). Timing of the Last Glacial Maximum from observed sea-level minima. Nature, 406, 713-716. 


\section{Appendix I}

Sources for the Geographical Information Systems compilation 


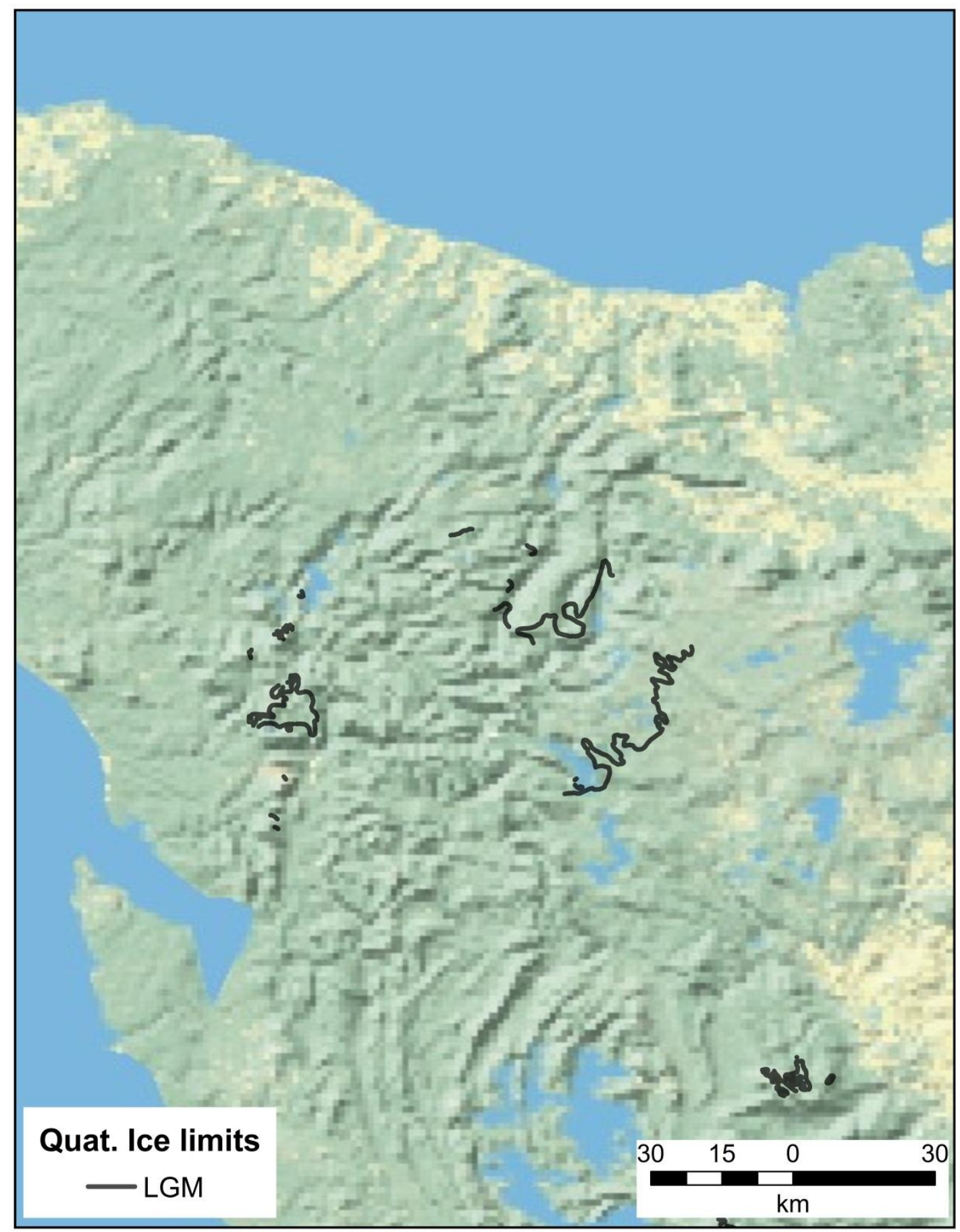

Figure 1: Last Glacial Maximum ice limits. These were sourced from: Caine (1983), Kiernan (1990a, 1999), Kiernan and Hannan (1991), Augustinus (1999a), Barrows et al. (2002), Kiernan et al. (2004), Mackintosh et al. (2006) and Augustinus (per. comms). 


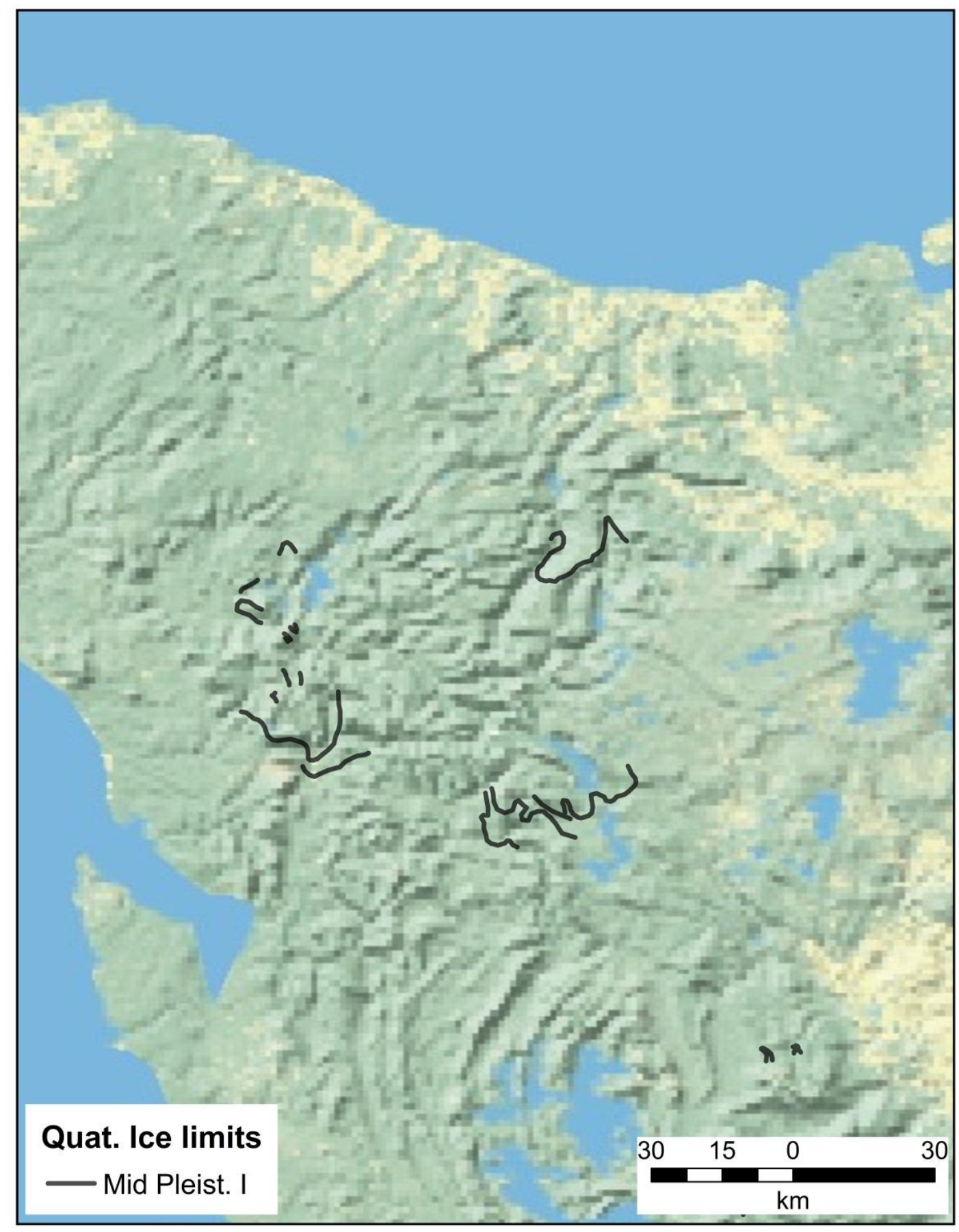

Figure 2: Middle Pleistocene I ice limits. These were sourced from : Fitzsimons and Colhoun (1991), Kiernan (1991), Kiernan and Hannan (1991), Augustinus et al. (1997), Kiernan et al. (2001) and Augustinus (per. comms.). 


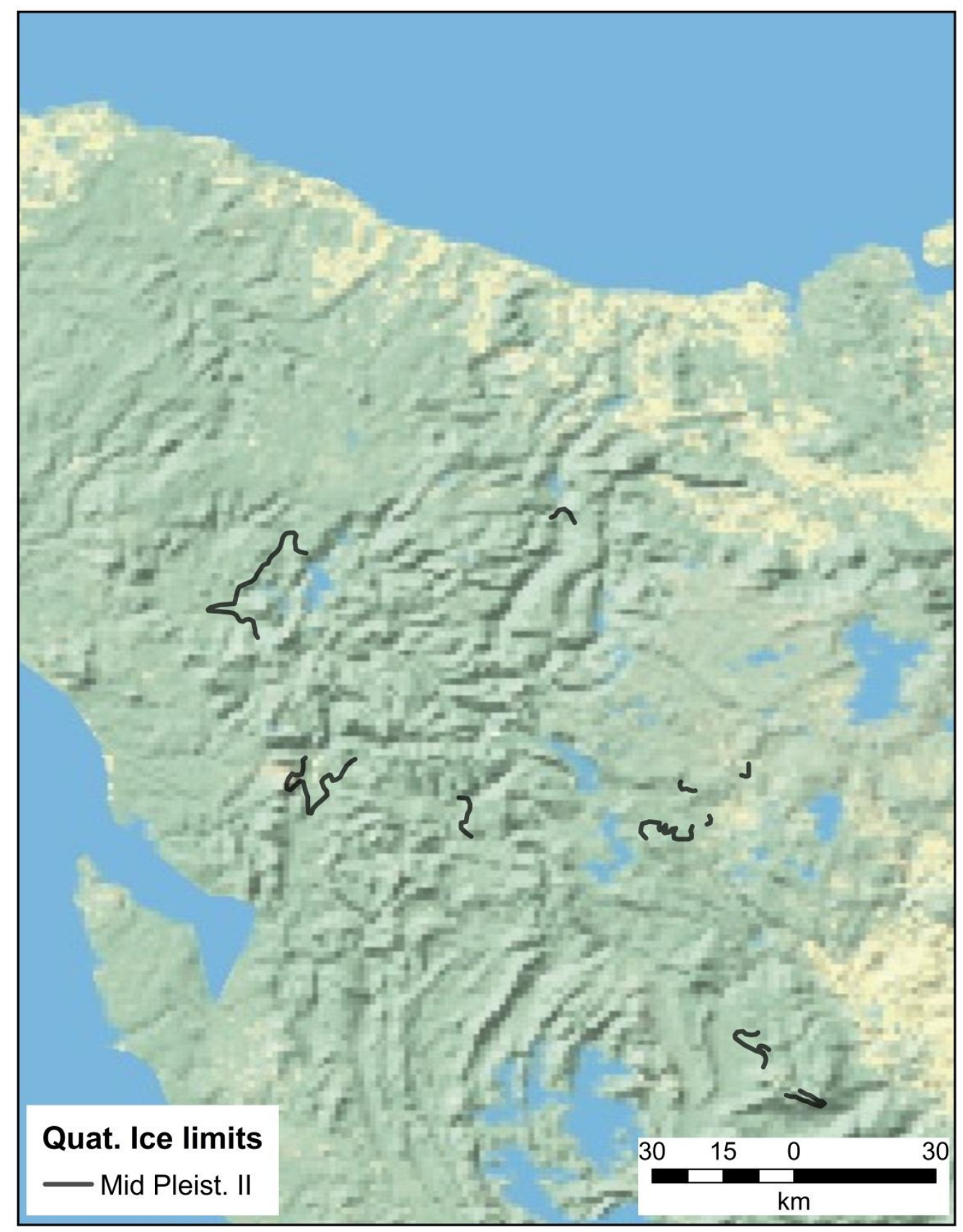

Figure 3: Middle Pleistocene II ice limits. These were sourced from: Fitzsimons and Colhoun (1991), Kiernan (1991), Kiernan and Hannan (1991), Augustinus and Macphail (1997), Kiernan et al. (2001) and Augustinus (per. comms). 


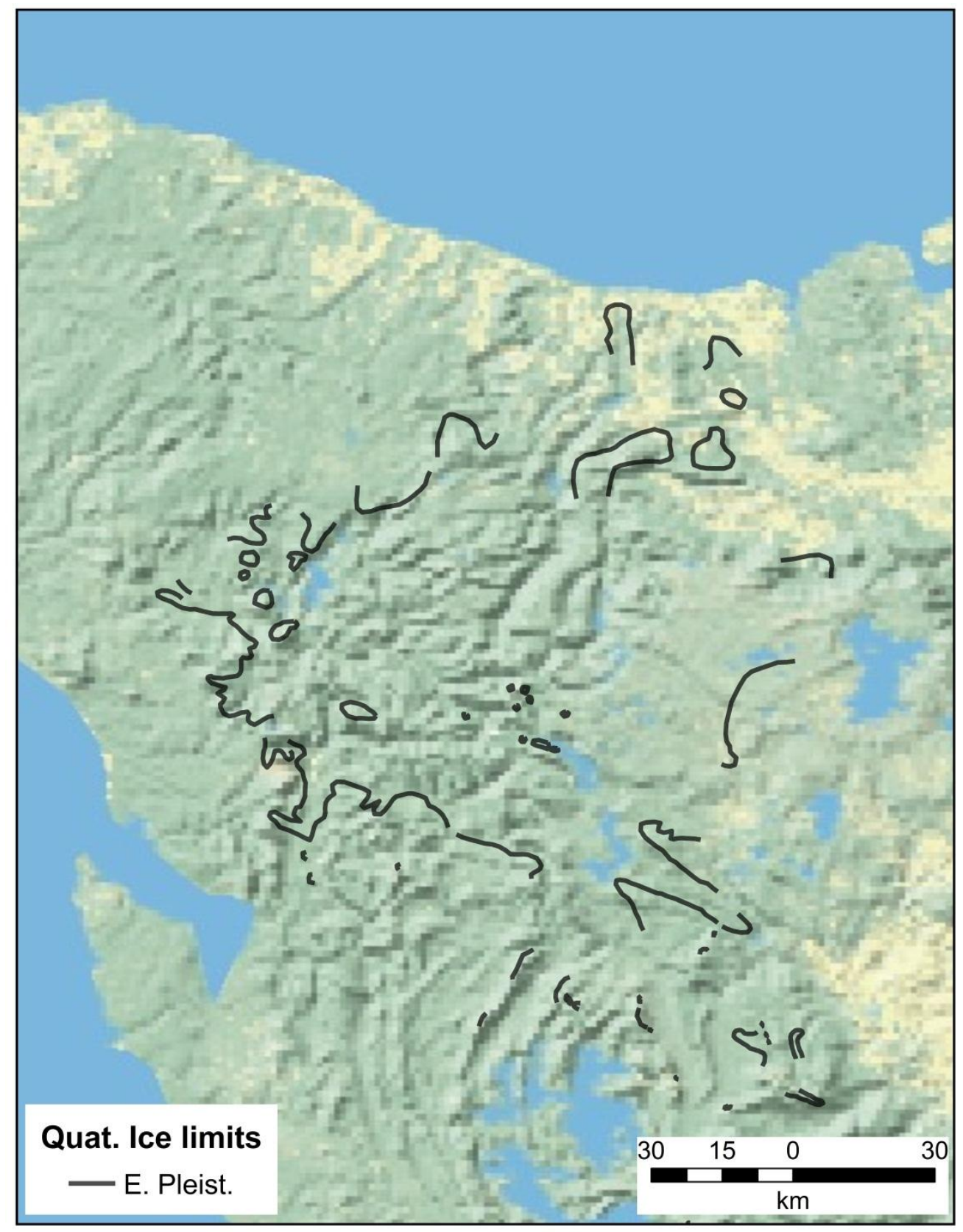

Figure 4: Early Pleistocene ice limits. These were sourced from: Kiernan (1990b; 1991), Augustinus (1999a; 1999b), Kiernan et al. (2001) and Augustinus (per. comms.). 